\title{
Groundwater Fate and Transport Modeling for Texarkana Wood Preserving Company Superfund Site, Texarkana, Texas
}

R. C. Arnett

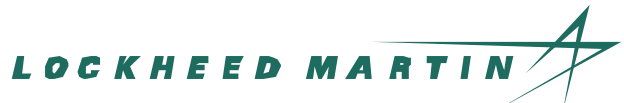




\title{
Groundwater Fate and Transport Modeling for Texarkana Wood Preserving Company Superfund Site, Texarkana, Texas
}

\author{
R. C. Arnett \\ Published August 1999 \\ Idaho National Engineering and Environmental Laboratory \\ Integrated Earth Sciences Department \\ Lockheed Martin Idaho Technologies Company \\ Idaho Falls, Idaho 83415
}

Prepared for Ken Brown

Technology Support Center for Monitoring and Site Characterization

U.S. Environmental Protection Agency

National Exposure Research Laboratory

Characterization Research Division

Las Vegas, Nevada 89193-3478 


\section{SUMMARY}

Fate and transport model results are presented for the Texarkana Wood Preserving Company (TWPC) superfund site. The conceptual model assumes two sources of contamination, specifically, the areas around the old and new process areas. Recent data show the presence of non-aqueous phase liquids (NAPL) in the aquifer that are also sources of dissolved contamination in the aquifer.

A flow model was constructed and calibrated against measured hydraulic heads at permanent monitoring wells. Good matches were obtained between model simulated heads and most measured heads. An unexplained exception occurs at monitoring well MW-13 down gradient of the site beyond the measured contaminant plume where the model predicts heads that are more than $2 \mathrm{ft}$. lower than reported field measurements. Adjusting hydraulic parameters in the model could not account for this anomaly and still preserve the head matches at other wells. There is likely a moderate deficiency in the conceptual model or perhaps a data error. Other information such as substantial amounts of infiltrating surface water in the area or a correction in surveyed elevation would improve the flow model.

A particle tracking model calculated a travel time from the new process area to the Day's Creek discharge location on the order of 40 years. Travel times from the old process area to Day's Creek were calculated to be on the order of 80 years. While these calculations are subject to some uncertainty, travel times of decades are indicated.

Contaminant transport and reaction modeling adequately simulate the contaminant movement and reactions. The model and field data are consistent with the concept that dissolved contaminants are strongly influenced by the presence of dense NAPL (DNAPL), which flows along the bottom of the aquifer in the direction of the aquitard dip. The direction of the dissolved contaminant plume closely follows the DNAPL and is less influenced by the direction of the hydraulic gradient. At the same time, both aerobic and anaerobic biodegradation appear to limit the extent of the dissolved plume. This is supported by the fact that several metabolic degradation products of a major contaminant, pentachlorophenol (PCP), were measured during the sampling program. The transport and reaction model included DNAPL dissolution of PCP and other lumped components of the wood-treating chemical, creosote. Both aerobic and anaerobic biodegradation were simulated because both conditions exist at the site and PCP has both aerobic and anaearobic degradation pathways. The model produced reasonable to good matches of the contaminant concentrations observed in the field.

A model sensitivity analysis confirmed the importance of DNAPL dissolution as well as aerobic and anaerobic degradation. PCP concentrations appear most sensitive to the PCP aerobic degradation rate constant. Effective solubilities of the various creosote components were calculated to constrain the DNAPL dissolution. The effective solubility of Benzo(a)pyrene (BAP), the dominant cancer producing component of creosote, was calculated to be less than the BAP action limit concentration. Thus, concentrations in the model were less than the action limit. There were higher BAP concentrations measured in the field, but in every case the well was located within or very near the DNAPL plume, suggesting that such samples could represent some undissolved BAP.

Because DNAPL dissolution rates are uncertain, calculating reliable contaminant degradation rates with the model is limited and documented evidence of strong biodegradation is incomplete. Additional data on the dissolution and/or degradation rates are needed to support natural attenuation. Determining the make-up of DNAPL presently in the aquifer, as opposed to fresh creosote, would be very helpful in estimating dissolution rates and effective solubility products. Monitored natural attenuation may be best coupled with an active remediation strategy such as DNAPL recovery. The relatively high and sensitive PCP aerobic degradation rate suggests that increasing the contaminated aquifer oxygen content could enhance PCP remediation. Thus, groundwater aeration and reinjection during DNAPL recovery might prove useful. 


\section{CONTENTS}

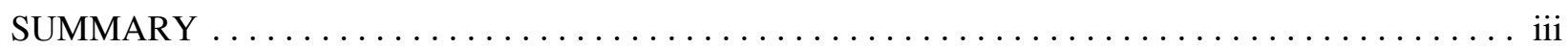

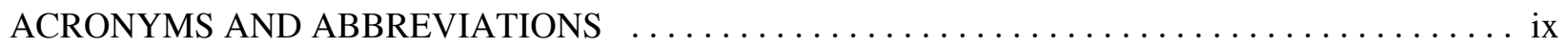

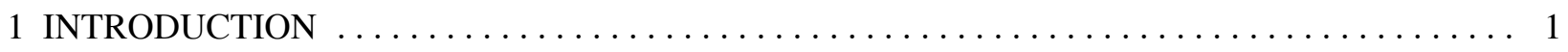

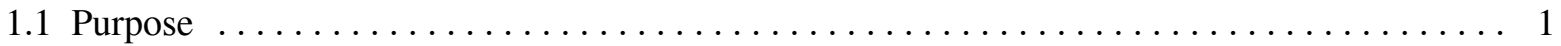

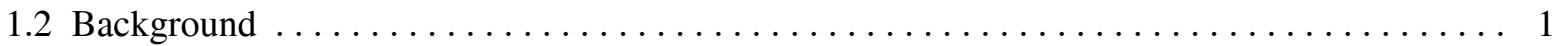

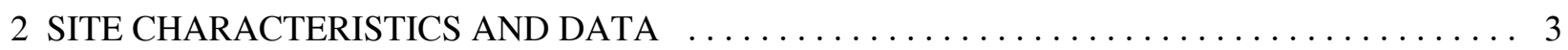

3 CREOSOTE COMPOSITION AND CHARACTERISTICS $\ldots \ldots \ldots \ldots \ldots \ldots \ldots \ldots \ldots$

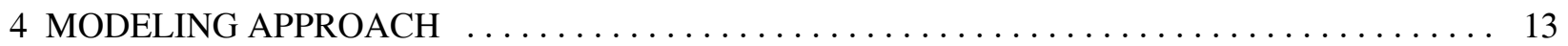

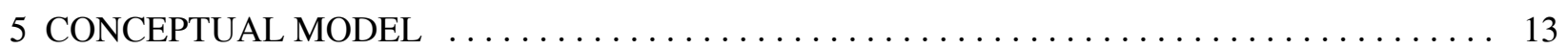

5.1 Contaminant Sources and Transport Pathway $\ldots \ldots \ldots \ldots \ldots \ldots \ldots \ldots \ldots \ldots \ldots$

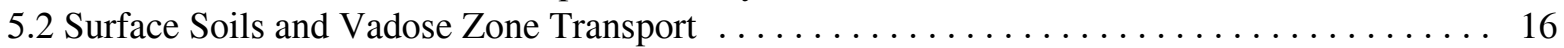

5.3 NAPL Sources of Dissolved Contaminants $\ldots \ldots \ldots \ldots \ldots \ldots \ldots \ldots \ldots \ldots \ldots \ldots \ldots \ldots$

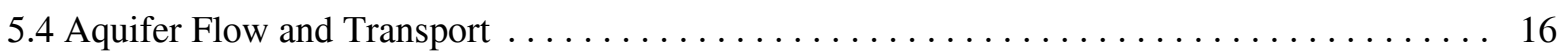

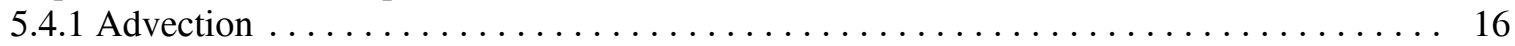

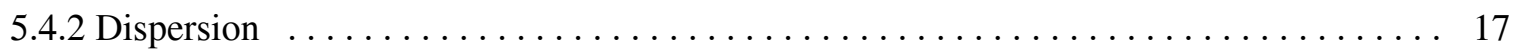

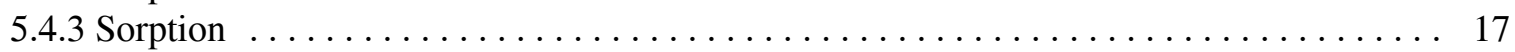

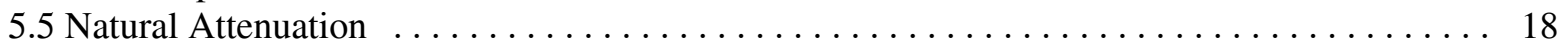

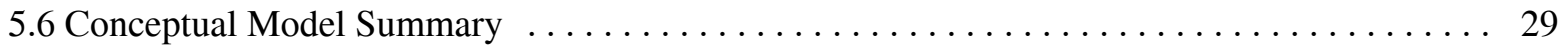

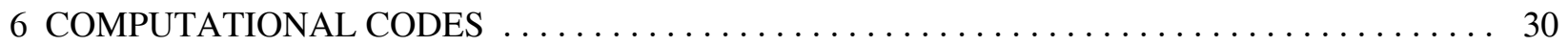

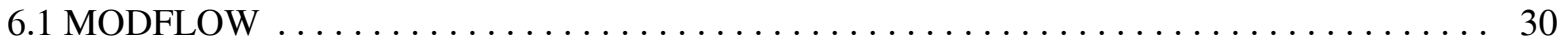

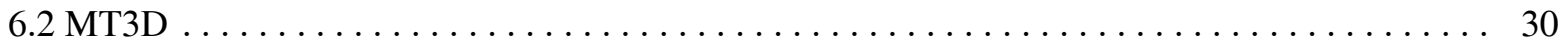

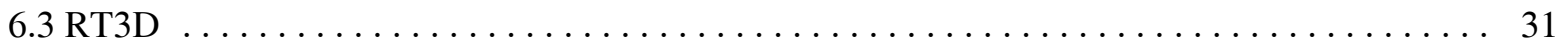

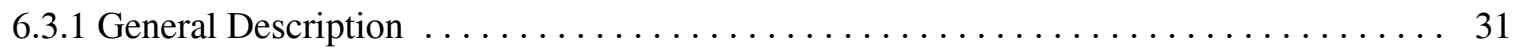

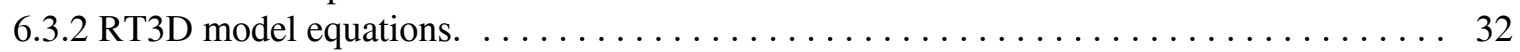

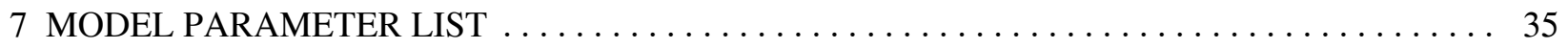

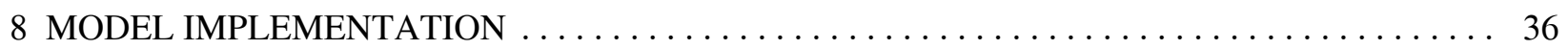

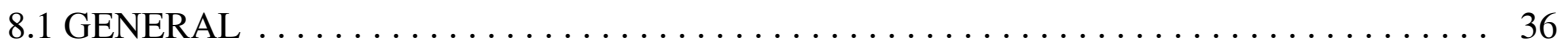

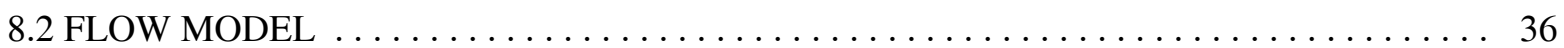

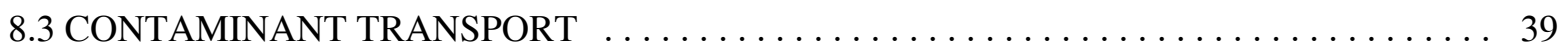

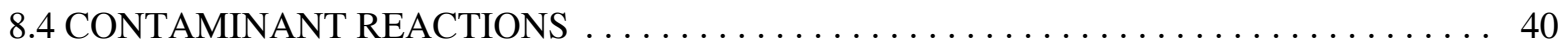

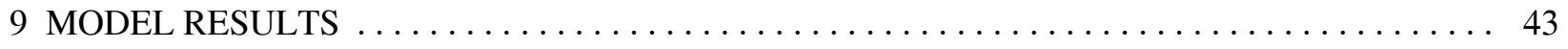

9.1 Shallow Aquifer Flow Model $\ldots \ldots \ldots \ldots \ldots \ldots \ldots \ldots \ldots \ldots \ldots \ldots \ldots \ldots \ldots \ldots \ldots \ldots$

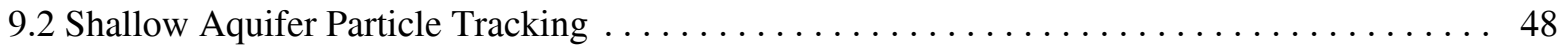

9.3 Aquifer Contaminant Transport and Reactions $\ldots \ldots \ldots \ldots \ldots \ldots \ldots \ldots \ldots \ldots \ldots$

10 REACTION MODEL CONSTANTS AND SENSITIVITY ANALYSIS $\ldots \ldots \ldots \ldots \ldots \ldots$

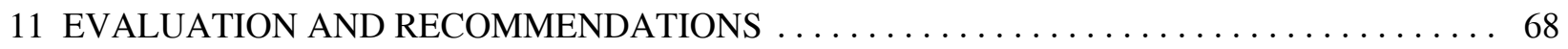


12 REFERENCES

APPENDIX A: COPIES OF SELECTED DATA REPORT FIGURES

A-1

APPENDIX B: CHLORINATED PHENOL DATA

B-1 


\section{FIGURES}

Figure 1. Map of the TWPC Site with location of groundwater monitoring wells. $\ldots \ldots \ldots \ldots \ldots 2$

Figure 2. Summary of soil contaminated above background in 1988 (from Weston, 1989). . . . . . . 4

Figure 3. Generalized geologic cross-section of the TWPC site (after Weston, 1989). . . . . . . . . 5

Figure 4. Gravel Zone groundwater elevation contours in 1989 (after Weston, 1989). . . . . . . . 7

Figure 5. Location of shallow monitoring wells and temporary well points. $\ldots \ldots \ldots \ldots \ldots \ldots$

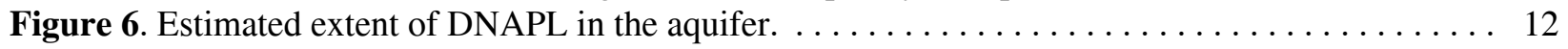

Figure 7. Maximum PCP or BAP concentrations in 1997- 1998 relative to action levels. . . . . . . . 15

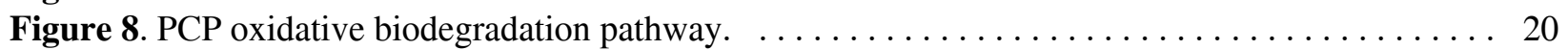

Figure 9. Example of PCP reductive biodegradation pathway $\ldots \ldots \ldots \ldots \ldots \ldots \ldots \ldots \ldots \ldots$

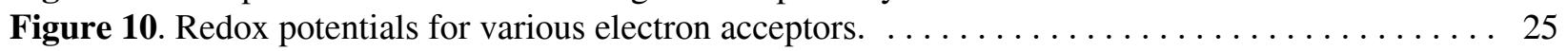

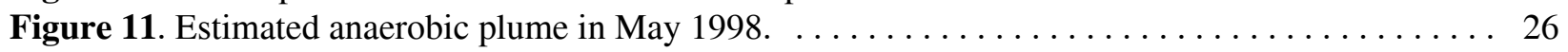

Figure 12. Wells with positive or nondetectable DCP or CP values. $\ldots \ldots \ldots \ldots \ldots \ldots \ldots \ldots \ldots 27$

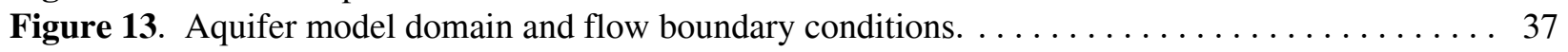

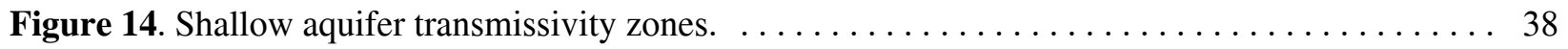

Figure 15. Transport and reaction model boundary conditions and sources during old process area operation

Figure 16. Transport and reaction model boundary conditions and sources during new process area operation

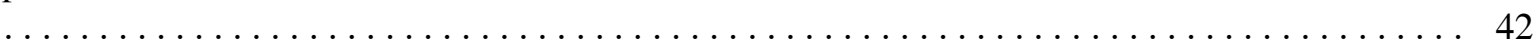

Figure 17. MODFLOW grid for aquifer model. $\ldots \ldots \ldots \ldots \ldots \ldots \ldots \ldots \ldots \ldots \ldots \ldots \ldots$

Figure 18. Shallow Aquifer Flow Model Head Contours and Observed Heads . . . . . . . . . . . 47

Figure 19. Shallow Aquifer Pathlines from Contaminated Areas to Day's Creek . . . . . . . . . 48

Figure 20. Model predicted PCP concentration factors (times action limit) and observed concentration

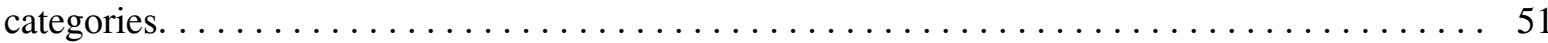

Figure 21. Model predicted light PAH concentrations and observed concentration categories (values $\mathrm{ug} / \mathrm{L})$.

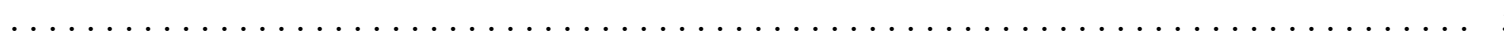

Figure 22. Model predicted BAP concentration factor isopleths (times action limit) and observed

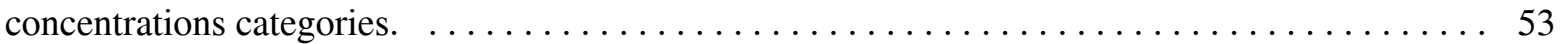

Figure 23. Model predicted DCP concentration isopleths (values $-\mathrm{ug} / \mathrm{L}$ ) $\ldots \ldots \ldots \ldots \ldots \ldots \ldots 54$

Figure 24. Model predicted oxygen concentration isopleths (values $-\mathrm{mg} / \mathrm{L}$ ). $\ldots \ldots \ldots \ldots \ldots \ldots 5$

Figure 25. PCP concentration differences $-\mathrm{kla}_{\mathrm{pcp}}=1 / 10$ calibrated valued (isopleth values in multiples of

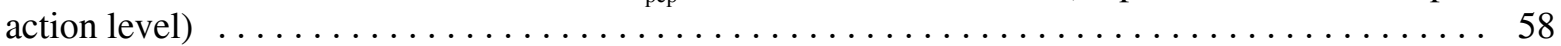

Figure 26. PCP concentration differences $-\mathrm{Kan}_{\mathrm{pcp}}=1 / 2$ calibrated value (isopleth values - multiples of

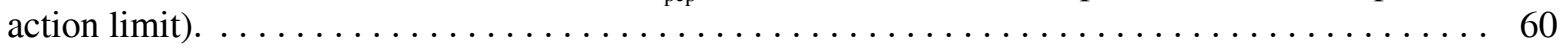

Figure 27. PCP concentration differences $-K_{p c p}=1 / 2$ calibrated value (isopleth values - multiples of action

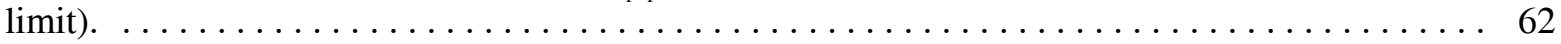

Figure 28. $\mathrm{LPAH}$ concentration differences $-\mathrm{kla}_{\mathrm{lpah}}=2 \mathrm{x}$ calibrated value (isopleth values in $\mathrm{ug} / \mathrm{L}$ ) $\ldots 64$

Figure 29. LPAH concentration differences $-K_{\text {lpah }}=1 / 2$ calibrated value (values ug/L) . . . . . . . 66

Figure 30. DCP concentration differences $-\mathrm{Kan}_{\mathrm{dcp}}=1 / 2$ calibrated value (isopleth values in ug/L) $\ldots 67$

\section{TABLES}

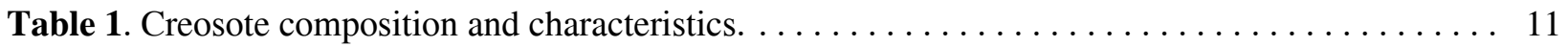

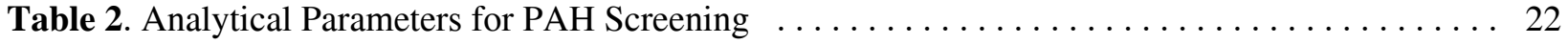

Table 3. Analytical Parameters and Weighting for Preliminary Screening of PCP $\ldots \ldots \ldots \ldots \ldots 23$ 


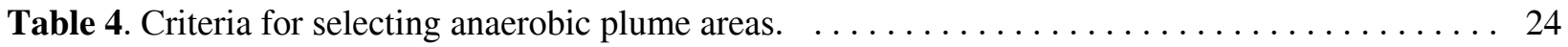

Table 5. Shallow and deep Surficial Silty Sand sorption data and estimates for TWPC contaminants. .. 39

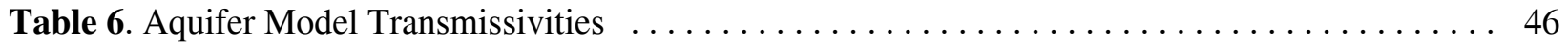

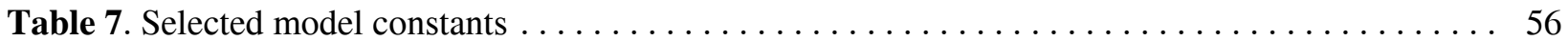

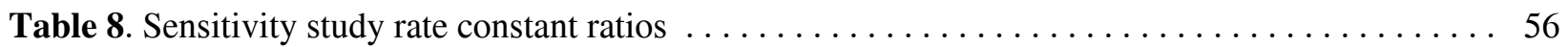




\section{ACRONYMS AND ABBREVIATIONS}

$\begin{array}{ll}\text { ACEX } & \text { Acid Extractables (other than PCP) } \\ \text { BAP } & \text { Benzo(a)pyrene } \\ \text { CP } & \text { [mono] Chlorophenol } \\ \text { DCP } & \text { Dichlorophenol } \\ \text { DNAPL } & \text { Dense non-aqueous phase liquid } \\ \text { DOC } & \text { Dissolved organic carbon } \\ \text { EPA } & \text { United States Environmental Protection Agency } \\ \text { HPAH } & \text { Heavy polycyclic aromatic hydrocarbon } \\ \text { LPAH } & \text { Light polycyclic aromatic hydrocarbon } \\ \text { MODFLOW } & \text { USGS modular three-dimensional finite-difference groundwater flow code } \\ \text { MT3D } & \text { Modular three-dimensional groundwater transport code } \\ \text { NAPL } & \text { Non-aqueous phase liquid } \\ \text { PAH } & \text { Polycyclic aromatic hydrocarbon } \\ \text { PCA } & \text { Pentachloroanisole } \\ \text { PCP } & \text { Pentachlorophenol } \\ \text { PVC } & \text { Polyvinyl chloride } \\ \text { ROD } & \text { Record of decision } \\ \text { RT3D } & \text { Modular reactive multi-species groundwater transport code } \\ \text { TCP } & \text { Trichlorophenol } \\ \text { TNRCC } & \text { Texas Natural Resource Conservation Commission } \\ \text { TOC } & \text { Total organic carbon } \\ \text { TPH } & \text { Total petroleum hydrocarbons } \\ \text { TWPC } & \text { Texarkana Wood Preserving Company } \\ \text { TeCP } & \text { Tetrachlorophenol } \\ \text { USGS } & \text { United States Geologic Survey } \\ \end{array}$


TWPC Fate and Transport Groundwater Model

\section{Texarkana Groundwater Modeling Approach and Results}

\section{INTRODUCTION}

\subsection{Purpose}

The purpose of this report is to document the groundwater fate and transport model of the Texarkana Wood Preserving Company (TWPC) Superfund site in Texarkana, Texas. This includes developing a conceptual model and modeling approach, identifying key model parameters and and appropriate model computational codes, and presenting the results to assist in determining clean-up options.

\subsection{Background}

The Texarkana Wood Preserving Company (TWPC) Superfund site in Texarkana, Texas was used for various lumber-related activities since the early 1900's. A map of the site including major features and groundwater monitoring well locations is presented in Figure 1. Analysis of aerial photos indicates that wood preserving operations were underway as early as 1954 in the southwest portion of the site. When TWPC took over in 1961, they used a combination of creosote and pentachlorophenol (PCP) to treat the wood. The wood treating activities leading to the current site configuration began in 1972 when TWPC moved the wood treating operation to a new process area north of the old process area (see Figure 1). The entire site is now abandoned and only remnants of the facility remain.

The predecessor of the Texas Natural Resource Conservation Commission (TNRCC) conducted several investigations after site operations were shut down, and documented the presence of polycyclic aromatic hydrocarbons (PAHs) (including benzo(a)pyrene [BAP]), PCP, and polychlorinated dibenzo-pdioxins and polychlorinated dibenzofurans (dioxins) in waste impoundments and site soils. The Environmental Protection Agency (EPA) placed the site on the National Priorities List and it became eligible for Superfund funding under the Comprehensive Environmental Response, Compensation and Liability Act in June 1986.

A remedial investigation (RI) was done in 1988, a remedial action selected, and record of decision issued in 1990 (ROD, 1990). The preferred action for contaminated soil was onsite thermal destruction and backfilling. Extraction, treatment, and reinjection was selected to remediate the groundwater. Since issuance of the ROD, community concern has been expressed about possible air contamination from onsite incineration and the regulatory agencies (the EPA and TNRCC) have amended the ROD to cap all soils on site above the remediation level. Therefore, a plan to evaluate the consequences on the groundwater system is needed. The selected alternative for the groundwater remedy documented in the ROD has not changed, but may need to be modified or refined based upon the changes in the soil remedy, revised conceptual model, and recent data. 
TWPC Fate and Transport Groundwater Model

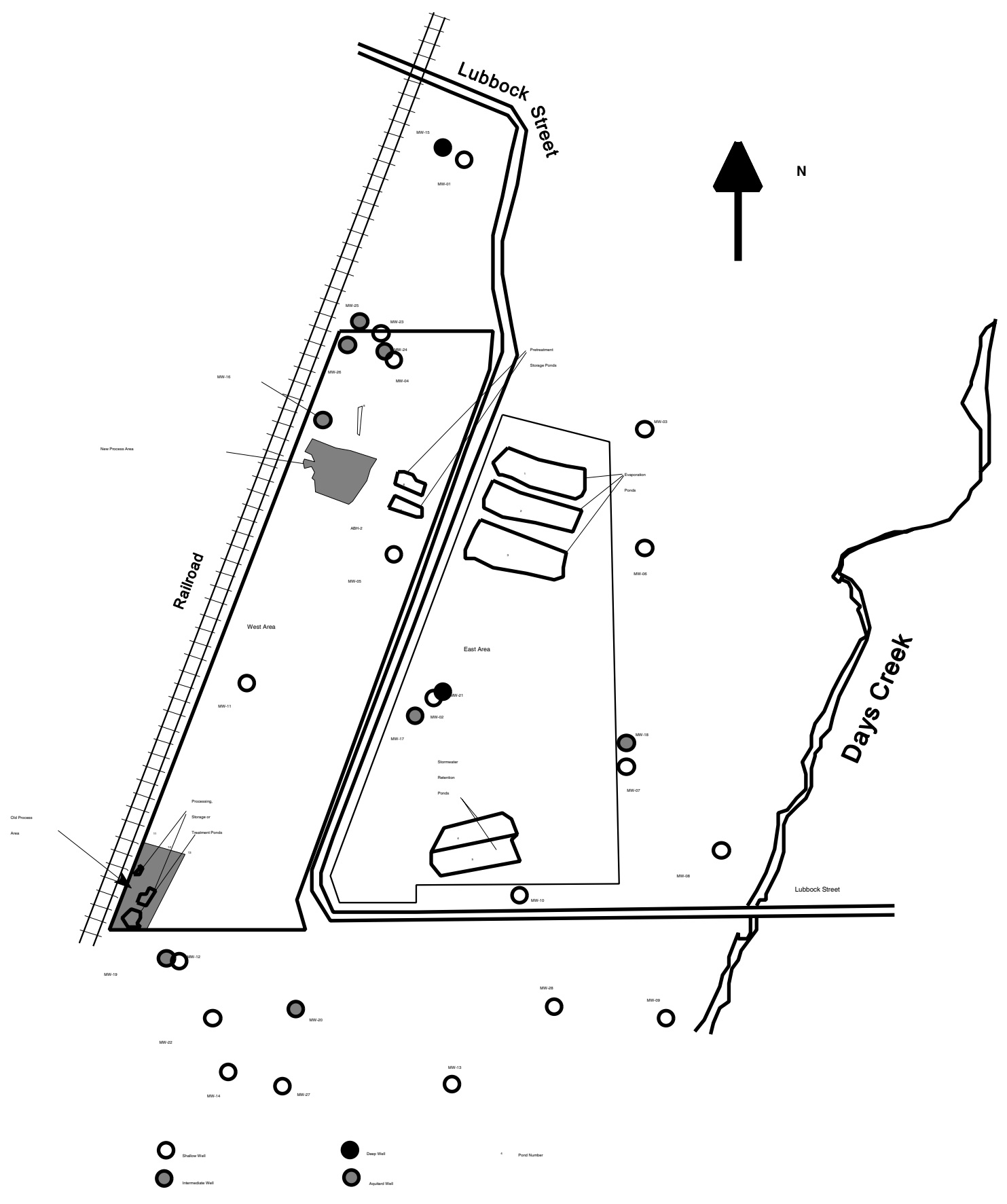

Figure 1. Map of the TWPC Site with location of groundwater monitoring wells. 
TWPC Fate and Transport Groundwater Model

\section{SITE CHARACTERISTICS AND DATA}

This section identifies and discusses characteristics and data related to the site and the contaminants that are important in developing the groundwater modeling approach and identifying data gaps. The following reports of the TWPC site were reviewed and used as resource material: EPA (1997), Key (1997), ROD (1990), Weston (1989), Weston (1992a), Weston (1992b), Weston (1996), Weston(1997), Weston (1998)and Weston (1999). Creosote and pentachlorophenol (PCP) wood treatment chemicals were released to the ground surface where they seeped downward contaminating the surficial alluvium and shallow aquifer.

A summary of estimated soil contamination in 1988 is shown on Figure 2. The highest concentrations of soil contamination are in the western portion of the site (West Area) near the old and new process areas (see Figure 1), but there were low levels of contaminated soil in the area east of Lubbock Street (East Area). The area of soil contamination in 1998 (Weston, 1999) was much smaller than in 1988 indicating some natural degradation of contaminants in the soils. The 1998 sampling was more comprehensive and detailed, which may also have influenced the 1998 estimated area of contaminated soils.

Figure 3 is a generalized geologic cross-section of the site from Weston (1989). The upper layer is a Surficial Silty Sand alluvium averaging $91 / 2 \mathrm{ft}$. thick across the site and ranging in thickness from $5 \frac{1}{2} \mathrm{ft}$. at MW-07 to $16 \mathrm{ft}$. at MW-01. Underlying the Surficial Silty Sand is a shallow Gravel Zone aquifer averaging about $4 \mathrm{ft}$. thick. There is evidence that the Gravel Zone aquifer is confined across most of the site (Weston, 1989), but likely receives some slowly infiltrating rainwater, particularly from the unlined ponds. The Gravel Zone aquifer is underlain by a 30 to $50 \mathrm{ft}$ thick layer of Clayey Sand that acts as an aquitard. An intermediate groundwater system is in the Silty Sand ( 50 to $90 \mathrm{ft}$ bls) and Lignite ( 90-110 $\mathrm{ft}$ bls) zones underlying the Gravel Zone aquifer. The Lignite layer is underlain by a thick Deep Clay layer. The Gravel Zone aquifer is the primary means of contaminant transport towards Day's Creek because the Silty Sand aquifer is generally protected by the Clayey Sand. Minimal contamination has been detected in the intermediate and deep well borings and monitoring wells of the Silty Sand Zone. Only wells MW-16 and MW-19 penetrating the Silty Sand Zone produced groundwater samples containing low concentrations of total PAH (Weston, 1989). The deep groundwater in the lower Silty Sand Zone and Lignite appears to be clean (Weston, 1989).

There is a low-lying area north of the new process area and south of the fence surrounding well MW04 (see Figures 1 and 3). During wet periods water collects in this area (Weston, 1989) to a depth of 1-2 ft (personal communication from G. Olinger, R.F. Weston, Houston, Texas) and apparently becomes a significant source of infiltrating water. Hydraulic head in MW-04 is higher than surrounding wells and is consistent with the concept of a "pond" source in the area. 
TWPC Fate and Transport Groundwater Model

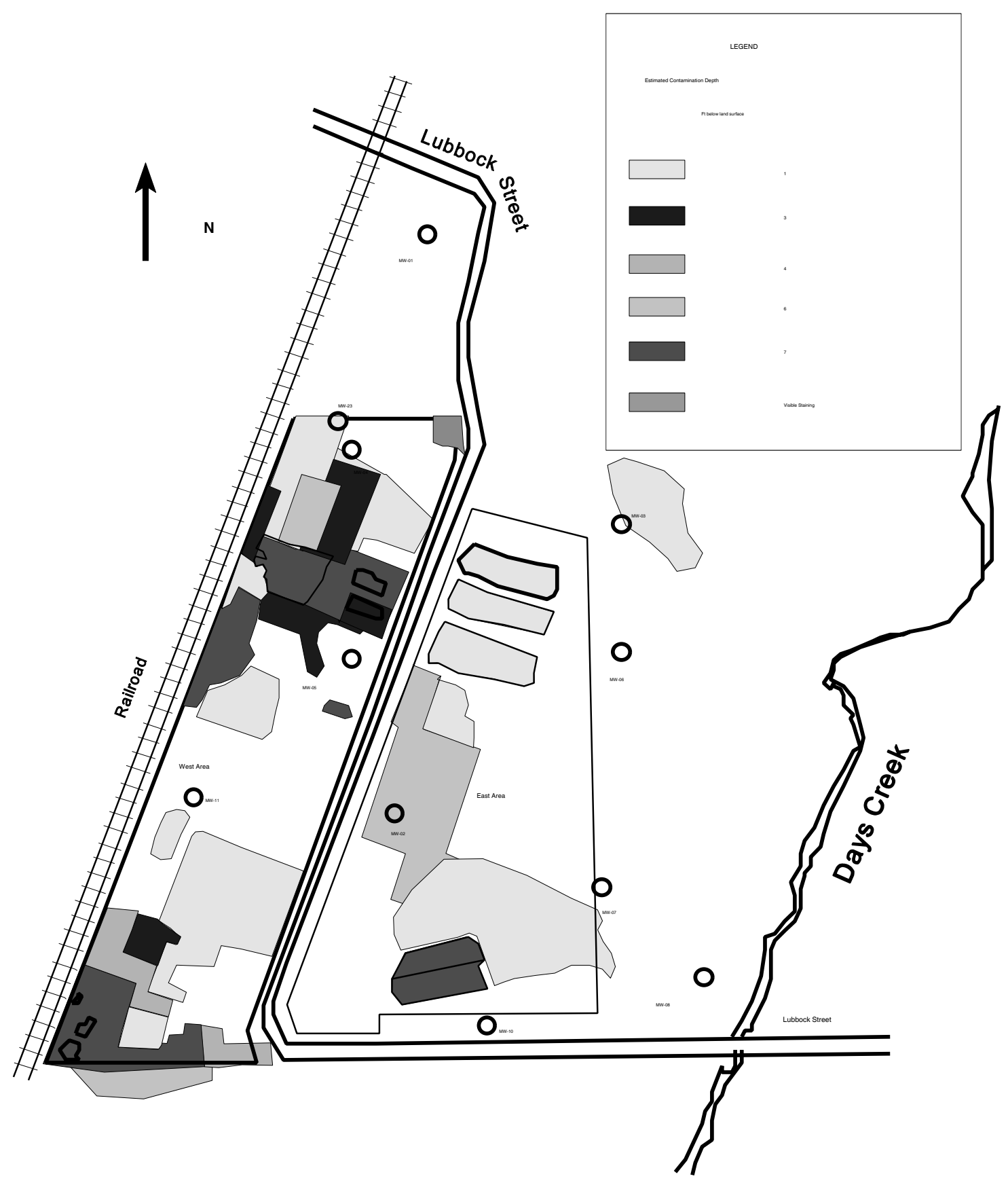

Figure 2. Summary of soil contaminated above background in 1988 (from Weston, 1989). 
TWPC Fate and Transport Groundwater Model

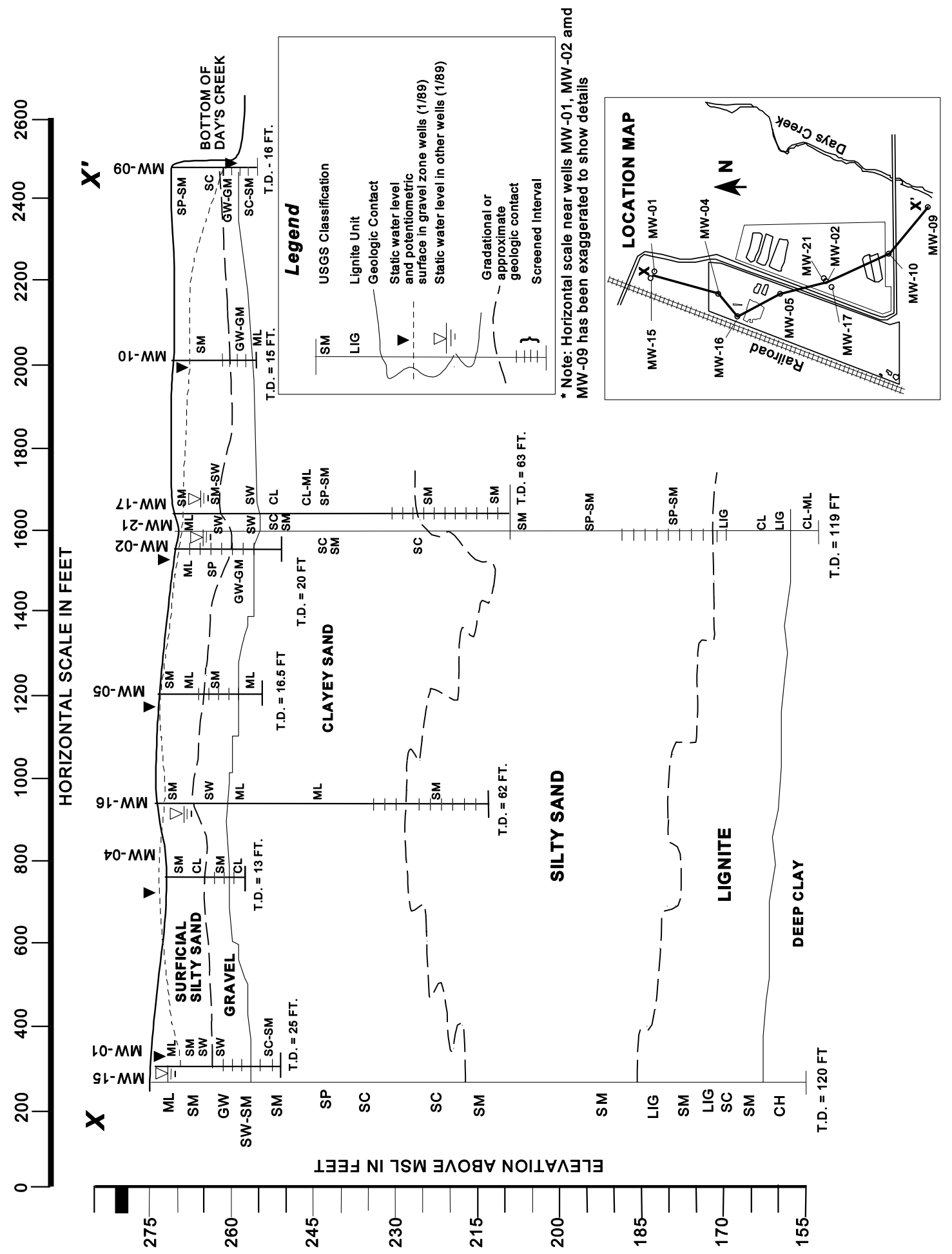

Figure 3. Generalized geologic cross-section of the TWPC site (after Weston, 1989). 


\section{TWPC Fate and Transport Groundwater Model}

The mean hydraulic conductivity $(\mathrm{K})$ in the shallow Gravel Zone aquifer was calculated from slug test data at seven wells in the gravel zone aquifer (Weston 1989a, Weston 1997). The $\mathrm{K}$ is about $0.1 \mathrm{ft} / \mathrm{day}$ at well MW-06, $0.4 \mathrm{ft} /$ day at MW-01, $0.6 \mathrm{ft} /$ day at MW-14, $5 \mathrm{ft} /$ day at MW-09, $1.2 \mathrm{ft} /$ day at MW-02, $4 \mathrm{ft} /$ day at MW-05, and $0.54 \mathrm{ft} / \mathrm{day}$ at MW-10. The arithmetic mean of the values from the 7 wells is about 1.7 $\mathrm{ft} / \mathrm{day}$ and the geometric mean is $0.88 \mathrm{ft} / \mathrm{day}$. The geometric mean might be a good estimate of the average $\mathrm{K}$ if each well was equally represented in the flow path. The geometric mean of the K for wells MW-05 and MW-02 that are on the flow path from the new process area to Day's Creek is $2.2 \mathrm{ft} / \mathrm{day}$ and $1.4 \mathrm{ft} / \mathrm{day}$ if MW-10 is included.

The groundwater flow direction is from the west to east or southeast from the process areas toward Day's Creek. The gravel zone groundwater elevation contours in 1989 are shown in Figure 4. The hydraulic gradient is the driving force for groundwater flow and is the change in hydraulic head or groundwater elevation divided by the distance between measurement points. It was calculated to be about 0.007 (Weston, 1989), which appears to be reasonable. In 1998, a series of temporary well points were installed in conjunction with a comprehensive soil sampling effort. These temporary well points were geoprobe borings with 1.25 in. slotted PVC pipe inserted to prevent the borehole from collapsing. Figure 5 shows the locations of the temporary well points together with the permanent monitoring wells. 
TWPC Fate and Transport Groundwater Model

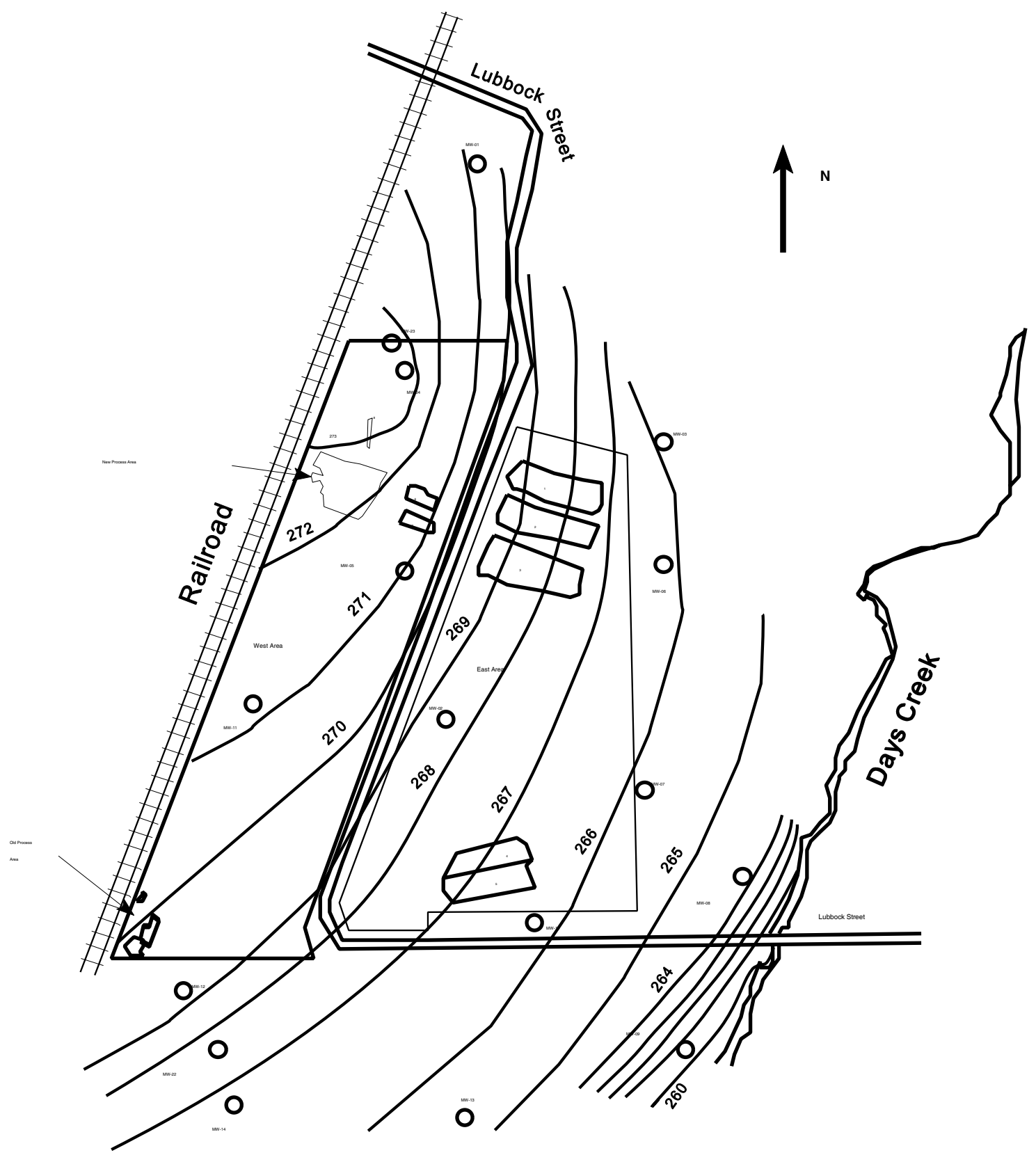

Figure 4. Gravel Zone groundwater elevation contours in 1989 (after Weston, 1989). 
TWPC Fate and Transport Groundwater Model

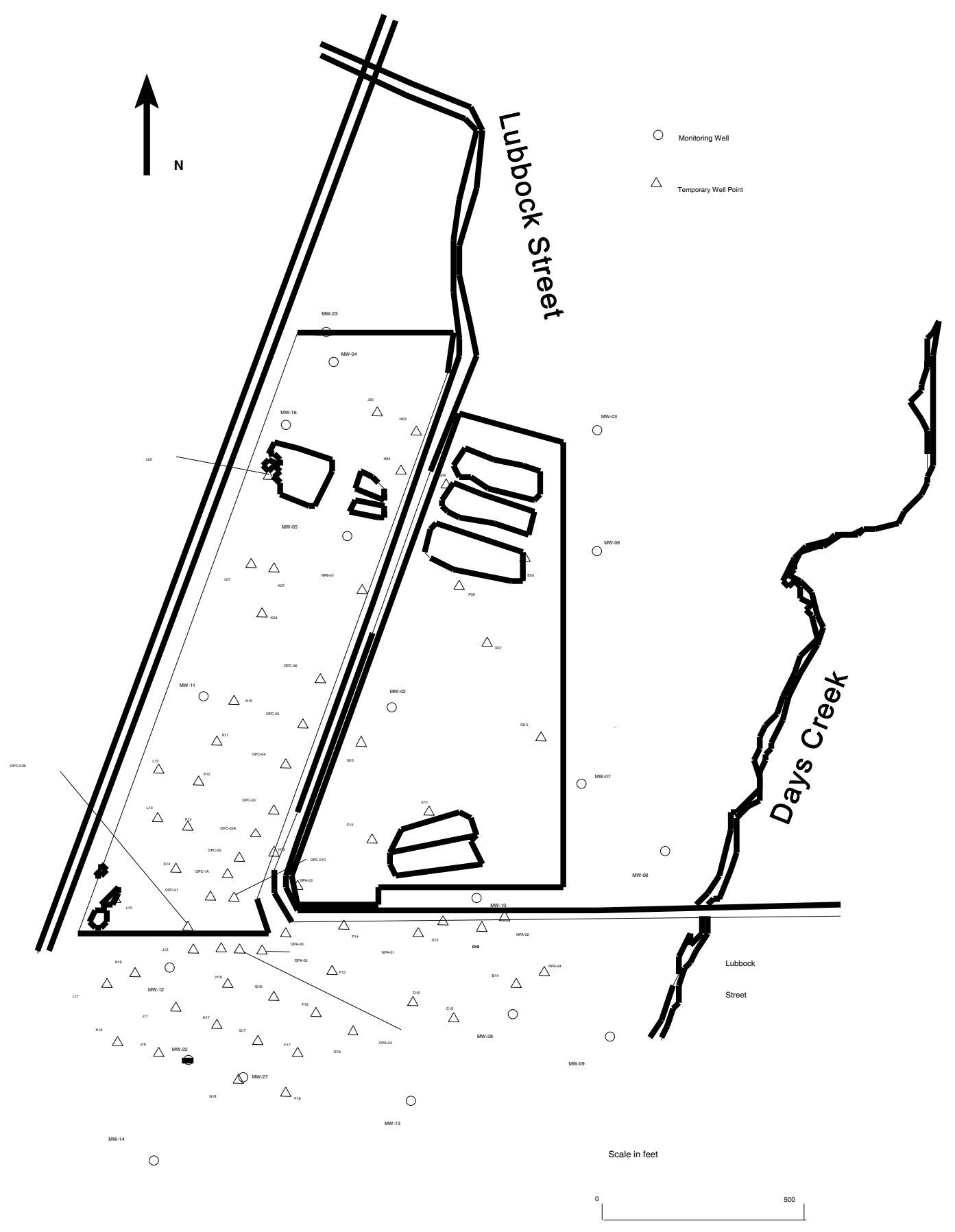

Figure 5. Location of shallow monitoring wells and temporary well points. 
TWPC Fate and Transport Groundwater Model

\section{CREOSOTE COMPOSITION AND CHARACTERISTICS}

Creosote is a complex mixture containing more then 250 individual compounds including $85 \%$ polycyclic aromatic hydrocarbons (PAHs), 10\% phenolic compounds, and 5\% N-, S-, and O- heterocyclic compounds (Cohen et al., 1993; Mueller et al., 1989). For wood treatment applications, creosote may be applied undiluted or mixed with coal tar or a petroleum oil (such as diesel fuel) in ratios that range from $80: 20$ to 50:50, creosote to carrier. The specific gravity of creosote is typically between 1.01 and 1.05 , but ranges up to 1.14 in certain blends. The viscosity of creosote is generally much greater than that of water, typically ranging from 10 to $70 \mathrm{cp}$. Chemical composition data for the type of creosote containing PCP are shown in Table 1.

Creosote was divided into five classes in Table 1, PCP, other acid extractable or phenolic compounds, light PAHs, heavy PAHs including BAP, and N,S,O-heterocyclics that include nitrogen, sulfur, or oxygen in their structure. PCP has been separated from the other acid extractable compounds because it is a specific contaminant of concern with a groundwater action limit. The heavy PAHs, particularly BAP, are also of concern. The groundwater action level of heavy PAH presented in the ROD is in terms of BAP equivalents, with BAP given a weighting of one and others a weighting of less than one according to toxicity relative to BAP. There is no concentration action limit for light PAHs in groundwater, but the mole fraction of the group is a high (85\%) fraction of the total, their concentrations are of interest, and most were included in the groundwater sampling. The N,S,O-heterocyclics also have no concentration action limit and they are a small mole fraction of the total (about 4.5\%, see Table 1). Consequently, they were not considered a significant group and not included as a model component. The creosote classes included in the model study were PCP, other acid extractables, light PAHs, and heavy PAHs.

The columns in Table 1 are numbered for convenience of reference and column descriptions are as follows:

- Column (1) is the weight fraction of the individual compound relative to its group (acid extractable, light PAH, or heavy PAH);

- Column (2) is the weight per cent of the individual compound relative to total creosote;

- Column (3) is the compound formula;

- Column (4) is the compound formula or molecular weight;

- Column (5) is compound concentration in creosote in millimoles per liter;

- Column (6) is the compound mole fraction in its group;

- Column (7) is the compound mole fraction in the total creosote;

- Column (8) is the number of carbon atoms in the compound molecule;

- Column (9) is the number of hydrogen atoms in the compound molecule;

- Column (10) is the number of oxygen atoms in the compound molecule;

- Column (11) is the solubility in milligrams/liter of the individual compound in water with no other organic compound present; 


\section{TWPC Fate and Transport Groundwater Model}

- Column (12) is compound water solubility in millimoles/liter taken alone;

- Column (13) is the effective solubility in millimoles/liter.

The effective solubility (column 13) was calculated by multiplying the individual compound solubility (column 12) by the creosote mole fraction (column 7). The rows entitled "Sum or weighted average" are the group millimoles, mole fraction per liter of creosote, group effective solubility, or weighted average number of carbon, hydrogen, or oxygen atoms per molecule. The table weighted average of the number of the various atoms is needed to estimate the number of molecules of oxygen needed in the aerobic degradation process.

The contaminants of concern at the TWPC site are organic compounds that are subject to sorption on organic material in the soil and to a limited degree on the inorganic soil matrix. Biodegradation appears to be a significant factor, but the rates are uncertain. The case for biodegradation is presented later under Section 5.5 Natural Attenuation.

Creosote and associated compounds have entered the aquifer as non-aqueous phase liquids (NAPL), primarily as dense NAPLs or DNAPLs because the specific gravity is greater than that of water. The DNAPLs have migrated along the top of the thick clay aquitard at the bottom of the aquifer and become a source within the aquifer of dissolved PAH hydrocarbons and PCP. The slope of the aquifer bottom, rather than the hydraulic gradient, controls the direction and rate of DNAPL movement. Figure 7 in Weston (1999) (copy included in Appendix A) is an elevation contour map of the top of the clay confining layer underlying the aquifer and shows a south-trending dip contrasted to the east or south-east direction of the groundwater gradient. The aquifer bottom from the new process area dips downward until it reaches a point between MW-2 and E11 (Figure 5) whereupon it rises before declining again just north of the retention ponds. The presence of DNAPL as a source of dissolved contaminants within the aquifer and the southerly dip of the aquifer bottom slope cause the direction of the observed dissolved contaminant concentration plume to be more southerly than would be indicated by the hydraulic gradient. The rise in the aquifer bottom north of the retention ponds may pose an impediment to DNAPL migration southward from the new process area. The approximate distribution of aquifer DNAPL levels in 1998 is shown on Figure 6 (see also Figure 5 of Weston, 1999; copy included in Appendix A). Note the presence of DNAPL free product near the old and new process levels and lack of free product (described in the boring logs as oily soil) away from the process areas. An exception is the presence of free product near the storm water retention ponds. Free product near those ponds and the possible impediment to NAPL migration from the new process area suggest that the retention ponds may also be a source of DNAPL. 
TWPC Fate and Transport Groundwater Model

Table 1. Creosote composition and characteristics.

\begin{tabular}{|c|c|c|c|c|c|c|c|c|c|c|c|c|c|}
\hline \multirow{2}{*}{\multicolumn{2}{|c|}{\begin{tabular}{|l} 
Creosote Composition \\
Data from (Mueller et al., 1989) and \\
\end{tabular}}} & \multirow[b]{3}{*}{ (2) } & \multirow{2}{*}{\multicolumn{5}{|c|}{$\begin{array}{l}\text { Note: Relative weight percents of dominant } \\
\text { compounds in each fraction given }\end{array}$}} & \multirow[b]{3}{*}{ (8) } & \multirow[b]{3}{*}{ (9) } & \multirow[b]{3}{*}{ (10) } & \multirow[b]{3}{*}{ (11) } & \multirow[b]{3}{*}{ (12) } & \multirow[b]{3}{*}{ (13) } \\
\hline & & & & & & & & & & & & & \\
\hline Cohen et al. (1993). & (1) & & (3) & (4) & (5) & (6) & (7) & & & & & & \\
\hline & & & & & & grp. & tot. & & & & & & Eff \\
\hline & & & & & & mole & mole & \# C & $\# \mathrm{H}$ & $\# \mathrm{O}$ & Sol. & Sol. & Sol. \\
\hline & $\begin{array}{l}\text { Rel. } \\
\text { fract. }\end{array}$ & $\begin{array}{c}\% \\
\text { of tot. }\end{array}$ & Formula & FW & $\begin{array}{c}\text { mmole } \\
/ \mathrm{L}\end{array}$ & fract & fract & atms & atms: & atms & $(\mathrm{mg} / \mathrm{L})$ & $(\mathrm{mm} / \mathrm{L})$ & $(\mathrm{mm} / \mathrm{L})$ \\
\hline $\begin{array}{c}\text { ACID } \\
\text { EXTRACTABLES }\end{array}$ & \multicolumn{3}{|c|}{$9.0 \%$ of total creosote } & & & & & & & & & & \\
\hline phenol & 0.20 & $2.0 \%$ & $\mathrm{C}_{6} \mathrm{H}_{6} \mathrm{O}$ & 94.113 & 0.213 & 0.338 & 0.034 & 6 & 6 & 1 & 82800 & 879.79 & $3.02 \mathrm{E}+01$ \\
\hline cresols & 0.30 & $3.0 \%$ & $\mathrm{C}_{21} \mathrm{H}_{24} \mathrm{O}_{3}$ & 324.42 & 0.092 & 0.147 & 0.015 & 20 & 24 & 3 & 19320 & 59.55 & 8.91E-01 \\
\hline Xylenols & 0.35 & $3.5 \%$ & $\mathrm{C}_{8} \mathrm{H}_{10} \mathrm{O}$ & 122.17 & 0.286 & 0.456 & 0.046 & 8 & 10 & 1 & 2000 & 16.37 & $7.59 \mathrm{E}-01$ \\
\hline 2,3,5-Trimethylphenol & 0.05 & $0.5 \%$ & $\mathrm{C}_{9} \mathrm{H}_{12} \mathrm{O}$ & 136.19 & 0.037 & 0.058 & 0.006 & 9 & 12 & 0 & 1000 & 7.34 & 4.36E-02 \\
\hline Sum or weighted average & & & & & 0.628 & 1.00 & 0.102 & 8.6 & 10.1 & 1.2 & & & 31.93 \\
\hline $\begin{array}{l}\text { SPECIAL ACID } \\
\text { EXTRACTABLE }\end{array}$ & \multicolumn{3}{|c|}{$1.0 \%$ of total creosote } & & & & & & & & & & \\
\hline PCP & 0.10 & $1.0 \%$ & $\mathrm{C}_{6} \mathrm{HCl}_{5} \mathrm{O}$ & 266.34 & 0.038 & 1.000 & 0.006 & 6 & 1 & 1 & 20 & 0.075 & 4.56E-04 \\
\hline BASE/NEUTRALS & \multicolumn{3}{|c|}{$85.0 \%$ of total creosote } & & & & & & & & & & \\
\hline \multicolumn{14}{|l|}{ Light PAH } \\
\hline Naphthalene & 0.13 & $11.1 \%$ & $\mathrm{C}_{10} \mathrm{H}_{8}$ & 128.17 & 0.862 & 0.169 & 0.139 & 10 & 8 & 0 & 31 & 0.24 & 3.37E-02 \\
\hline Methylnaphthalenes & 0.21 & $17.9 \%$ & $\mathrm{C}_{11} \mathrm{H}_{10}$ & 142.20 & 1.255 & 0.245 & 0.203 & 11 & 10 & & 24.6 & 0.14 & 2.86E-02 \\
\hline Dimethylnaphthalenes & 0.08 & $6.8 \%$ & $\mathrm{C}_{12} \mathrm{H}_{12}$ & 156.23 & 0.435 & 0.085 & 0.070 & 12 & 12 & & 10 & 0.064 & 4.51E-03 \\
\hline Biphenyl & 0.08 & $6.8 \%$ & $\mathrm{C}_{12} \mathrm{H}_{10}$ & 154.21 & 0.441 & 0.086 & 0.071 & 12 & 10 & & 6 & 0.065 & 4.62E-03 \\
\hline Acenaphthene & 0.04 & $3.4 \%$ & $\mathrm{C}_{12} \mathrm{H}_{10}$ & 154.21 & 0.220 & 0.043 & 0.036 & 12 & 10 & & 4.24 & 2.75E-02 & $9.80 \mathrm{E}-04$ \\
\hline Fluorene & 0.08 & $6.8 \%$ & $\mathrm{C}_{13} \mathrm{H}_{10}$ & 166.23 & 0.409 & 0.080 & 0.066 & 13 & 10 & & 1.98 & 1.19E-02 & $7.88 \mathrm{E}-04$ \\
\hline Phenanthrene & 0.13 & $11.1 \%$ & $\mathrm{C}_{14} \mathrm{H}_{10}$ & 178.24 & 0.620 & 0.121 & 0.100 & 14 & 10 & & 1.18 & $6.62 \mathrm{E}-03$ & $6.64 \mathrm{E}-04$ \\
\hline Anthracene & 0.13 & $11.1 \%$ & $\mathrm{C}_{14} \mathrm{H}_{10}$ & 178.24 & 0.620 & 0.121 & 0.100 & 14 & 10 & & 0.043 & $2.43 \mathrm{E}-04$ & $2.44 \mathrm{E}-05$ \\
\hline Fluoranthene & 0.04 & $3.4 \%$ & $\mathrm{C}_{16} \mathrm{H}_{10}$ & 202.26 & 0.168 & 0.033 & 0.027 & 16 & 10 & & 0.206 & $1.02 \mathrm{E}-03$ & 2.77E-05 \\
\hline Pyrene & 0.02 & $1.7 \%$ & $\mathrm{C}_{16} \mathrm{H}_{10}$ & 202.26 & 0.084 & 0.016 & 0.014 & $16 \mid$ & 10 & & 0.135 & 6.67E-04 & 9.07E-06 \\
\hline Sum or weighted average & & & & & 5.12 & 1.00 & 0.83 & 12.2 & 9.8 & & & & 7.86E-02 \\
\hline \multicolumn{14}{|l|}{ Heavy PAH } \\
\hline Chrysene & 0.02 & $1.7 \%$ & $\mathrm{C}_{18} \mathrm{H}_{12}$ & 228.3 & 0.074 & 0.389 & 0.012 & 18 & 12 & & 0.0016 & 7.01E-06 & $8.44 \mathrm{E}-08$ \\
\hline 2,3-Benzo(b)fluorene & 0.01 & $0.9 \%$ & $\mathrm{C}_{20} \mathrm{H}_{12}$ & 216.28 & 0.039 & 0.205 & 0.006 & 17 & 12 & & 0.1 & 4.62E-04 & $2.94 \mathrm{E}-06$ \\
\hline Methylanthracene & 0.01 & $0.9 \%$ & $\mathrm{C}_{15} \mathrm{H}_{12}$ & 192.26 & 0.044 & 0.231 & 0.007 & 15 & 12 & & 0.1 & $5.20 \mathrm{E}-04$ & 3.72E-06 \\
\hline Benzo(a)pyrene & 0.01 & $0.9 \%$ & $\mathrm{C}_{20} \mathrm{H}_{12}$ & 252.32 & 0.034 & 0.176 & 0.005 & \begin{tabular}{|l|}
20 \\
\end{tabular} & 12 & & 0.0016 & $6.42 \mathrm{E}-06$ & $3.50 \mathrm{E}-08$ \\
\hline Sum or weighted average & & & & & 0.192 & & 0.031 & 17.5 & 12 & & & & $6.78 \mathrm{E}-06$ \\
\hline Anthraquinone & 0.01 & $0.9 \%$ & $\mathrm{C}_{14} \mathrm{H}_{8} \mathrm{O}_{2}$ & 208.22 & 0.041 & 0.213 & 0.007 & 14 & 8 & 1 & 500 & $2.40 \mathrm{E}+00$ & 1.59E-02 \\
\hline N,S,O-HETEROCYCLICS & \multicolumn{3}{|c|}{$5.0 \%$ of total creosote } & & & & & & & & & & \\
\hline Quinoline & 0.10 & $0.5 \%$ & $\mathrm{C}_{9} \mathrm{H}_{7} \mathrm{~N}$ & 129.16 & 0.039 & 0.156 & 0.006 & 9 & 7 & & 100 & 7.74E-01 & $4.85 \mathrm{E}-03$ \\
\hline Isoquinoline & 0.10 & $0.5 \%$ & $\mathrm{C}_{9} \mathrm{H}_{7} \mathrm{~N}$ & 129.16 & 0.039 & 0.156 & 0.006 & 9 & 7 & & 100 & 7.74E-01 & 4.85E-03 \\
\hline Carbazole & 0.10 & $0.5 \%$ & $\mathrm{C}_{12} \mathrm{H}_{9} \mathrm{~N}$ & 167.21 & 0.030 & 0.121 & 0.005 & 12 & 9 & & 7.48 & $.98 \mathrm{E}+00$ & $2.16 \mathrm{E}-04$ \\
\hline 2,4-Dimethylpyridine & 0.10 & $0.5 \%$ & $\mathrm{C}_{7} \mathrm{H}_{9} \mathrm{~N}$ & 107.15 & 0.047 & 0.188 & 0.008 & 7 & 9 & & 100 & 9.33E-01 & 7.04E-03 \\
\hline Benzo(a)thiophene & 0.10 & $0.5 \%$ & $\mathrm{C}_{8} \mathrm{H}_{6} \mathrm{~S}$ & 134.2 & 0.037 & 0.150 & 0.006 & 8 & 6 & & 100 & $7.45 \mathrm{E}-01$ & $4.49 \mathrm{E}-03$ \\
\hline Dibenzothiophene & 0.10 & $0.5 \%$ & $\mathrm{C}_{12} \mathrm{H}_{8} \mathrm{~S}$ & 184.3 & 0.027 & 0.109 & 0.004 & 12 & 8 & & 100 & $5.43 \mathrm{E}-01$ & $2.38 \mathrm{E}-03$ \\
\hline Dibenzofuran & 0.10 & $0.5 \%$ & $\mathrm{C}_{12} \mathrm{H}_{8} \mathrm{O}$ & 168.19 & 0.030 & 0.120 & 0.005 & 12 & 8 & 1 & 10 & $.95 \mathrm{E}+00$ & $2.86 \mathrm{E}-04$ \\
\hline Sum or weighted average & & & & & 0.248 & & 0.04 & 9.5 & 7.7 & .14 & & & 0.024 \\
\hline TOTAL & & $97.5 \%$ & & & 6.1832 & & 1.01 & & & & & & \\
\hline
\end{tabular}


TWPC Fate and Transport Groundwater Model

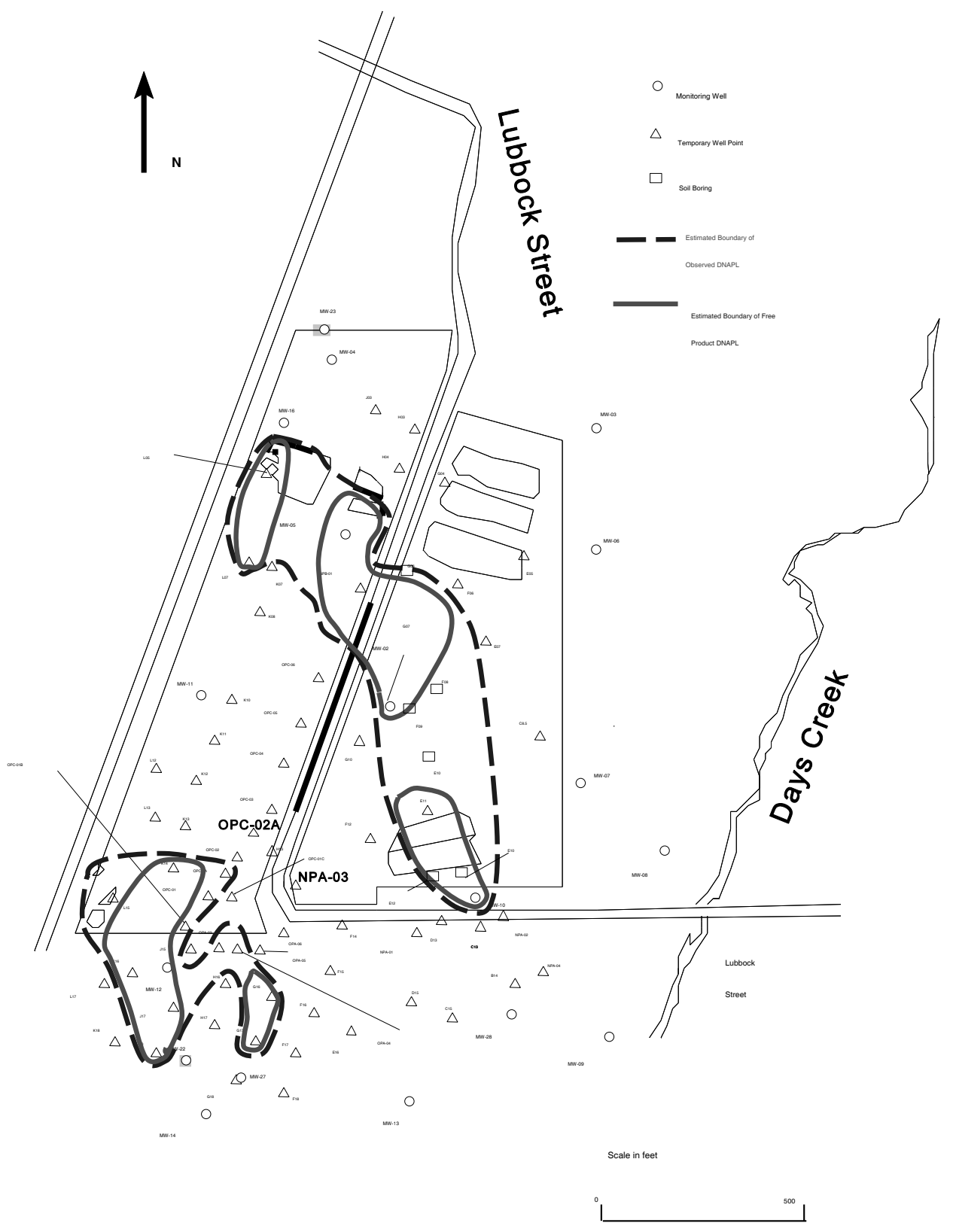

Figure 6. Estimated extent of DNAPL in the aquifer. 
TWPC Fate and Transport Groundwater Model

\section{MODELING APPROACH}

After reviewing site characteristics, data, and the project goals, an approach to modeling the groundwater flow and contaminant transport at the Texarkana Wood Preserving (TWPC) Superfund site was developed by:

(1) constructing a site conceptual model of flow and transport,

(2) identifying an appropriate mathematical framework and computational codes which adequately represent groundwater flow, NAPL dissolution, and contaminant reactions and transport at the site,

(3) identifying code input parameters,

(4) developing parameter values and identifying the key parameters that control contaminant movement, and

(5) making preliminary and final model runs and evaluating the results.

These are discussed in order.

\section{CONCEPTUAL MODEL}

A properly developed conceptual model is a key to successful computer modeling of contaminant fate and transport. Key elements of the conceptual model are presented here along with a discussion of the limitations.

Contaminants in the form of NAPL seep downward or dissolved contaminants are leached from the surface soils by rainfall or by infiltrating pond water and transported vertically through the vadose zone to the shallow aquifer. Horizontal transport towards Day's Creek occurs in the shallow aquifer. Sorption may retard trace contaminant transport relative to water flow. The degree of such retardation will depend on the organic content of the soil and will be limited by high concentrations of organic matter in the groundwater. Biodegradation causes a reduction of contaminant concentrations with time. The amount of dissolved contaminant available for transport is limited by the contaminant solubility.

Advection (transport by groundwater flow) and dispersion (contaminant spreading within the flow regime) are other features of the conceptual model. Dispersion may be significant in the aquifer, but not as important as DNAPL flow along the bottom of the aquifer. The Gravel Zone aquifer component is a thin, single layer and thus flow is considered two-dimensional. For particle tracking and contaminant transport a constant aquifer thickness is assumed.

Two or more contaminated source areas (at least the old and new process areas) mean several separate surface soil/vadose zone/NAPL components exist that could contaminate the aquifer. An alternative to evaluating the surface soils and vadose zone is to assume that the vadose zone around the process areas is saturated with creosote and NAPL is present in the aquifer adjacent to the process areas. DNAPL flow follows the dip of the clay layer underlying the aquifer and thus spreads the DNAPL source of dissolving contaminants. The DNAPL in the aquifer may become the primary source of contamination and DNAPL water solubility influences the rate of contaminant release. Recent data showing that DNAPL is present in aquifer wells at significant distances down-dip of both the old and new process areas indicated that DNAPL dissolution in the aquifer is an important, perhaps the dominant, source of dissolved contaminants. 
TWPC Fate and Transport Groundwater Model

A steady-state flow model has been assumed. Head gradients calculated from water levels measured at different years are comparable (see Figure 4 and Figure 7 of Weston (1999). Head data show seasonal fluctuations up to two feet, but the total travel time from the process areas to Day's Creek is on the order of decades and seasonal fluctuations have little impact on overall contaminant migration over that period. Using average hydraulic heads or even heads measured at a particular time will have little impact on the final results of contaminant transport analysis as long as the hydraulic gradients across the site are correctly represented.

\subsection{Contaminant Sources and Transport Pathway}

Components of the contaminant transport pathway are:

(1) contaminated surface soils,

(2) a short vadose zone between the contaminated surface soils and the aquifer, and

(3) DNAPL in the aquifer that is a source of dissolved contaminants,

(4) the shallow Gravel Zone aquifer between the site and Day's Creek.

The most important feature of the soil contamination are the location of "hot spots" that are significant sources of aquifer contamination. It is clear from Figure 2 that soils are contaminated down to the aquifer around the old and new process areas and such soils are sources of aquifer contamination. It is also clear from Figure 6 (see also Figure 5 of Weston, 1999) that NAPL has contaminated the aquifer over a rather large area and this is probably the dominant source of current dissolved contaminants in the aquifer. The stormwater retention ponds (ponds 4 and 5) on the east side of the site (see Figures 1 and 3) may also have been a source of contamination. The soil beneath those ponds was estimated to be contaminated down to at least $7 \mathrm{ft}$ in 1988 (see Figure 3). Recent sampling in the ponds shows evidence of creosote saturation in the pond bottoms (Weston, 1999, particularly the sampling logs).

Figure 7 (see also Figure 4 of Weston, 1999) shows contaminant concentrations compared to action levels during the 1997-98 sampling campaign at the monitoring wells and temporary well points. There is a strong correlation between the NAPL plumes and the dissolved contaminant concentrations in well samples. It is also of note that the direction of the dissolved contaminant plumes is not well oriented with the hydraulic gradient, indicating that the DNAPL is the primary source of dissolved contaminants rather than contaminated soils in the immediate vicinity of the old and new process areas. At the same time, the dissolved contaminant plumes do not extend much beyond the DNAPL plume indicating the presence of a significant contaminant reduction process such as biodegradation. 
TWPC Fate and Transport Groundwater Model

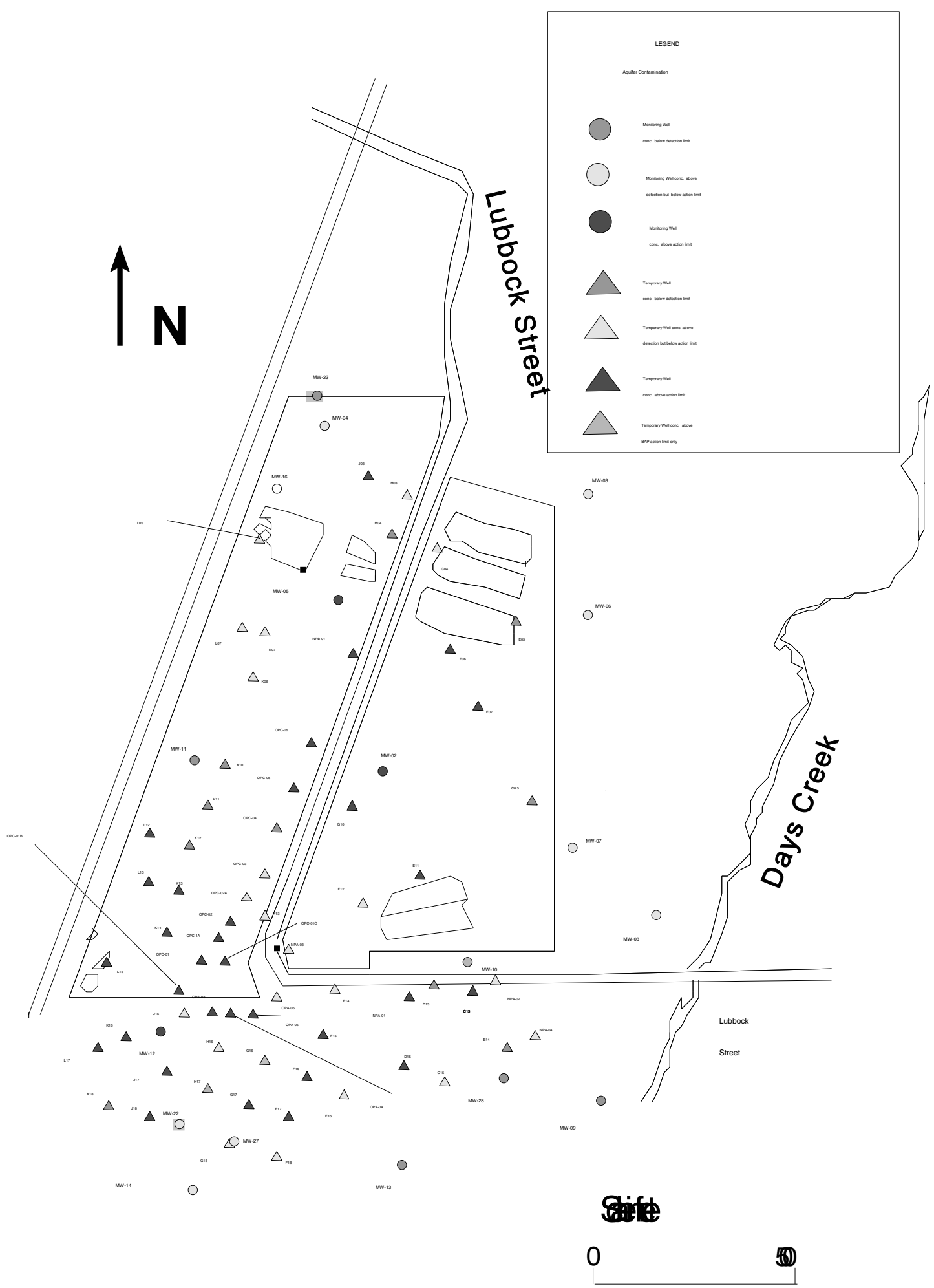

Figure 7. Maximum PCP or BAP concentrations in 1997- 1998 relative to action levels. 
TWPC Fate and Transport Groundwater Model

\subsection{Surface Soils and Vadose Zone Transport}

A simple surface soil and vadose zone conceptual model is used. The conceptual model consists of DNAPL seepage and dissolved contaminants infiltrating downward from shallow contaminated surface soils to the aquifer. A detailed evaluation of transport in the surface soils and vadose zone would require an elaborate conceptual model including multi-phase transport and very sophisticated computer codes. Such a detailed conceptual model would require a comprehensive and expensive data collection effort to quantitatively define the system and cannot be justified. As the location, volume, area, and degree of contamination of the soil to be capped is refined, some additional detail may be indicated in evaluating contaminant transport from the capped soil down to the aquifer. A simplified conceptual model of the surface soil and vadose zone pathway was used.

\subsection{NAPL Sources of Dissolved Contaminants}

When released at the surface, NAPLs move downward under the force of gravity and tend to follow preferential pathways such as along the surface of sloping fine-grained layers or through fractures in soil or rock. Large NAPL releases can extend laterally much farther from the release point than would otherwise be expected. Most of the creosote/PCP wood preservative treatment liquid is DNAPL, which is heavier than water and migrates downward upon entering the aquifer. This DNAPL releases more soluble constituents into the groundwater solution over time with the individual compound release rates dependent on solubility and mole fraction in the creosote. After surface releases have stopped, NAPLs remaining in the subsurface tend to "weather" over time as volatile and soluble components are depleted from NAPL surfaces. Even considering this "weathering" effect, subsurface NAPLS continue to be a source of contaminants to ground water for a very long time. It is impractical to simulate hundreds of individual PAH compounds from Naphthalene to BAP. Our approach was to divide the compounds identified in Table 1 into four classes each with an average solubility and molecular structure. PCP is modeled individually because of its status as a contaminant of concern. Most other acid extractable or phenolic compounds are grouped together. Light PAHs form one group and heavy PAHs form another.

\subsubsection{Advection}

\subsection{Aquifer Flow and Transport}

The aquifer flow velocity is one of the key elements in estimating contaminant fate and transport. There are two ways to estimate the groundwater velocity. One is to obtain data for a conservative (moving with the groundwater) tracer and the other is to calculate velocity from the hydraulic parameters. The former method is more reliable and is preferred, but such tracer data are difficult and expensive to collect and are not available for the TWPC site. However, contaminant data at selected wells and past operational history of the site can be used to estimate velocity along the flow path from the new process area to Day's Creek. Calculating velocity from sparse measurements of the hydraulic parameters is subject to uncertainty because of large spatial variability in hydraulic conductivity. Our initial approach was to calculate a reasonable range of average velocities from hydraulic parameters and attempt to narrow or constrain the range with historical contaminant data. The value of this approach is shown by preliminary calculations using K data from RI slug tests in 4 wells (MW-01, MW-06, MW-09, and MW-14) available prior to 1997. Those calculations yielded a low average linear velocity and groundwater travel time that was higher than indicated by observed aquifer contaminant concentrations. Additional K measurements in 1997 (Weston, 1997) allowed estimating a higher and more consistent average linear velocity. Average groundwater pore velocity or average linear velocity is given by

$$
\mathrm{v}_{\mathrm{p}}=\mathrm{KI} / \mathrm{n}_{\mathrm{e}}
$$




\section{TWPC Fate and Transport Groundwater Model}

where

$\mathrm{v}_{\mathrm{p}}=$ average linear (pore) velocity,

$\mathrm{K}=$ average hydraulic conductivity,

$\mathrm{I}=$ average hydraulic gradient, and

$\mathrm{n}_{\mathrm{e}}=$ average effective porosity.

Measured $\mathrm{K}$ at the site ranges from 0.1 to $4 \mathrm{ft} /$ day. Average $\mathrm{K}$ is estimated at about 1.4 from the geometric means of K measurements in Wells MW-05, MW-02, and MW-10. If only data from MW-02 and MW-05 are used, the geometric mean K is $2.2 \mathrm{ft} /$ day. However, the small number of tests, a very limited aquifer volume measured in each slug test, and experience with spatial variability suggest that the true average $\mathrm{K}$ along the flow path could be somewhat higher or lower than these values. Effective porosity has not been measured, but the range of this parameter is generally much less than the range of $\mathrm{K}$ and probably falls between 0.10 to 0.35 based on the lithology. An average hydraulic gradient of 0.007 is reported in Weston (1989). Using a K range of 1.4-2.2 ft/day, the assumed range of $\mathrm{n}_{\odot}$ and the reported value of $\mathrm{I}$, the average linear velocity is calculated to range between 0.03 and $0.15 \mathrm{ft} / \mathrm{day}$.

\subsubsection{Dispersion}

Dispersion refers to a process whereby a plume will spread out from the position indicated by strictly advective flow. Such spreading occurs in a longitudinal direction (along the direction of groundwater flow), transversely (horizontally perpendicular to groundwater flow), and vertically downwards due to mechanical mixing in the aquifer and chemical diffusion. Selecting dispersivity values is difficult given the impracticability of measuring dispersion in the field. One of the important features about dispersion is its dependence on scale. Simple estimation techniques based on the length of the plume or distance to a measuring point ("scale") are available from a compilation of field data. The scale estimation technique of $\mathrm{Xu}$ and Eckstein (1995) is used herein. Dispersion or spreading is a real phenomenon, but our experience is that the degree or intensity is very hard to quantify and dispersion often becomes the model feature that is made to account for other unknowns. The approach used in this study is to assign dispersivities based upon a simple relationship to scale and adjust other advective and chemical parameters to match observed data.

\subsubsection{Sorption}

Contaminant sorption along the flow path might be significant, but is likely to be a strong function of the percentage of organic carbon in the uncontaminated soil matrix of the surface soil, vadose zone, and particularly the aquifer. Measurements of organic carbon in site soils were obtained, so it was possible to estimate potential trace contaminant sorption. The concept of sorption is most valuable for trace contamination. Where dissolved organic concentrations are high, the limited number of sorption sites on the matrix are quickly filled and sorption ceases to be a factor. Sorption may be most noticeable in retarding the contaminants far downgradient of the sources where anthropogenic organic compounds including contaminants are present in low concentrations. In the end, sorption was not included in the model because a continuing supply of organic material from the dissolving DNAPL was believed to overwhelm the significance of sorption for the greater part of the flow path. Ignoring sorption was conservative near the end of the flow path where the total dissolved organic carbon concentration was low. 
TWPC Fate and Transport Groundwater Model

\subsection{Natural Attenuation}

One of the potential processes affecting transport that is of particular interest is monitored natural attenuation. The EPA's Office of Solid Waste and Emergency Response (OSWER) define natural attenuation in their Directive 9200.4-17 (EPA, 1997) as:

The term "monitored natural attenuation," as used in this Directive, refers to the reliance on natural attenuation processes (within the context of a carefully controlled and monitored clean-up approach) to achieve site-specific remedial objectives within a time frame that is reasonable compared to other methods. The "natural attenuation processes" that are at work in such a remediation approach include a variety of physical, chemical, or biological processes that, under favorable conditions, act without human intervention to reduce the mass, toxicity, mobility, volume, or concentration of contaminants in soil and ground water. These in-situ processes include, biodegradation, dispersion, dilution, sorption, volatilization, and chemical or biological stabilization, transformation, or destruction of contaminants.

Monitored natural attenuation is appropriate as a remedial approach only when it can be demonstrated capable of achieving a site's remedial objectives within a time frame that is reasonable compared to that offered by other methods and where it meets the applicable remedy selection program for a particular OSWER program. EPA, therefore, expects that monitored natural attenuation typically will be used in conjunction with active remediation measures (e.g., source control), or as a follow-up to active remediation measures that have already been implemented.

Dispersion and dilution are expected to cause a measurable, but not a large, effect on contaminant concentrations and hence toxicity. The Gravel Zone aquifer is not thick and the distance from the process areas to Day's Creek is not large (about 1,100 feet). These geometric considerations alone reduce the effects of dispersion. The Gravel Zone layer has been identified as a confined aquifer (Weston 1989), but there is undoubtedly some rainfall infiltrating to the aquifer along the flow path. The flow added to the aquifer is probably small relative to flow in the aquifer as it enters the site from the west. Dilution caused by infiltrating rainfall is therefore assumed to be small. Volatilization and chemical and biochemical stabilization are not expected to be factors at the TWPC site.

When relying on natural attenuation processes for site remediation, EPA prefers those processes that degrade contaminants (EPA, 1997). Biodegradation is perhaps the only component of natural attenuation at the TWPC site that has the potential to significantly reduce the total contaminant mass. Other components (dispersion, dilution, sorption) may reduce the concentration or delay movement, but biodegradation can reduce the total contaminant mass in the system. In order to predict the long-term behavior of the total noncarcinogenic or light PAHs (LPAH), total carcinogenic or heavy PAHs (HPAH), and PCP, it is important to have a good understanding of the operant natural attenuation mechanisms including the interactions between contaminants, anthropogenic/natural carbon, and inorganic electron acceptors at the site. Detailed site characterization was needed to adequately understand these processes. A technical protocol for natural attenuation of chlorinated solvents in groundwater tied closely with the OSWER directive was also developed for the EPA (Wiedemeier et al, 1998). There are additional considerations with PAH and PCP, but the technical protocol has considerable applicability in evaluating biodegradation at the TWPC site.

The OSWER Directive 9200.4-17 (EPA, 1997) identifies three lines of evidence that can be used to estimate natural attenuation of chlorinated aliphatic hydrocarbons, including: 


\section{TWPC Fate and Transport Groundwater Model}

(1) Historical ground water and/or soil chemistry data that demonstrate a clear and meaningful trend of decreasing contaminant mass and/or concentration over time at appropriate monitoring or sampling points. (In the case of a ground water plume, decreasing concentrations should not be solely the result of plume migration. In the case of inorganic contaminants, the primary attenuating mechanism should also be understood.)

(2) Hydrogeologic and geochemical data that can be used to demonstrate indirectly the type(s) of natural attenuation processes active at the site, and the rate at which such processes will reduce contaminant concentrations to required levels. For example, characterization data may be used to quantify the rates of contaminant sorption, dilution, or volatilization, or to demonstrate and quantify the rates of biological degradation processes occurring at the site.

(3) Data from field or microcosm studies (conducted in or with actual contaminated site media) which directly demonstrate the occurrence of a particular natural attenuation process at the site and its ability to degrade the contaminants of concern (typically used to demonstrate biological degradation processes only).

The EPA natural attenuation technical protocol for chlorinated solvents (Wiedemeier et al, 1998) states the following:

The OSWER Directive provides the following guidance on interpreting the lines of evidence: Unless EPA or the implementing state agency determines that historical data (Number 1 above) are of sufficient quality and duration to support a decision to use monitored natural attenuation, EPA expects that data characterizing the nature and rates of natural attenuation processes at the site (Number 2 above) should be provided. Where the latter are also inadequate or inconclusive, data from microcosm studies (Number 3 above) may also be necessary. In general, more supporting information may be required to demonstrate the efficacy of monitored natural attenuation at those sites with contaminants which do not readily degrade through biological processes (e.g., most non-petroleum compounds, inorganics), at sites with contaminants that transform into more toxic and/or mobile forms than the parent contaminant, or at sites where monitoring has been performed for a relatively short period of time. The amount and type of information needed for such a demonstration will depend upon a number of site-specific factors, such as the size and nature of the contamination problem, the proximity of receptors and the potential risk to those receptors, and other physical characteristics of the environmental setting (e.g., hydrogeology, ground cover, or climatic conditions).

The first line of evidence does not prove that contaminants are being destroyed. Reduction in contaminant concentration could be the result of advection, dispersion, dilution from recharge, sorption, and volatilization (i.e., the majority of apparent contaminant loss could be due to dilution). However, this line of evidence is critical for determining if any exposure pathways exist for current or potential future receptors. In order to evaluate remediation by natural attenuation at most sites, the investigator will have to determine whether contaminant mass is being destroyed. This is done using either, or both, of the second or third lines of evidence. The second line of evidence relies on chemical and physical data to show that contaminant mass is being destroyed, not just being diluted or sorbed to the aquifer matrix. For many contaminants, biodegradation is the most important process, but for certain contaminants nonbiological reactions are also important. The second line of evidence is divided into two components:

- Using chemical analytical data in mass balance calculations to show that decreases in contaminant and electron acceptor/donor concentrations can be directly correlated to increases 


\section{TWPC Fate and Transport Groundwater Model}

in metabolic end products/daughter compounds. This evidence can be used to show that electron acceptor/donor concentrations in ground water are sufficient to facilitate degradation of dissolved contaminants. Solute fate and transport models can be used to aid mass balance calculations and to collate and present information on degradation.

- Using measured concentrations of contaminants and/or biologically recalcitrant tracers in conjunction with aquifer hydrogeologic parameters such as seepage velocity and dilution to show that a reduction in contaminant mass is occurring at the site and to calculate biodegradation rate constants.

The biodegradation rate constants are used in conjunction with the other fate and transport parameters to predict contaminant concentrations and to assess risk at downgradient performance evaluation wells and within the area of the dissolved plume. Microcosm studies may be necessary to physically demonstrate that natural attenuation is occurring. Microcosm studies can also be used to show that indigenous biota are capable of degrading site contaminants at a particular rate. Microcosm studies for the purpose of developing rate constants should only be undertaken when they are the only means available to obtain biodegradation rate estimates.

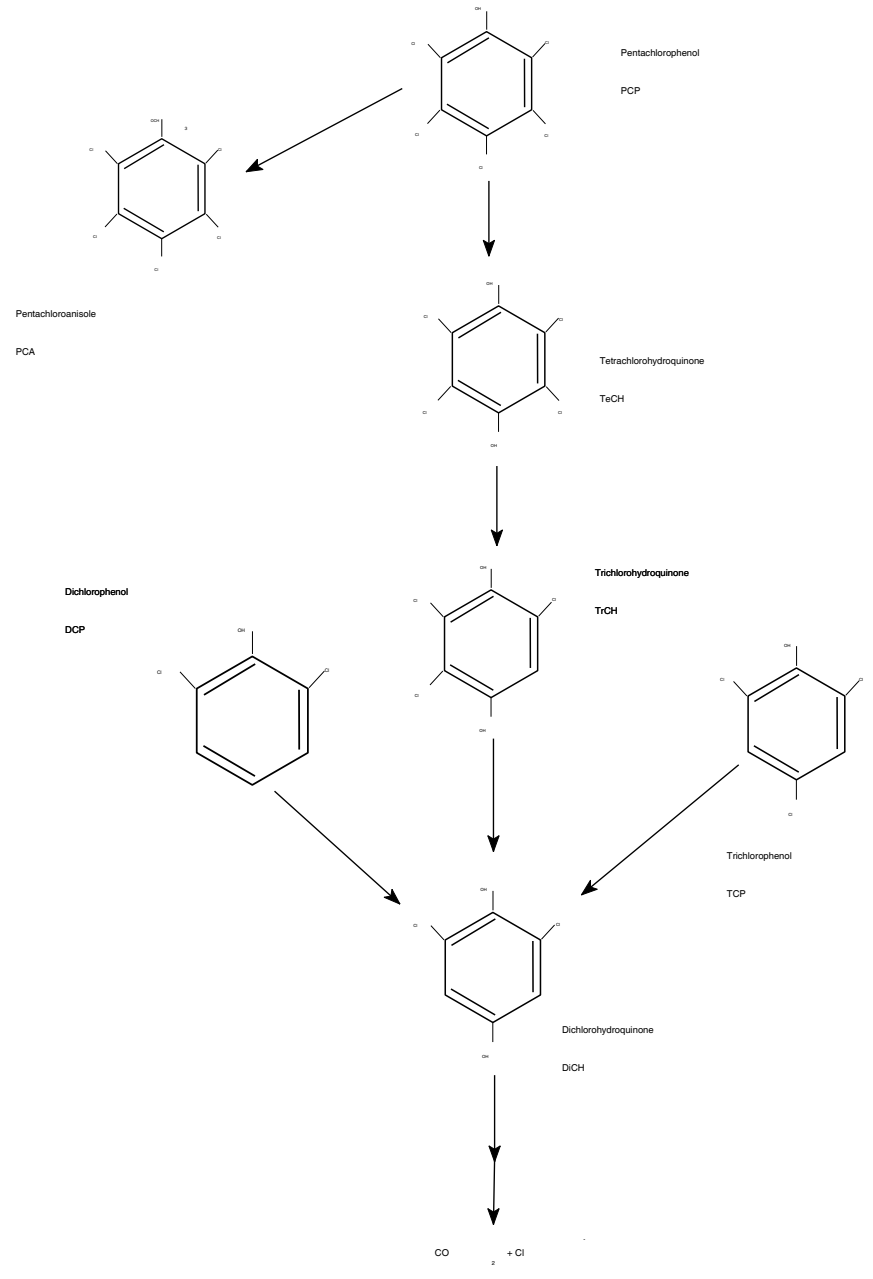

Figure 8. PCP oxidative biodegradation pathway.
The microbial degradation of PAHs is generally an aerobic process; the bacteria require oxygen to grow and metabolize the contaminants. PCP can be oxidized to pentachloroanisole (PCA) and less chlorinated derivatives, typically anisoles and hydroquinones (Davis, et al. 1994, Chanama, 1996). Oxidation is associated with a decrease in oxygen concentration, an accumulation of daughter products, and an increase in the concentration of chloride ions. The oxidative PCP pathway is graphically presented on Figure 8.

Reductive dechlorination under anaerobic conditions is also an important process for natural biodegradation of PCP. Because oxygen and other electron acceptors have been depleted, the chlorinated hydrocarbon is used as an electron acceptor, not as a source of carbon, and a chlorine atom is removed and replaced with a $\mathrm{OH}$ molecule. Reductive dechlorination of PCP is also 
TWPC Fate and Transport Groundwater Model

associated with an accumulation of daughter products and an increase in the concentration of chloride ions. Successive dechlorination produces daughter products with fewer chlorine atoms per molecule as shown in Figure 9 (Davis et al., 1994, Chanama, 1996). Unfortunately, technical-grade PCP used in treating wood is impure, containing only $85-90 \%$ PCP, with tetrachlorophenol (TeCP) and trichlorophenol (TCP) present as impurities in the original formulation. Hence, only the presence of dichlorophenol (DCP) and chlorophenol (CP) are evidence of PCP reductive dechlorination.

High concentrations of PCP appear to be toxic to the bacteria. Davis, et al. (1994) determined a biocidal threshold of $20 \mathrm{mg} / \mathrm{L}$ using more than 80 field samples at their site. They summed the mole fraction of daughter products not in the original formulation

$(\mathrm{DCP}+\mathrm{CP}+\mathrm{PCA})$ and compared the total with the PCP concentration measured in that sample. Their data demonstrated that biodegradation occurred where concentrations were less than $20 \mathrm{mg} / \mathrm{L}$. Above this level, degradation occurs, but the sum of daughter product mole fractions decreases substantially.

Wiedemeier et al. (1995) presented an analytical protocol including all the parameters necessary to document natural attenuation of fuel hydrocarbons. Wiedemeier et al. (1998) outline a screening process to determine whether biodegradation of chlorinated solvents is occurring. We have adapted the protocols to apply to PAH and PCP biodegradation, respectively. The first step is to identify analytical parameters for PAH and PCP for preliminary screening. Table 2 presents the analytical parameters for PAH adapted from the fuel hydrocarbon protocol and Table 3 lists the parameters for PCP adapted from the chlorinated solvent protocol.

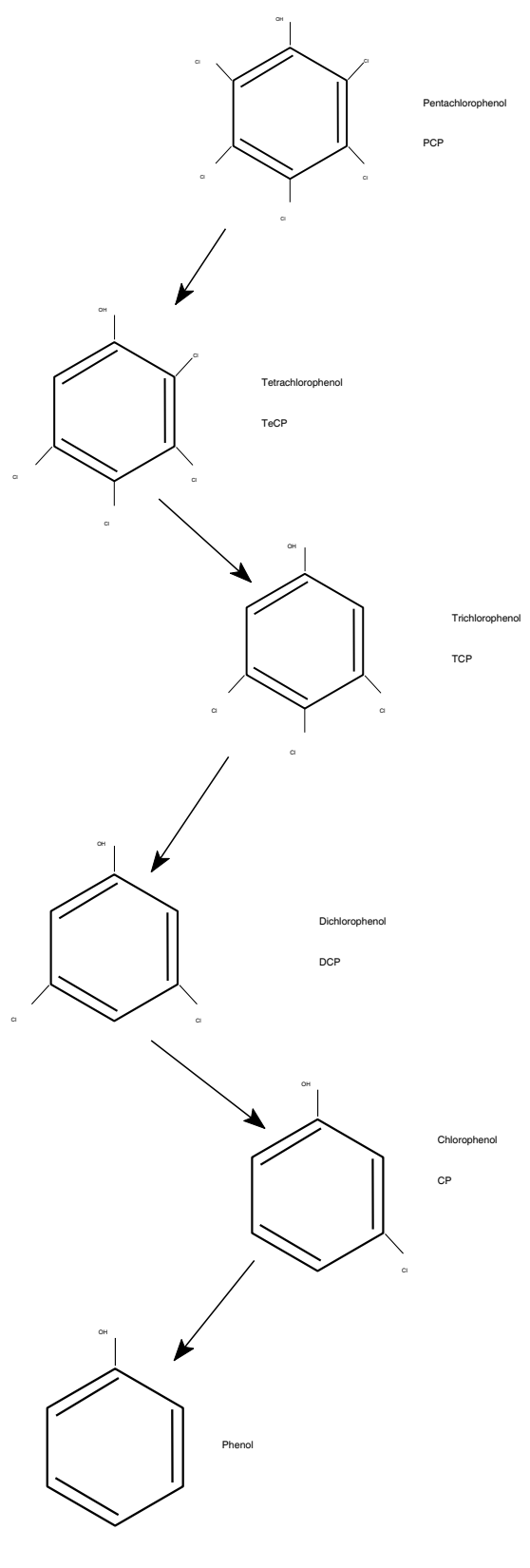

Figure 9. Example of PCP reductive biodegradation pathway 
TWPC Fate and Transport Groundwater Model

Table 2. Analytical Parameters for PAH Screening

\begin{tabular}{|c|c|c|}
\hline Analyte & Concentration & Interpretation \\
\hline Dissolved Oxygen & $\begin{array}{l}\text { below } \\
\text { background }\end{array}$ & indicative of anaerobic conditions \\
\hline Dissolved Oxygen & near background & aerobic biodegradation of $\mathrm{PAH}$ possible \\
\hline $\begin{array}{l}\text { Oxidation Reduction } \\
\text { Potential }\end{array}$ & & Indicates aerobic or anaerobic conditions \\
\hline $\mathrm{pH}$ & $5<\mathrm{pH}<9$ & Range for biodegradation \\
\hline Temperature & $>20^{\circ} \mathrm{C}$ & At $\mathrm{T}>20^{\circ} \mathrm{C}$, biochemical process is accelerated \\
\hline Conductivity & & General water quality parameter \\
\hline Alkalinity & $\begin{array}{l}\text { above } \\
\text { background }\end{array}$ & $\begin{array}{l}\text { Results from interaction of carbon dioxide with aquifer } \\
\text { minerals }\end{array}$ \\
\hline Nitrate & $\begin{array}{l}\text { below } \\
\text { background }\end{array}$ & $\begin{array}{l}\text { anaerobic conditions, denitrification, reduced } \\
\text { biodegradation for PAH }\end{array}$ \\
\hline Sulfate & $\begin{array}{l}\text { below } \\
\text { background }\end{array}$ & $\begin{array}{l}\text { anaerobic conditions, sulfanogenesis, reduced } \\
\text { biodegradation for PAH }\end{array}$ \\
\hline Sulfide & $\begin{array}{l}\text { above } \\
\text { background }\end{array}$ & $\begin{array}{l}\text { anaerobic conditions, sulfanogenesis, reduced } \\
\text { biodegradation for } \mathrm{PAH}\end{array}$ \\
\hline Ferrous Iron & $\begin{array}{l}\text { elevated } \\
\text { concentrations }\end{array}$ & $\begin{array}{l}\text { anaerobic conditions, ferric hydroxide reduction, } \\
\text { reduced biodegradation for } \mathrm{PAH}\end{array}$ \\
\hline Carbon Dioxide & $\begin{array}{l}\text { above } \\
\text { background }\end{array}$ & ultimate oxidative daughter product \\
\hline DOC or TOC & $\begin{array}{l}\text { above } \\
\text { background }\end{array}$ & $\begin{array}{l}\text { Carbon and energy source; can be natural or } \\
\text { anthropogenic }\end{array}$ \\
\hline TPH & $\begin{array}{l}\text { above } \\
\text { background }\end{array}$ & Competing anthropogenic carbon and energy source \\
\hline LPAH & $\begin{array}{l}\text { above } \\
\text { background }\end{array}$ & $\begin{array}{l}\text { non-carcinogenic contaminant, carbon and energy } \\
\text { source }\end{array}$ \\
\hline HPAH & $\begin{array}{l}\text { above } \\
\text { background }\end{array}$ & carcinogenic contaminant, carbon and energy source \\
\hline
\end{tabular}


TWPC Fate and Transport Groundwater Model

Table 3. Analytical Parameters and Weighting for Preliminary Screening of PCP

\begin{tabular}{|c|c|c|}
\hline Analyte & Concentration & Interpretation \\
\hline Oxygen & above background & aerobic conditions, oxidative pathway \\
\hline Oxygen & well below background & anaerobic conditions, reductive pathway \\
\hline Nitrate & below background & anaerobic conditions, denitrification \\
\hline Iron (II) & above background & anaerobic conditions, ferric hydroxide reduction \\
\hline Sulfate & below background & anaerobic conditions, sulfanogenesis \\
\hline Sulfide & above background & anaerobic conditions, sulfanogenesis \\
\hline Methane & elevated concentrations & indicative of methanogenesis \\
\hline $\begin{array}{l}\text { Oxidation reduction } \\
\text { potential }\end{array}$ & & indicates reductive or oxidative pathway \\
\hline $\mathrm{pH}$ & $5<\mathrm{pH}<9$ & tolerated range for reductive pathway \\
\hline DOC or TOC & above background & $\begin{array}{l}\text { Carbon and energy source, natural or } \\
\text { anthropogenic }\end{array}$ \\
\hline Temperature & $>20^{\circ} \mathrm{C}$ & biochemical processes accelerated \\
\hline Alkalinity & above background & Interaction of $\mathrm{CO}_{2}$ with aquifer materials \\
\hline Chloride & above background & $\begin{array}{l}\text { reductive/oxidative daughter product, } \\
\text { biodegradation occurring }\end{array}$ \\
\hline $\mathrm{TPH}$ & above background & $\begin{array}{l}\text { Carbon and energy source; drives reductive } \\
\text { dechlorination }\end{array}$ \\
\hline PCP & & Contaminant released \\
\hline $\mathrm{DCP}$ & above detection & $\begin{array}{l}\text { Reductive daughter product, biodegradation } \\
\text { occurring }\end{array}$ \\
\hline $\mathrm{CP}$ & above detection & $\begin{array}{l}\text { Reductive daughter product, biodegradation } \\
\text { occurring }\end{array}$ \\
\hline PCA & above detection & $\begin{array}{l}\text { Oxidative daughter product, biodegradation } \\
\text { occurring }\end{array}$ \\
\hline $\mathrm{DiCH}$ & above detection & $\begin{array}{l}\text { Oxidative daughter product, biodegradation } \\
\text { occurring }\end{array}$ \\
\hline
\end{tabular}


TWPC Fate and Transport Groundwater Model

Figure 10 is a reproduction of a figure from Wiedemeier, et al (1996) showing the relative redox potentials for various electron acceptors and the possible and optimum ranges for reductive dechlorination. Oxidation-reduction potential can be used to the position of the contaminant plume, especially in areas undergoing anaerobic biodegradation. Figure 11 shows the areas of the shallow aquifer that are strongly anaerobic, mildly anaerobic, and slightly anaerobic or aerobic based on the December 1997 and May 1998 groundwater sampling. The criteria used to designate the different categories are presented in Table 4. If a well sample satisfied two of the three criteria for a give category, the well location was usually considered to fall in that category.

Table 4. Criteria for selecting anaerobic plume areas.

\begin{tabular}{|l|l|l|l|}
\hline & $\begin{array}{l}\text { Strongly } \\
\text { Anaerobic }\end{array}$ & Mildly Anaerobic & $\begin{array}{l}\text { Slightly Anaerobic or } \\
\text { Aerobic }\end{array}$ \\
\hline Oxygen Conc. & $<1 \mathrm{mg} / \mathrm{L}$ & $<2 \mathrm{mg} / \mathrm{L}$ & $>3 \mathrm{mg} / \mathrm{L}$ \\
\hline Redox Potential & $<-50 \mathrm{mV}$ & $<200 \mathrm{mV}$ & $>200 \mathrm{mV}$ \\
\hline $\mathrm{Fe}^{+2}$ Conc. & $>5 \mathrm{mg} / \mathrm{L}$ & $<5 \mathrm{mg} / \mathrm{L}$ & undetected \\
\hline
\end{tabular}

TCP, DCP, and CP were analyzed at a limited number of wells and temporary well points during the October and December 1997 and May 1998 groundwater sampling rounds. Figure 12 shows wells that yielded positive or nondetectable values for DCP and CP. As mentioned previously, the presence of DCP or $\mathrm{CP}$ (but not $\mathrm{TeCP}$ or TCP) is taken as evidence of anaerobic degradation. Concentrations of every chlorinated phenol including PCP analyzed during those sampling rounds are presented in Appendix B. 
TWPC Fate and Transport Groundwater Model

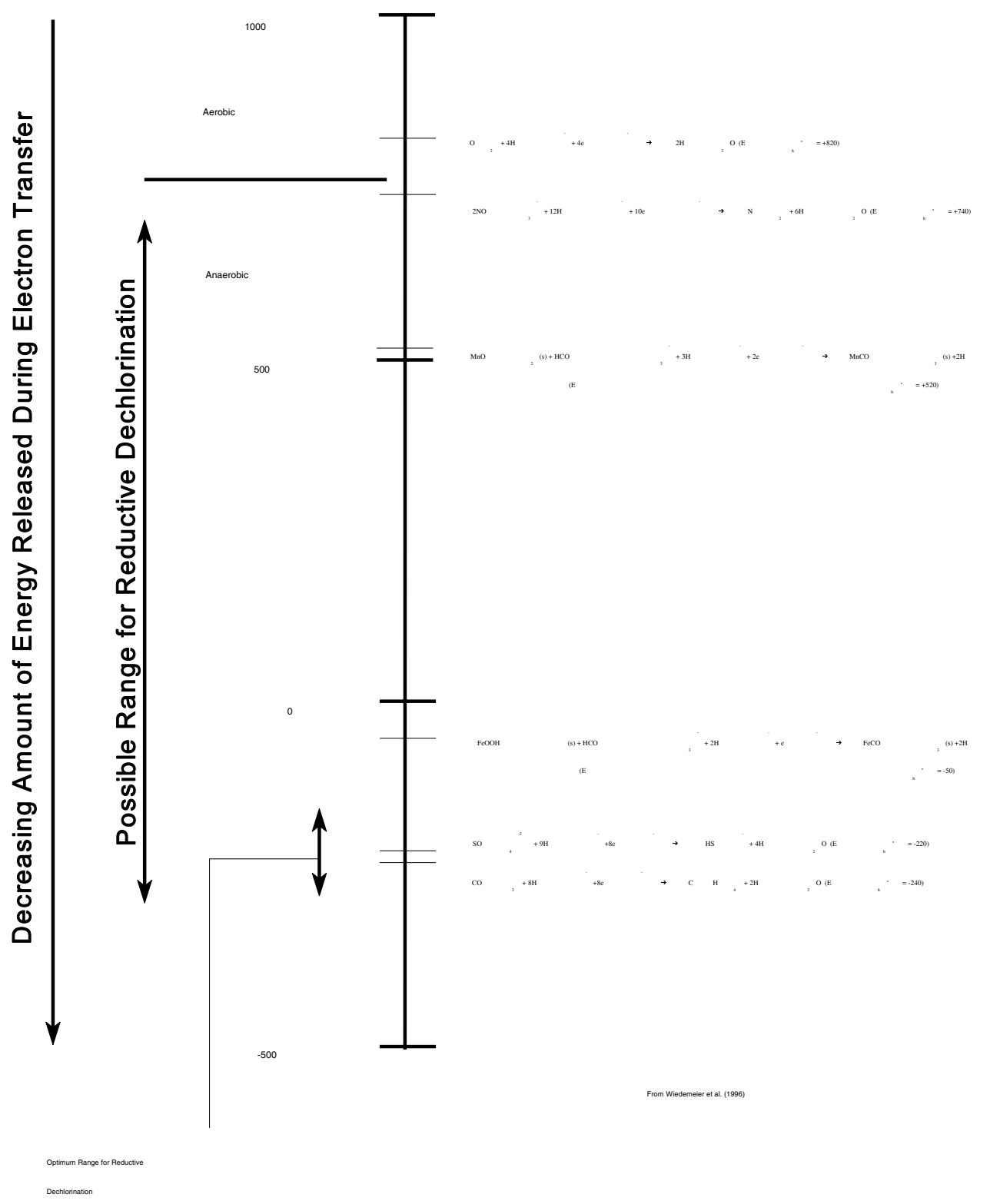

Figure 10. Redox potentials for various electron acceptors. 
TWPC Fate and Transport Groundwater Model

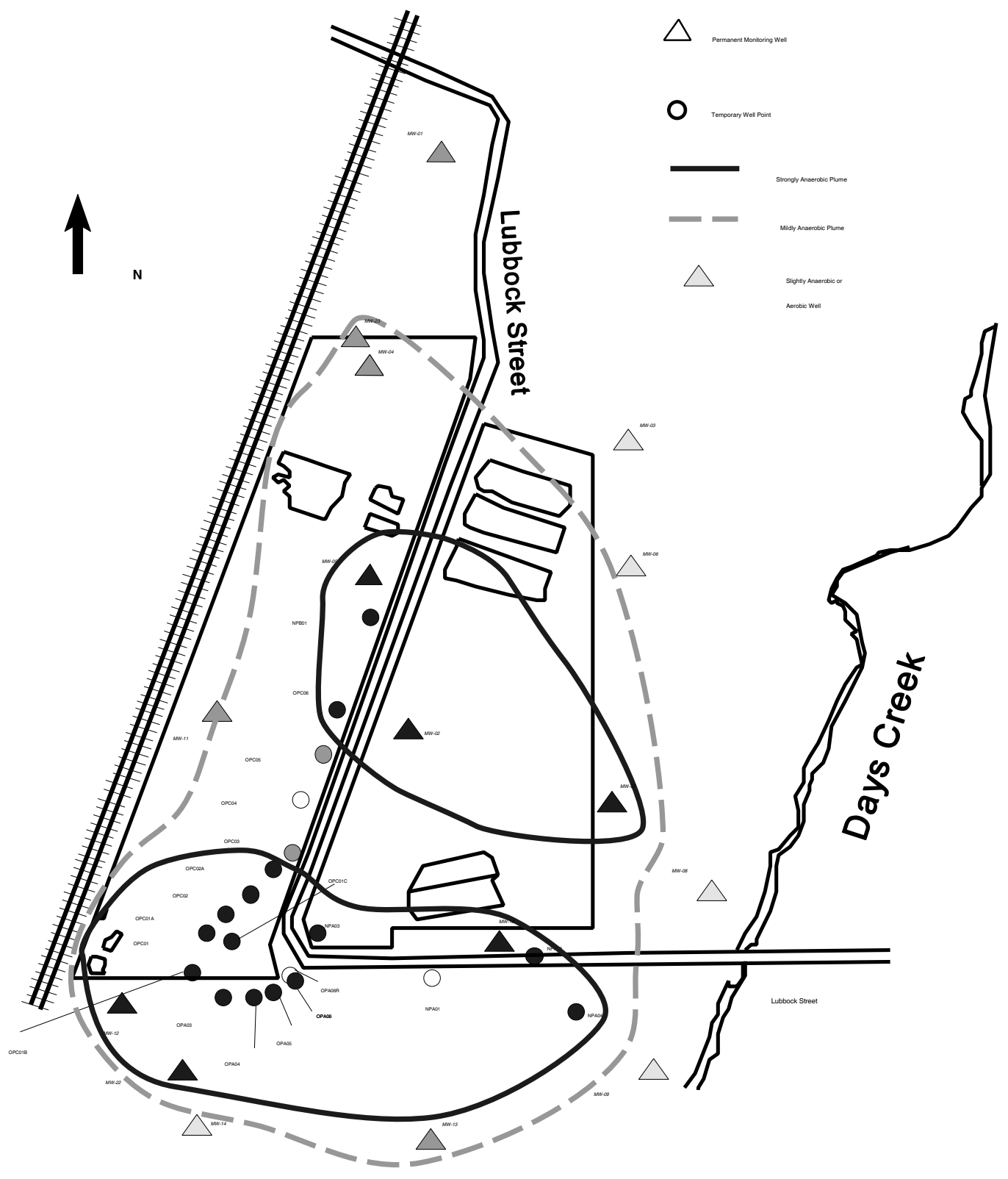

Figure 11. Estimated anaerobic plume in May 1998. 
TWPC Fate and Transport Groundwater Model

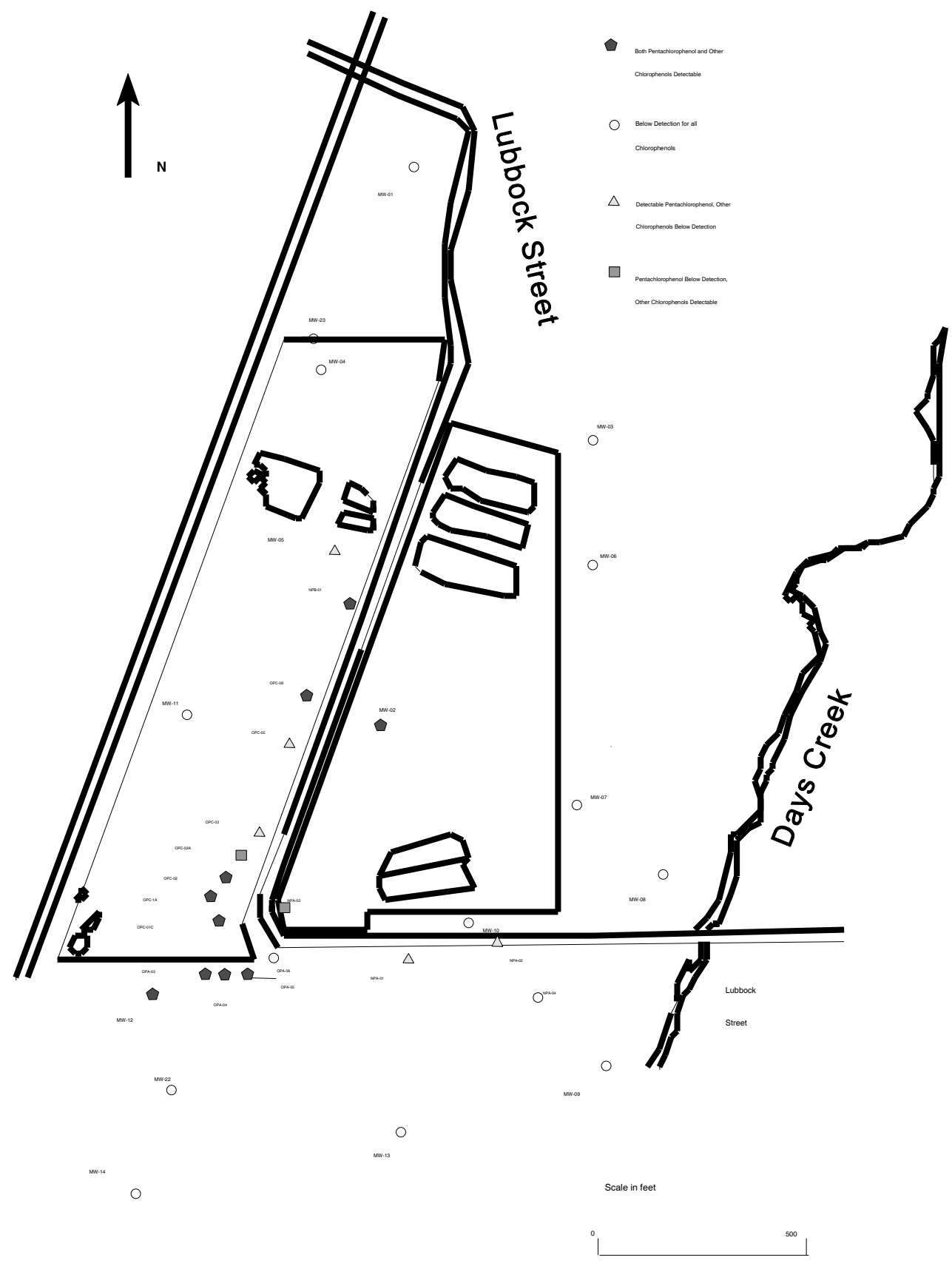

Figure 12. Wells with positive or nondetectable DCP or CP values. 


\section{TWPC Fate and Transport Groundwater Model}

EPA Directive 9200.4-17 lists the advantages and disadvantages of monitored natural attenuation. We have numbered the advantages and disadvantages for convenience of reference, but they are presented in the directive without particular order. Potential advantages are:

1) As with any in situ process, generation of lesser volume of remediation wastes, reduced potential for cross-media transfer of contaminants commonly associated with ex situ treatment, and reduced risk of human exposure to contaminated media;

2) Less intrusion as few surface structures are required;

3) Potential for application to all or part of a given site, depending on site conditions and cleanup objectives;

4) Use in conjunction with, or as a follow-up to, other (active) remedial measures; and

5) Lower overall remediation costs than those associated with active remediation.

The potential disadvantages include:

1) Longer time frames may be required to achieve remediation objectives, compared to active remediation;

2) Site characterization may be more complex and costly;

3) Toxicity of transformation products may exceed that of the parent compound;

4) Long term monitoring will generally be necessary;

5) Institutional controls may be necessary to insure long term protectiveness;

6) Potential exists for continued contamination migration, and/or cross-media transfer of contaminants;

7) Hydrologic and geochemical conditions amenable to natural attenuation are likely to change over time and could result in renewed mobility of previously stabilized contaminants, adversely impacting remedial effectiveness; and

8) More extensive education and outreach efforts may be required in order to gain public acceptance of monitored natural attenuation. 
TWPC Fate and Transport Groundwater Model

\subsection{Conceptual Model Summary}

In summary, the traditional groundwater flow and contaminant movement processes of advection, dispersion, and sorption are included in the model. Sorption is less important than originally believed because of the extensive presence of NAPL in the aquifer. It can be a significant process when the organic contaminants are present in trace amounts. Large concentrations of organic material in the groundwater overwhelm the limited number of sorption sites and reduce the effective sorption to zero. Perhaps only near the leading edge of the plume where the contaminants are present in trace concentrations would sorption be significant.

The model also needed to address dissolution of DNAPL composed of several creosote components. Because creosote is composed of hundreds of individual compounds, four compound categories were developed that reflect different properties, contaminants of concern, and a practical limit in the number of components in the model. These categories are PCP, other (than PCP) acid extractable compounds, light PAHs, and heavy PAHs including BAP. Dissolution of each category depends on the category effective solubility, concentration, and other factors. A simple DNAPL contaminant dissolution model can be given by a first-order reaction (Clement,1998b):

rate of dissolution $=\mathrm{k}\left(\mathrm{C}^{*}-\mathrm{C}\right)$,

where

$\mathrm{k}$ is an empirical mass transfer constant,

$\mathrm{C}$ is the dissolved concentration, and

$\mathrm{C}^{*}$ is the effective solubility.

There are indications of both anaerobic and aerobic biodegradation of PCP and aerobic biodegradation of all the major creosote components. Model reactions need to include anaerobic degradation or reductive dechlorination of PCP. PCP reductive dechlorination is a five step process (5 chlorides removed) to completion (see Figure 9). For practical reasons, it makes sense to simplify this to a two step process, lumping some of the reaction steps together. In symbolic form the PCP anaerobic degradation model is of the form

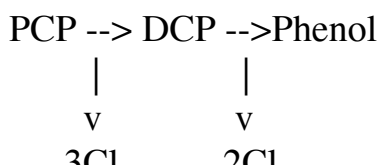

Aerobic degradation is probably occurring in areas of significant oxygen concentration, but independent evidence (i.e. daughter product measurements) are lacking. In simplified form PCP aerobic degradation follows a path of various hydroquinones with successively fewer chlorides. Because the hydroquinones were not part of the suite of analytes measurable by the laboratories used, it was not feasible to analyze for the chlorinated phenol intermediate oxidative daughter products. Ultimately the carbon and hydrogen would be oxidized to $\mathrm{CO}_{2}$ and water, but oxidation may be incomplete. For the purposes of the model, the following symbolic reactions are included:

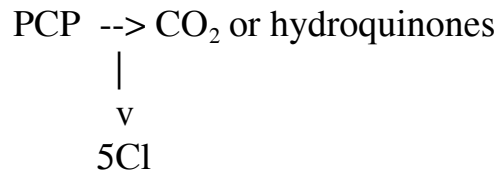


TWPC Fate and Transport Groundwater Model

$$
\begin{aligned}
& \text { LPAH ---> lower } \mathrm{C} \text { oxidation products } \\
& \text { HPAH ---> lower } \mathrm{C} \text { oxidation products } \\
& \text { ACEX ---> lower } \mathrm{C} \text { oxidation products }
\end{aligned}
$$

where LPAH, HPAH, and ACEX represent light PAHs, heavy PAHs, and other acid extractables, respectively. Oxygen consumption depends on the concentrations of PCP, LPAH, HPAH, ACEX and the degree of oxidation. If oxidation were complete, oxygen consumption could be calculated using the mean molecular structure of LPAH, HPAH, and ACEX shown in Table 1. Details of the reaction model will be discussed under the section on the RT3D code.

\section{COMPUTATIONAL CODES}

Several codes were evaluated for application to the TWPC site. The INEEL screening code GWSCREEN was used for the initial site evaluation. Other conditions and requirements have caused the final modeling to be performed by a combination of the more sophisticated MODFLOW and MT3D/RT3D codes. The criteria that determined code selection were:

- A short vadose zone and the extensive presence of dissolving NAPL in the aquifer.

- A two-dimensional, heterogeneous aquifer with multiple sources.

- A possible future need to evaluate the effect of aquifer flow barriers.

- The need to include dispersion, sorption, and specific biodegradation processes in both aerobic and anaerobic zones.

\subsection{MODFLOW}

MODFLOW is a widely used modular, quasi-3D, cell-centered, finite difference, saturated flow code developed by the United States Geological Survey (McDonald and Harbaugh, 1988). It can perform both steady state and transient analysis of heterogeneous systems and has a wide variety of boundary conditions and input options. The program is divided into modules that are in turn grouped into "packages." Each package deals with a specific feature of the hydrologic system that is to be simulated. As the need arises, new packages are developed and included as options to the simulator. Thus a variety of different conditions or processes can be addressed depending on the set of packages invoked by the user. The reader is referred to the MODFLOW documentation for further details.

\subsection{MT3D}

MT3D is a modular 3D groundwater transport model that simulates combined advection, dispersion, and decay or sorption of a dissolved constituent in groundwater systems (Zheng, 1990 documents the EPA version). It has a modular structure similar to MODFLOW and uses the hydraulic head and Darcian flow field simulated by MODFLOW as input to calculate the pore space advective flow field in a two-step flow and transport simulation. MT3D includes a nonlinear Langmuir sorption isotherm that has a limited number of sorption sites. The reader is referred to the MT3D documentation for further details. 
TWPC Fate and Transport Groundwater Model

\subsection{RT3D}

\subsubsection{General Description}

The following general description of RT3D is taken from Clement (1997) and Clement (1998). RT3D (Reactive Transport in 3-Dimensions) is computer code that solves the coupled partial differential equations describing flow and reactive transport of multiple mobile and/or immobile species in threedimensional saturated groundwater systems. It is a generalized multi-species reactive version of the transport code, MT3D (Zheng, 1990). The current version of RT3D uses the advection and dispersion solvers from the DOD_1.5 (1997) version of MT3D. As with MT3D, RT3D also requires MODFLOW for computing spatial and temporal variations in groundwater head distribution.

The RT3D code includes an implicit reaction solver that makes the code sufficiently flexible for simulating various types of chemical and microbial reaction kinetics. RT3D v1.0 supports seven preprogrammed reaction modules that can be used to simulate different types of reactive contaminants including benzene-toluene-xylene mixtures (BTEX), and chlorinated solvents such as tetrachloroethene (PCE) and trichloroethene (TCE). In addition, RT3D has a user-defined reaction option that can be used to simulate any other types of user-specified reactive transport systems. A user-defined module was used to define DNAPL dissolution and the specific aerobic and anaerobic pathways of PAH and PCP biodegradation needed in this study.

The RT3D author, T. P. Clement, developed a NAPL dissolution option. The following is a discussion of the traditional approach from Clement (1998).

Although NAPL dissolution is an important subsurface transport process, current research in this area seems to be highly empirical. This is because the dissolution NAPL process in porous media systems is an inherently complex process, which can be influenced by several parameters. Miller et al. (1990) concluded that the inter-phase mass transfer rate from a NAPL phase to a mobile aqueous phase is a function of at least ten dimensional variables! Unfortunately, the experimental work required to investigate the system in terms of all these variables has not been accomplished, even under ideal laboratory conditions. Therefore, for most practical field simulations, if NAPL is known or suspected to be present in certain nodes then the simple way to model the nodes is to use the constant concentration boundary condition.

He then presents a somewhat more rigorous, first-order approach for modeling NAPL dissolution processes that are coupled with biodegradation kinetics. (Clement, 1998).

Most groundwater plumes originate from spills or leaks of immiscible fluids, commonly referred as NAPLs (Non Aqueous Phase Liquids). If the amount of spilled (or leaked) NAPL mass is large enough then the NAPL will eventually penetrate the unsaturated zone and will reach the saturated groundwater table. At the groundwater table, lighter NAPLs (with density less than water density, also known as LNAPLs) will spread in lateral direction whereas, heavier NAPLs (known as DNAPLs) will continue their downward migration towards the aquifer bottom.

During the migration process, a portion of NAPL may also be trapped as discontinuous "globules or blobs" in selected pore spaces within the saturated zone. They can also pool over low permeable zones. Evolution of dissolved plumes from a NAPL contaminated zone (with either pools or blobs) would depend on the NAPL solubility and the mass-transfer characteristics of the NAPL-water interface. Several researchers have studied the characteristics of NAPL dissolution processes in saturated porous media. In all of these studies, the contaminant transfer from NAPL phase to aqueous phase is described using a first-order mass-transfer model. 
TWPC Fate and Transport Groundwater Model

Using this model, the fate and transport of contaminants originating from a NAPL zone can be predicted using a coupled set of equations that describe biodegradation reactions and NAPL dissolution with a lumped mass transfer rate between the NAPL and groundwater.

\subsubsection{RT3D model equations.}

The equations of flow used by MODFLOW and non-reactive transport used in MT3D are presented in the respective documentation and are straight-forward. The NAPL dissolution and reactive equations used in RT3D were adapted or developed in the user-defined reaction module specifically for this application and are presented below.

The general macroscopic equations describing the fate and transport of aqueous- and solid-phase species, respectively, in multi-dimensional saturated porous media are written as:

$$
\frac{\partial C}{\partial t}=\frac{\partial}{\partial x}\left[D \frac{\partial C}{\partial x}\right]-\frac{\partial}{\partial x}(v C)+\frac{q}{\phi} C_{k}+r-r+r \text { wee } k=1,2, . . m
$$

for the aqueous phase, and

$$
\frac{d \underline{C}}{d}=\underline{r}+r-r \text { whe } \quad, \text { in }=1,2, \ldots(n-m)
$$

for the solid phase, where $\mathrm{n}$ is the total number of species, $\mathrm{m}$ is the total number of aqueous-phase (mobile) species (thus, $\mathrm{n}$ minus $\mathrm{m}$ is the total number of solid-phase or immobile species), $\mathrm{Ck}$ is the aqueous-phase concentration of the kth species $\left[\mathrm{ML}^{-3}\right], \underline{\mathrm{C}}_{\text {im }}$ is the immobile-phase concentration of the $\mathrm{im}^{\text {th }}$ species $\left[\mathrm{MM}^{-1}\right], \mathrm{D}_{\mathrm{ij}}$ is the hydrodynamic dispersion coefficient $\left[\mathrm{L}^{2} \mathrm{~T}^{-1}\right], \mathrm{v}$ is the pore velocity $\left[\mathrm{LT}^{-1}\right], \phi$ is the soil porosity, $\mathrm{q}_{\mathrm{s}}$ is the volumetric flux of water per unit volume of aquifer representing sources and sinks $\left[\mathrm{T}^{-1}\right]$, $\mathrm{C}_{\mathrm{s}}$ is the concentration of source/sink $\left[\mathrm{ML}^{-3}\right], \mathrm{r}_{\mathrm{c}}$ is the reaction rate that describes the mass of the species removed or produced per unit volume per unit time $\left[\mathrm{ML}^{3} \mathrm{~T}^{-1}\right], \underline{r}_{\mathrm{c}}$ is the reaction rate in the immobile phase $\left[\mathrm{MM}^{-1} \mathrm{~T}^{-1}\right]$, and $\mathrm{r}_{\mathrm{a}}$ and $\mathrm{r}_{\mathrm{d}}$, respectively, are attachment (or sorption) and detachment (or desorption) rates that describe the kinetic exchange of the transported species between aqueous and solid phases $\left[\mathrm{M}^{-3} \mathrm{~T}^{-1}\right]$.

The RT3D transport/reaction code includes a NAPL dissolution reaction module. One of the $r_{c}$ reactions in the aqueous phase equation (1) above is NAPL dissolution, which is a function of the mass transfer coefficient and the specific interfacial area between the phases. Clement(1998) points out the extreme difficulties in estimating the values of the mass transfer coefficient and the interfacial area. Consequently, it is common to model NAPL dissolution using a lumped mass transfer coefficient that is the product of the mass transfer coefficient and the specific interfacial area. Equations (1) and (2) adapted for NAPL dissolution are thus given by:

$$
\frac{\partial C}{\partial t}=\frac{\partial}{\partial x}\left[D \frac{\partial C}{\partial x}\right]-\frac{\partial}{\partial x}(v C)+\frac{q}{\phi} C+k(C-C)
$$

for the aqueous phase and 
TWPC Fate and Transport Groundwater Model

$$
\frac{\mathbb{C}}{d}=-k(C-C)
$$

for the immobile NAPL phase, where $\mathrm{C}$ is the aqueous-phase contaminant concentration, $\mathrm{C}^{*}$ is the equilibrium aqueous phase concentration (or solubility limit), and $\mathrm{k}_{\mathrm{la}}$ is the lumped mass transfer rate coefficient. The NAPL concentration is defined for convenience as the mass of contaminant per unit liquid volume (i.e., in terms of aqueous-phase concentration basis). This definition helps avoid the use of bulk density and porosity values in the transport equations, and it also facilitates direct comparison of contaminant mass present at NAPL and aqueous phases. In the present work, the value of $k_{l a}$ is assumed to remain a constant thorough out an entire simulation.

As mentioned previously, the creosote components have been divided into four components, PCP, light PAHs, heavy PAHs including BAP, and acid extractables. This division was a compromise to allow modeling some of the specific contaminants of interest and at the same time limit the total number of compounds included in the model to a practical number. Dissolution of the four creosote components from immobile NAPL is a very important factor in the fate and transport of contaminants at the TWPC site. The equations of NAPL component dissolution were developed specifically for the TWPC site analysis. The NAPL dissolution equations are:

$$
\frac{\mathbb{C}}{d}=\| l \quad(C,-C)
$$

for PCP dissolution,

$$
\frac{\mathbb{C}}{\mathbb{d}}=\mathbb{a} a \quad\left(C_{-}-C_{-}\right)
$$

for light PAH dissolution,

$$
\frac{\mathbb{C}}{d}=\mathbb{a} a \quad\left(C \quad-C_{-}\right)
$$

for heavy PAH dissolution, and

$$
\frac{\mathbb{C} \ldots}{d}=\| l a-\left(C_{-}-C_{-}\right)
$$

for dissolution of acid extractables.

Under anaerobic conditions, PCP is assumed to degrade to DCP and then to a non-chlorinated compound such as phenol. This results in the production of chloride. This is a simplified version of the $\mathrm{PCP}>\mathrm{TeCP}>\mathrm{TCP}>\mathrm{DCP}>\mathrm{CP}>$ phenol anaerobic path described earlier. This simplification of the degradation path from 5 to 2 steps requires estimating two lumped rate constants versus five constants and is consistent with measuring a limited number of degradation products in the field. Wiedemeier, et al. 
TWPC Fate and Transport Groundwater Model

(1998) state that biodegradation of chlorinated aliphatic hydrocarbons can be represented with a first-order rate constant. It was assumed that first-order reaction kinetics also represent biodegradation of chlorinated aromatic hydrocarbons such as PCP. The reaction equations for anaerobic degradation are:

$$
\frac{\mathbb{C}_{m}}{d}=-\boldsymbol{K} \quad C_{n} / \boldsymbol{R}
$$

for PCP degradation, where $\mathrm{C}_{\mathrm{pcp}}$ is the concentration of PCP in the groundwater, $\mathrm{Kan}_{\mathrm{pcp}}$ is the PCP anaerobic degradation rate, and $\mathrm{Rd}_{\mathrm{pcp}}$ is the PCP retardation coefficient;

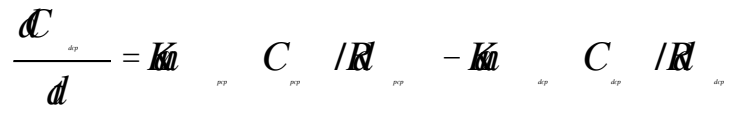

for DCP degradation, where $\mathrm{C}_{\mathrm{dcp}}$ is the concentration of DCP in the groundwater, $\mathrm{Kan}_{\mathrm{dcp}}$ is the DCP anaerobic degradation rate, and $\mathrm{Rd}_{\mathrm{dcp}}$ is the PCP retardation coefficient, and

$$
\frac{\mathbb{C}}{d}=3 \boldsymbol{k} \quad C_{n} / \boldsymbol{R}+2 \boldsymbol{k}, C_{*} / \boldsymbol{R}
$$

for $\mathrm{Cl}$ production. Reductive dechlorination of PCP to DCP produces three chloride atoms per molecule of $\mathrm{PCP}$ reduced and DCP reduction to phenol produces 2 atoms of chloride per molecule.

Complete aerobic degradation of the organic contaminants involves oxidation of $\mathrm{PCP}$ to $\mathrm{CO}_{2}$ and $\mathrm{Cl}$. Light and heavy PAH and acid extractable components of creosote may be ultimately oxidized to $\mathrm{CO}_{2}$. The equations for aerobic degradation are:

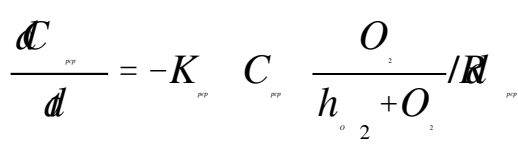

for PCP oxidation, where $\mathrm{K}_{\mathrm{pcp}}$ is the PCP aerobic degradation rate, $\mathrm{h}_{\mathrm{O} 2}$ is the monod oxygen half-saturation constant. Monod-type functions are used to limit the reactions when low oxygen concentrations are present. Oxidation of light PAHs is given by

$$
\frac{\mathbb{C}}{d}=-K_{-} \quad C_{-} \frac{O}{h_{o_{2}}+O_{2}} / \mathbb{R}
$$

where $\mathrm{K}_{\mathrm{lpah}}$ is the light PAH aerobic degradation rate;

$$
\frac{\mathbb{C}_{w}}{d}=-K_{-} \quad C_{-2} \quad \frac{O}{h_{0_{2}}+O} / \mathbb{R}
$$

for oxidation of heavy PAHs, where $\mathrm{K}_{\mathrm{hpah}}$ is the heavy PAH aerobic degradation rate; 
TWPC Fate and Transport Groundwater Model

$$
\frac{\mathbb{C}}{d}=-C_{-} \quad \frac{O}{h_{0_{2}}+O} / \mathbb{R}
$$

for oxidation of acid extractables, and

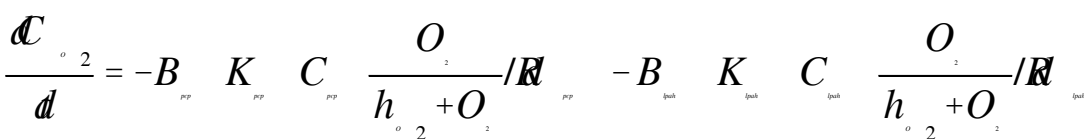

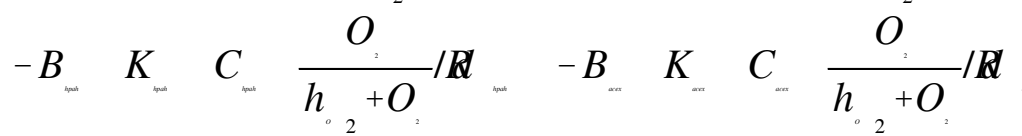

for consumption of oxygen. $\mathrm{B}_{\mathrm{pcp}}, \mathrm{B}_{\text {lpah }}, \mathrm{B}_{\mathrm{hpah}}$, and $\mathrm{B}_{\mathrm{acex}}$ are the number of oxygen molecules consumed per molecule of PCP, light PAHs, heavy PAHs, and acid extractables oxidized, respectively. If it is assumed that all components are completely oxidized to $\mathrm{CO}_{2}$, the ratios would be estimated from the weighted average group mole fraction of carbon and hydrogen per "average" contaminant molecule in Table 1. It is believed that complete oxidation is unlikely so the ratios ultimately used were less than the values that represent complete oxidation.

\section{MODEL PARAMETER LIST}

This section presents a list of the model parameters by code. The parameter values were developed from the conceptual model, data, and from model calibration.

\section{MODFLOW}

- Domain geometry

- Distribution of hydraulic parameters (hydraulic conductivity or transmissivity)

- Boundary conditions

- $\quad$ Recharge locations (ponds, etc.)

- Recharge rates

MT3D

- Initial contaminant concentrations

- Continued release rates of contaminants

- Effective porosity

- $\quad$ Longitudinal and transverse dispersivities

- Sorption for each contaminant

- $\quad$ Decay rate (MT3D)

RT3D

- Reaction rate constants

- Oxygen consumption factors

- Solubility of NAPL components

- Mass transfer rate between NAPL and groundwater 
TWPC Fate and Transport Groundwater Model

\section{MODEL IMPLEMENTATION}

\subsection{GENERAL}

Values of some of the straight-forward model parameters were estimated using TWPC site specific data and information and literature values where appropriate or necessary. Geometric lengths were obtained or estimated from maps, borehole locations, and soil contaminant data. Thicknesses were estimated from borehole lithology. General chemical properties were obtained from chemical reference sources (see Table 1). Bulk density of the soil was estimated to vary from $1.7-1.9 \mathrm{~g} / \mathrm{cm}^{3}$ from site reports and the literature. Estimating these parameters was relatively straightforward and the actual values are not expected to vary greatly from the estimates.

After estimating values for the above parameters, a group of parameters were left that were uncertain and controlled the rate of contaminant movement. These parameters are discussed by code below.

\subsection{FLOW MODEL}

A MODFLOW model was prepared based on the conceptual model outlined in section 5. A model domain was defined with planar dimensions somewhat larger than the site including all site features, monitoring wells and the discharge location (Day's Creek). The northwestern boundary was defined as a specified head boundary to allow flow across the site from the regional system to the west. Heads were specified along the boundary consistent with measurements in site wells. The southeast boundary is defined as a specified head boundary at Day's Creek, which is the Gravel Zone aquifer discharge location. Heads along the southeast boundary were varied linearly consistent with water level measurements made in the creek. The aquifer was assumed to have a constant thickness of $4 \mathrm{ft}$., but spatially variable transmissivity. The model domain and boundary conditions are shown in Figure 13 together with locations of monitoring wells and hydraulic heads measured in May 1998.

The domain was divided into 15 hydraulic material property zones based upon site data and the ultimate need for model detail. The location of the hydraulic property zones and hydraulic conductivities $(\mathrm{K})$ at the wells where slug tests were performed is shown on Figure 14. Initial transmissivity $(\mathrm{T})$ values were assigned to the zones from with the measured $\mathrm{K}$ values times the average aquifer thickness. Final $\mathrm{T}$ values were obtained by adjusting zonal $\mathrm{T}$ values to obtain a reasonable match with observed heads in a process known as model calibration. The Ks and Ts obtained from the slug tests are representative of the local area near the well, but not necessarily fully representative of the average over the entire zone. Hence the indirect model calibration method was employed to estimate zonal averages. 
TWPC Fate and Transport Groundwater Model

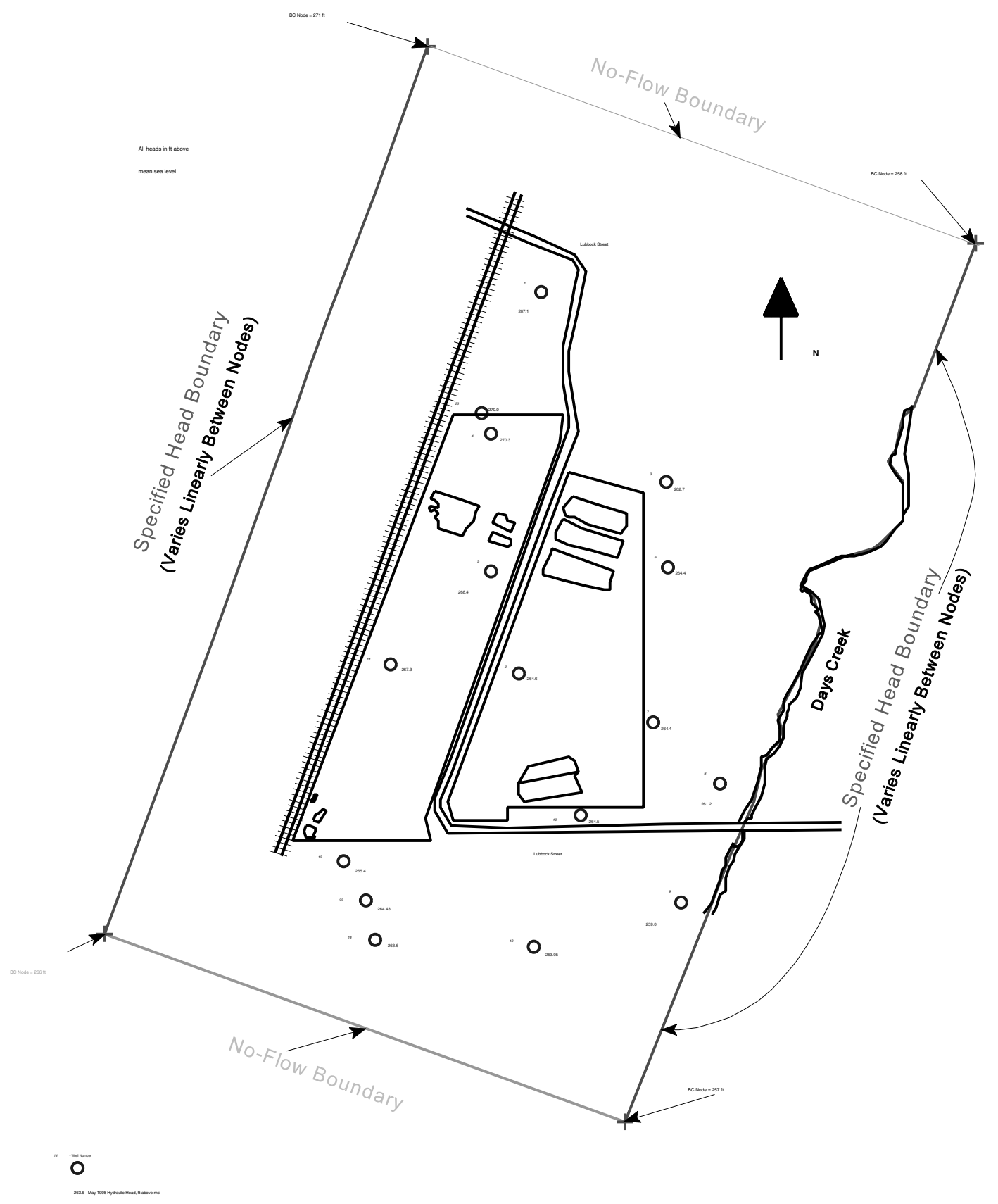

Figure 13. Aquifer model domain and flow boundary conditions. 
TWPC Fate and Transport Groundwater Model

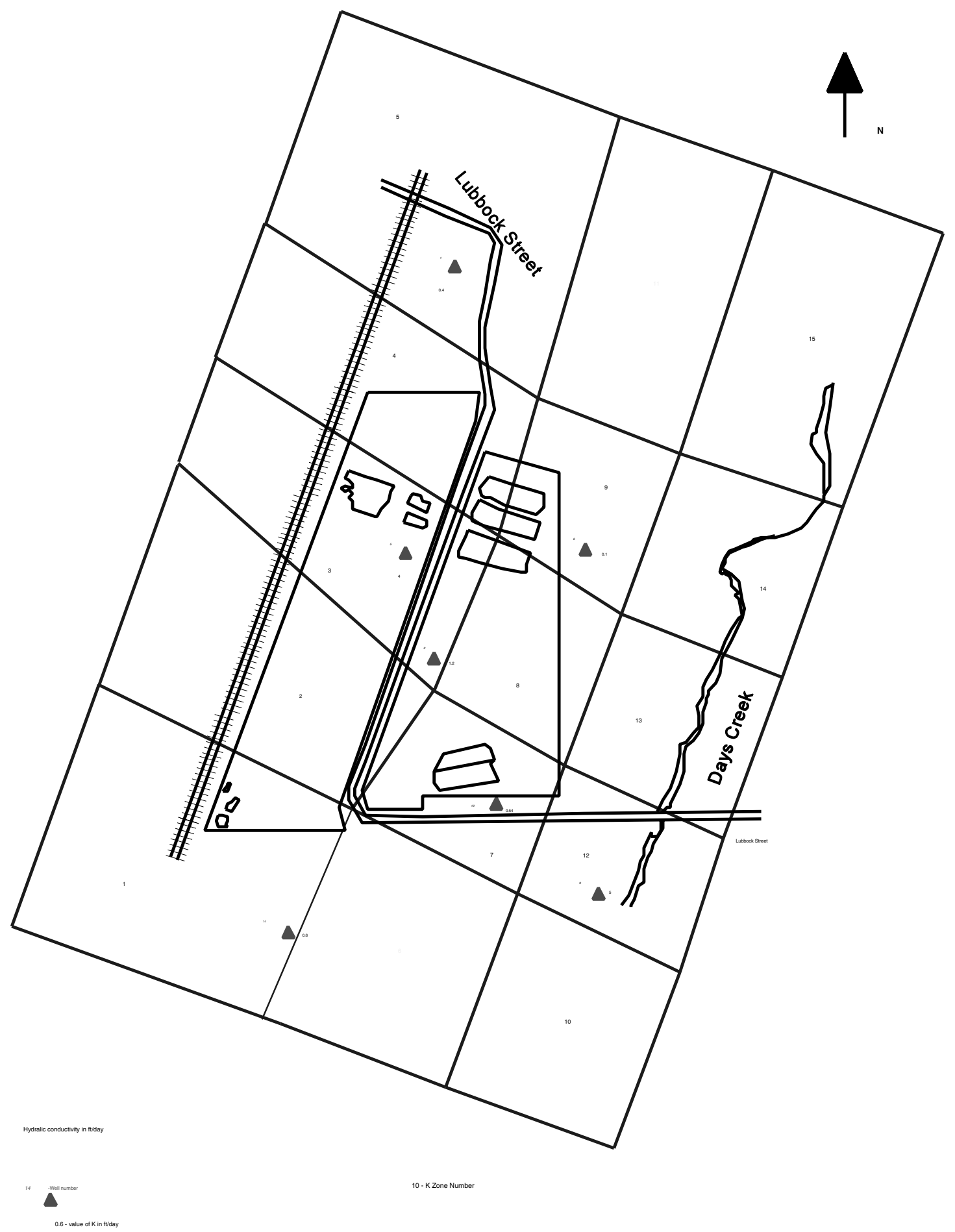

Figure 14. Shallow aquifer transmissivity zones. 
TWPC Fate and Transport Groundwater Model

\subsection{CONTAMINANT TRANSPORT}

Aquifer dispersivities were calculated from distance to receptor points (Day's Creek or monitoring wells) and the relationship between scale and dispersivity was given by $\alpha_{\mathrm{L}}=0.83\left(\log _{10} \mathrm{~L}\right)^{2.414}(\mathrm{Xu}$, Moujin, and Eckstein, 1995) where $\alpha_{\mathrm{L}}$ is the dispersivity and $\mathrm{L}$ is the field scale. The effective porosity of the aquifer was assumed to be a constant 0.2 .

The sorption coefficient $\left(\mathrm{K}_{\mathrm{d}}\right)$ for organic materials is normally computed as the product of the fraction of organic carbon in the soil, $\mathrm{f}_{\mathrm{oc}}$, and the organic carbon partitioning coefficient, $\mathrm{K}_{\mathrm{oc}}$, or $\mathrm{K}_{\mathrm{d}}=\mathrm{f}_{\mathrm{oc}} \mathrm{K}_{\mathrm{oc}} \cdot \mathrm{K}_{\mathrm{oc}}$ values are contaminant specific and reported in various sources (see Key, 1997; Jeng et al., 1992, EPA, 1989; ASTM, 1995). The $\mathrm{f}_{\text {oc }}$ in the uncontaminated soil was estimated to range from 0.001 to 0.02 based on guidance in Newell, et al. (1996) and the characteristics of the TWPC site. Two boreholes sample were measured for $\mathrm{f}_{\text {oc }}$ in January, 1998. In one sample on the west side, $\mathrm{f}_{\text {oc }}$ values were $0.009,0.011$, and 0.003 for the shallow soil, deep surficial silty sand just above the aquifer, and shallow aquifer material, respectively. The other sample location, also on the west side had $\mathrm{f}_{\mathrm{oc}}$ values of 0.004 and 0.001 for the deep soil just above the aquifer and the aquifer material, respectively. The sorption data and estimates for several contaminants at TWPC are summarized in Table 5.

Table 5. Shallow and deep Surficial Silty Sand sorption data and estimates for TWPC contaminants.

\begin{tabular}{|l|l|l|l|}
\hline Contaminant & Range of $\mathrm{f}_{\mathrm{oc}}$ & $\mathrm{K}_{\mathrm{oc}}(\mathrm{ml} / \mathrm{g})$ & Range of $\mathrm{K}_{\mathrm{d}}(\mathrm{ml} / \mathrm{g})$ \\
\hline BAP & $.004-.011$ & $9.69 \times 10^{5}(\mathrm{EPA} 1996)$ & $3.9 \times 10^{3}-1.1 \times 10^{4}$ \\
\hline PCP & $.004-.011$ & $\begin{array}{l}1000-2000(\text { EPA 1996, } \\
\text { depending on pH })\end{array}$ & $4-22$ \\
\hline Naphthalene & $.004-.011$ & $1.19 \times 10^{3}($ EPA 1996) & $4.8-13$ \\
\hline Phenanthrene & $.004-.011$ & $1.26 \times 10^{4}($ Key, 1997) & $50-139$ \\
\hline Acenaphthalene & $.004-.011$ & $4.9 \times 10^{3}($ EPA 1996) & $20-54$ \\
\hline Fluorene & $.004-.011$ & $2.7 \times 10^{3}($ EPA 1996) & $11-30$ \\
\hline
\end{tabular}

The values of $\mathrm{K}_{\mathrm{oc}}$ reported in the literature vary so the values in Table 5 are somewhat uncertain. The $\mathrm{K}_{\mathrm{oc}}$ for PCP and its derivatives are particularly sensitive to $\mathrm{pH}$ (EPA, 1996). Naphthalene, Phenanthrene, Acenaphthalene, and Fluorene are listed because they are major components of PAH. The retardation factor is the factor by which the contaminants are slowed relative to water velocity and is calculated by

$$
R=1+\frac{K \rho}{n}
$$

where

$\mathrm{R}_{\mathrm{d}}=$ retardation factor

$\mathrm{K}_{\mathrm{d}}=$ sorption coefficient

$\rho=$ bulk density

$\mathrm{n}_{\mathrm{e}}=$ effective porosity or water content 
It's clear that even the smallest $\mathrm{K}_{\mathrm{d}}$ in the table would result in a high retardation factor. However, the linear sorption model using $\mathrm{K}_{\mathrm{d}}$ assumes that there are no competing sorbants and an infinite number of sorption sites. The high concentrations of organic material dissolving in the groundwater from the creosote mixture would overwhelm the soil sorption capability for those soil locations receiving large quantities of the wood treating liquid. Long before the soil becomes saturated with organic liquid, it would lose any capability to sorb contaminants. The last sampling round revealed the extent of the DNAPL and, in the end, sorption was not included in the model.

\subsection{CONTAMINANT REACTIONS}

The dispersivities and effective porosity estimated for MT3D were also used for RT3D. Because DNAPL was discovered to be present over significant areas and total organic concentration in the groundwater was high, sorption of the organic contaminants was believed to be relatively unimportant and was not included in the RT3D runs. A retardation coefficient of $1(\mathrm{Kd}=0)$ was assumed. Figure 15 shows boundaries and sources including DNAPL at the beginning of the simulation. Figure 16 shows the same information for the second phase of the simulation beginning with the operation of the new process area. The DNAPL was assumed to be creosote with the initial relative composition of the selected components as presented in Table 1. Dissolved contaminant concentrations in the pond source areas (old and new process areas) were assumed to be at the solubility limit except for ACEX, which was assumed to be have concentrations much less than the solubility limit. The ponding area north of the new process area was assumed to be contaminant free.

The advective flow field for RT3D was input from MODFLOW. Transport and reactions of the various contaminants were then simulated with RT3D for three periods, 1954 to 1974 corresponding to the operational period for the old process area, 1974 to 1986 corresponding to the operational period for the new process area, and 1986 to present. Because DNAPL was simulated as an immobile phase, it was necessary to set DNAPL as an initial condition at the beginning of the first two periods (operational periods of the old and new process areas). DNAPL levels at the end of the old process area period were input as initial conditions for the second period. Additional DNAPL levels corresponding to the new process area were added as initial conditions for the second period. There are limitations to this approach. DNAPL does not suddenly appear over an extensive area at the beginning of operations. Ideally, one would like to simulate DNAPL movement as a second phase and a multi-phase model was considered. Such a complex model was not employed for several reasons. The extent of the DNAPL was only recognized after the July 1998 sampling and historical DNAPL data is lacking. Biodegradation was considered important and a code that included multiphase transport and both anaerobic and aerobic degradation of creosote was not available. The complexity of such an undertaking was not considered to be justified.

An implied assumption of our approach is that the DNAPL plume is established rather early in the simulation period. This also may not be strictly true because creosote DNAPL could be added to the "pool" over longer times. We have compensated for this to some degree by establishing the DNAPL areas smaller than the final extent as measured in 1998, but larger than they probably were in the early portion of the operational periods. The general concept of a somewhat average plume size over the operational period was used. This approach was approximate but useful in including DNAPL as a necessary source of dissolved contaminants. 
TWPC Fate and Transport Groundwater Model

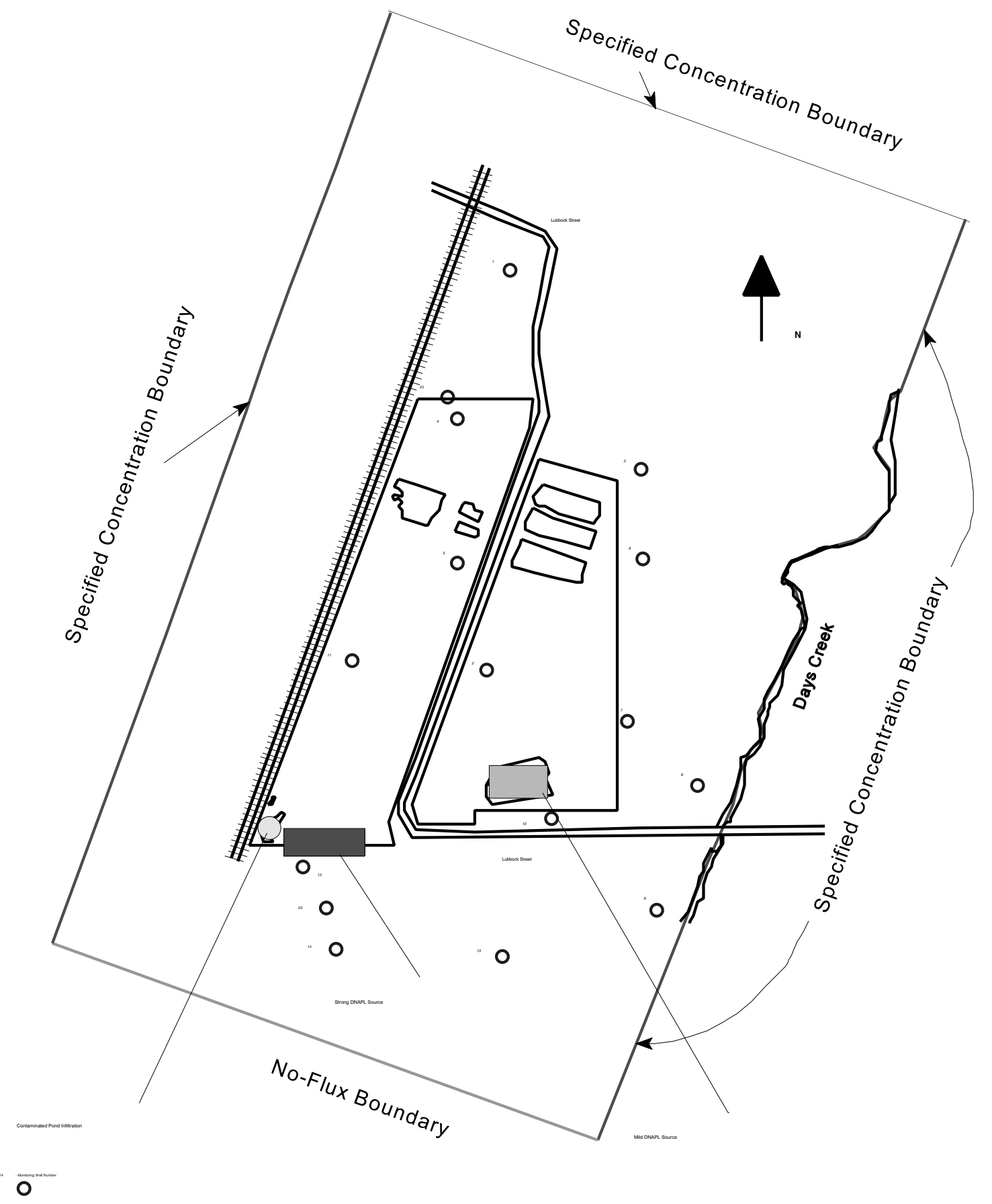

Figure 15. Transport and reaction model boundary conditions and sources during old process area operation 
TWPC Fate and Transport Groundwater Model

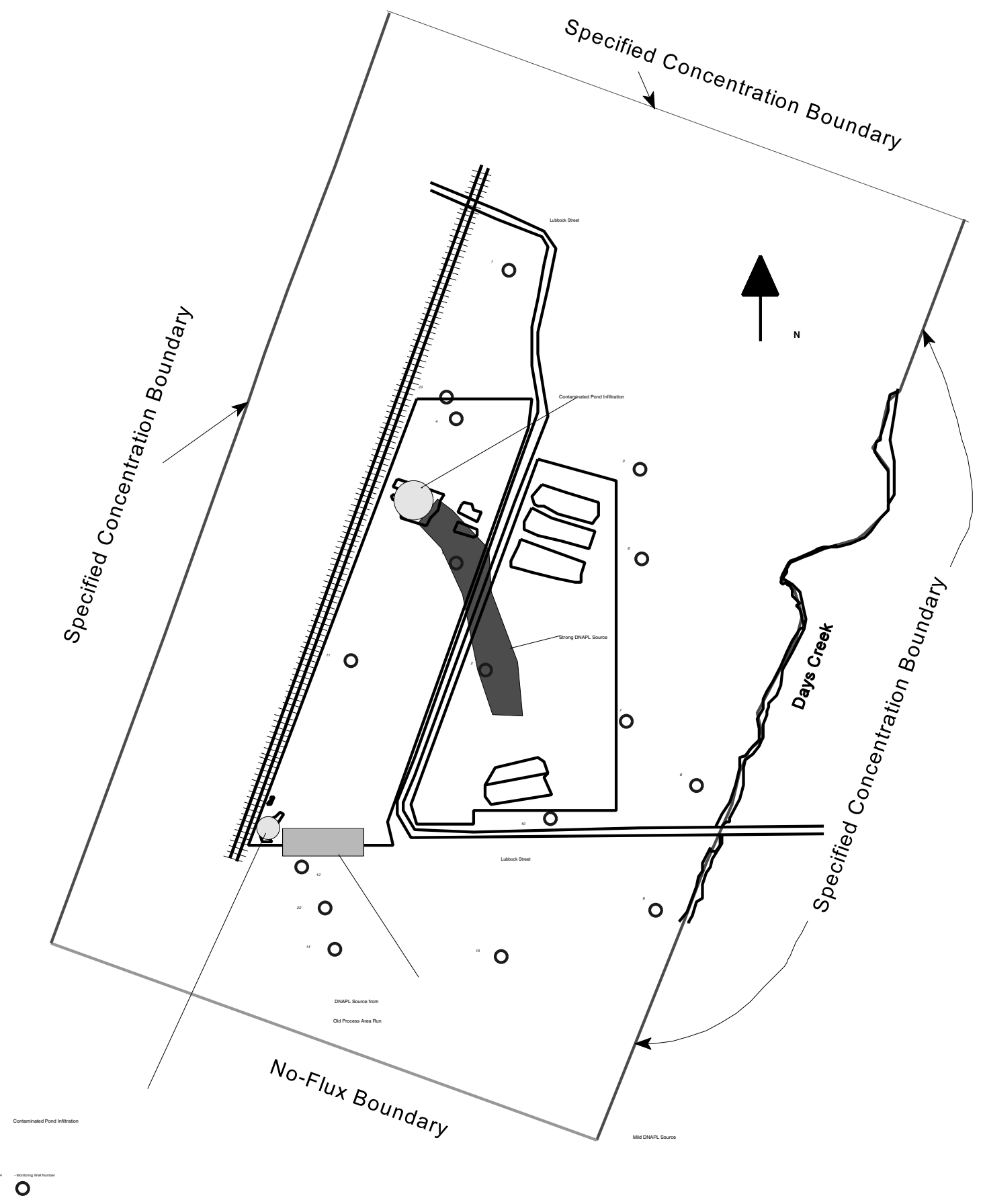

Figure 16. Transport and reaction model boundary conditions and sources during new process area operation 
TWPC Fate and Transport Groundwater Model

\section{MODEL RESULTS}

The steady-state MODFLOW model was calibrated to May 1998 measured aquifer water levels and a reasonable advective flow field obtained. Particle tracking was applied to provide a preliminary idea of directions and travel time from the process areas to the discharge location (Day's Creek). A few MT3D runs were made early in the modeling process (before the extent of DNAPL was known) to obtain a preliminary idea of the effects of dispersion and sorption. At this point it was clear that the dissolved contaminant plumes were not following the direction of the hydraulic gradient and that additional sources existed on the east portion of the site. After the July 1998 soil sampling, the full extent of the DNAPL plumes and the dip of the aquifer bottom became known. A strong correlation between the DNAPL plumes and the dissolved contaminant plumes became obvious. At the same time, the dissolved contaminant plumes did not extend much beyond the DNAPL plume indicating the presence of a significant contaminant reduction process such as biodegradation.

The limited aquifer thickness and water flow in the aquifer indicated that dispersion could not account for the limited extent of the dissolved contaminant plumes. The relatively high levels of organic material in the groundwater suggested that the limited sorption sites would be quickly overwhelmed. Recent groundwater analysis was modified to test for the presence of PCP degradation products. DCP and CP were found to be present in significant concentrations (Figure 12) and considered to be evidence that anaerobic biodegradation was occurring. The aerobic degradation products of PCP (principally various hydroquinones, see Figure 8) are not part of the suite of analyses done by standard laboratories. Also, it was felt that they would themselves degrade rather quickly and their detection would be difficult even though aerobic degradation was probably significant. All this prompted the development of the special reaction model in the RT3D code to address DNAPL dissolution and both anaerobic and aerobic biodegradation.

\subsection{Shallow Aquifer Flow Model}

The MODFLOW grid is shown in Figure 17 together with the permanent monitoring wells. The locations of the specified head nodes are identified with green diamond symbols. The hydraulic conductivities derived from slug test data are posted on Figure 14 and hydraulic conductivities and transmissivities from model calibration are presented in Table 4 . The Ks range from a low of $0.6 \mathrm{ft} /$ day to a high of $5 \mathrm{ft} /$ day. These conductivities are consistent with the average conductivity of 2.2-2.5 ft/day along the path from the new process presented under the section on the flow and transport conceptual model. Figure 18 presents the model results as a set of head contour lines together with the measured heads in May, 1998 (the observed head calibration set). The filled circles are permanent monitoring well locations (monitoring wells MW-27 and MW-28 were drilled in July 1998 and are thus not included in the Figure). A green circle indicates that the model and measured head agreed within about 0.5 feet. A tan circle indicates that the model result is about $1 \mathrm{ft}$. or less below the measured value. A violet circle indicates that the model head is about $1 \mathrm{ft}$. or less higher than the measured head. A red circle indicates that the model and measured heads are different by more that $1 \mathrm{ft}$. A black circle is used at MW-23 because the measuring point elevation was unavailable and the head was calculated based on an assumed measuring point elevation.

The differences between model simulated and measured heads at wells MW-08 and MW-09 can be explained by the steep drop in land surface near the creek. There is a sharp local gradient between those wells and the Creek that would require changing the bottom elevation of model cells near the creek to correctly simulate heads. The model simulates a more gradual head gradient towards the river over a longer distance. This means that the model simulated head gradient just west of wells MW-8 and MW-9 is greater than seen in the field, but the model gradient between those wells and the Creek is smaller. 
Model simulated groundwater velocities just west of those wells were higher than in reality, but velocities from those wells to the Creek were lower. This was considered acceptable because the model would over predict contaminant transport to the wells and thus be conservative. The difference at MW-10 may be attributable to the presence of DNAPL in the well. Also, the head in MW-10 in May 1998 was higher than at other times relative to that in nearby wells so the May 1998 measurement may be anomalous. The difference between the model results and measured heads at MW-13 are unexplained at this time. Heads at MW-13 are consistently higher than expected. There may be rainwater ponding and consequent recharge in the vicinity. Insufficient information was available to determine the cause of head differences. Transmissivities (T) in zones 1 and 6 that produced a satisfactory match of head for well MW-13 caused the head matches at MW-12, MW-22, and MW-14 to be unsatisfactory. Some improvement might be expected if hydraulic property zone 6 were divided into 2 zones and assigned quite different Ts, but it is believed that factors other than spatially variable Ts control the head at MW-13. The influence of the permanent ponds in the old process area and the intermittent pond north of the new process area are evident from Figure 18. Both sets of ponds are needed to obtain a satisfactory head match.

Travel times can be calculated from observed hydraulic properties. Average linear (pore) velocity from the new process area to Day's Creek were estimated to range from 0.03 to $0.15 \mathrm{ft} / \mathrm{d}$ in section 5.4 using a range to hydraulic properties. The shortest distance from the new process area to Day's Creek is about $1100 \mathrm{ft}$. Dividing distance by velocity yield a travel time range of $20-100$ years. Figure 19 shows a series of model pathlines using spatially variable properties (see Table 4) from the old and new process areas to Day's Creek. The filled circles on Figure 19 represent particle starting locations, ten year travel time markers, or particle termination points at Day's Creek. The calculated travel time from old process area to Day's Creek is about 80 years and about 40 years from the new process area. These travel times are somewhat uncertain and the travel time from the old process area are believed to be more uncertain than those from the new process area, but decades of travel time are involved. 
TWPC Fate and Transport Groundwater Model

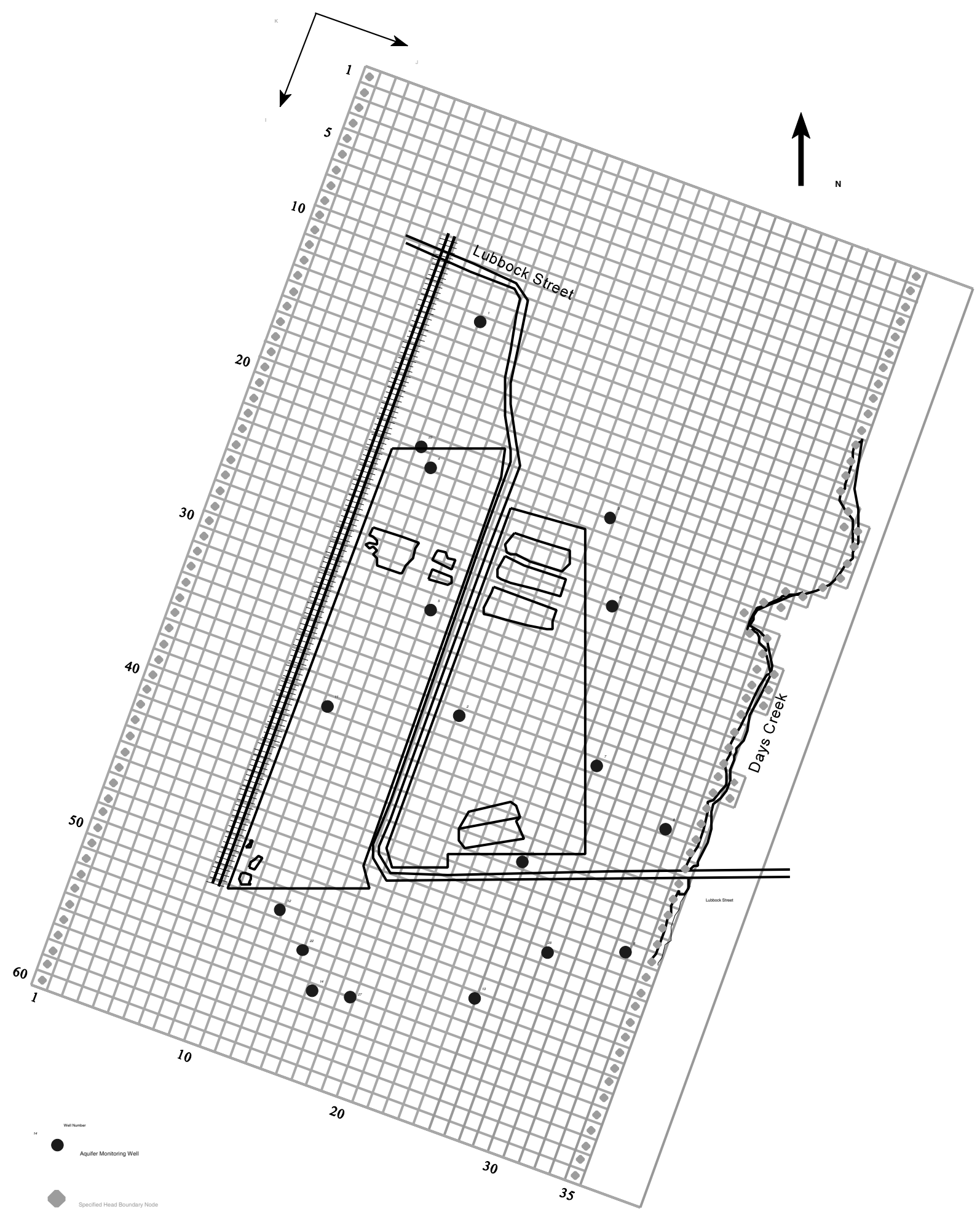

Figure 17. MODFLOW grid for aquifer model. 
TWPC Fate and Transport Groundwater Model

The transmissivities used in the model are presented in Table 6.

Table 6. Aquifer Model Transmissivities

\begin{tabular}{|c|c|c|}
\hline Zone & $\begin{array}{c}\text { Hydraulic } \\
\text { Conductivity } \\
\text { (ft/day) }\end{array}$ & $\begin{array}{l}\text { Transmissivity } \\
\qquad\left(\mathrm{ft}^{2} / \text { day }\right)\end{array}$ \\
\hline 1 & 1 & 4 \\
\hline 2 & 0.6 & 2.4 \\
\hline 3 & 4 & 16 \\
\hline 4 & 5 & 20 \\
\hline 5 & .2 & 0.8 \\
\hline 6 & 1 & 4 \\
\hline 7 & 2 & 8 \\
\hline 8 & 2 & 8 \\
\hline 9 & 0.6 & 2.4 \\
\hline 10 & 1 & 4 \\
\hline 11 & 0.6 & 2.4 \\
\hline 12 & 2 & 8 \\
\hline 13 & 0.6 & 2.4 \\
\hline 14 & 2 & 8 \\
\hline 15 & 1 & 4 \\
\hline
\end{tabular}


TWPC Fate and Transport Groundwater Model

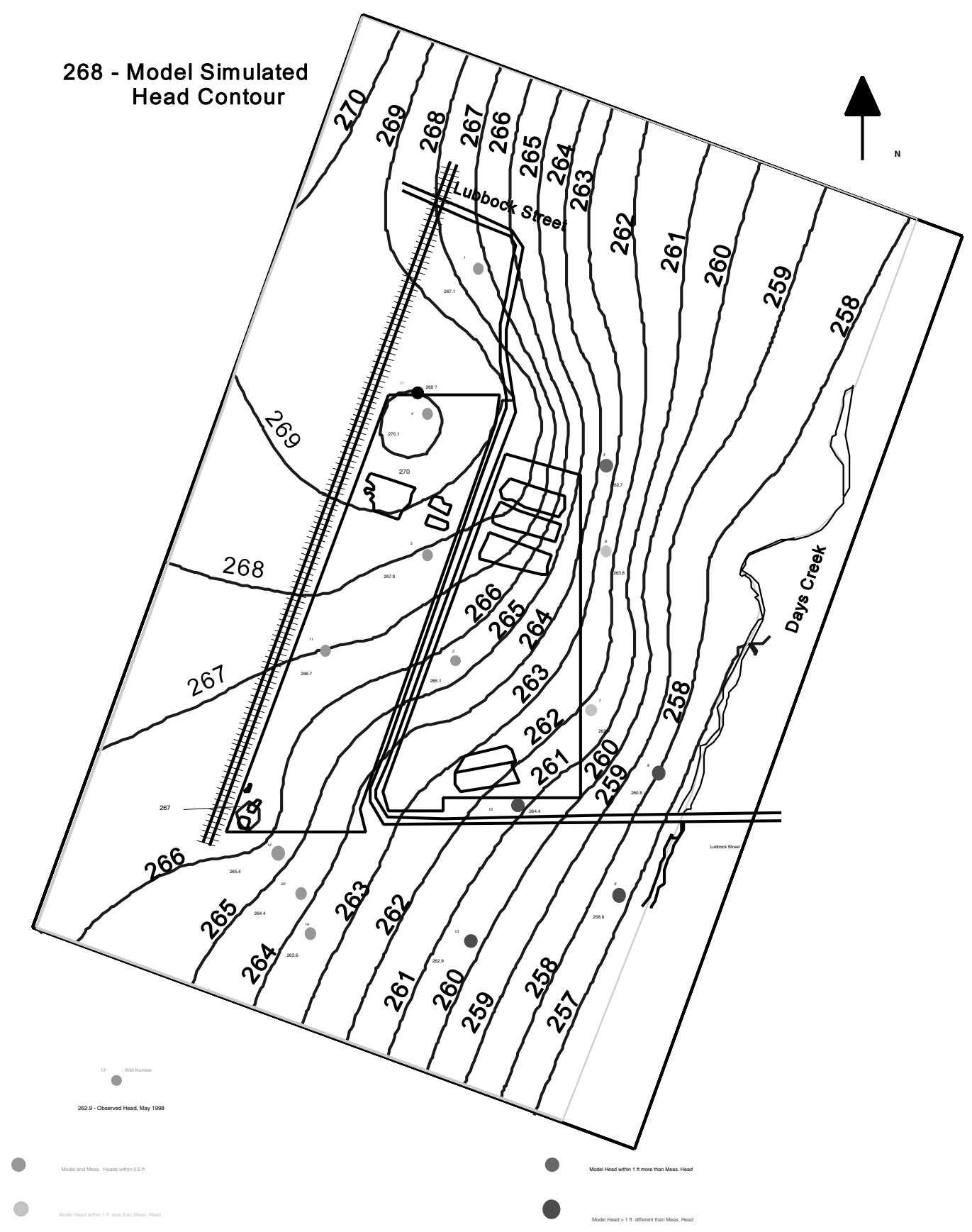

Figure 18. Shallow Aquifer Flow Model Head Contours and Observed Heads 
TWPC Fate and Transport Groundwater Model

\subsection{Shallow Aquifer Particle Tracking}

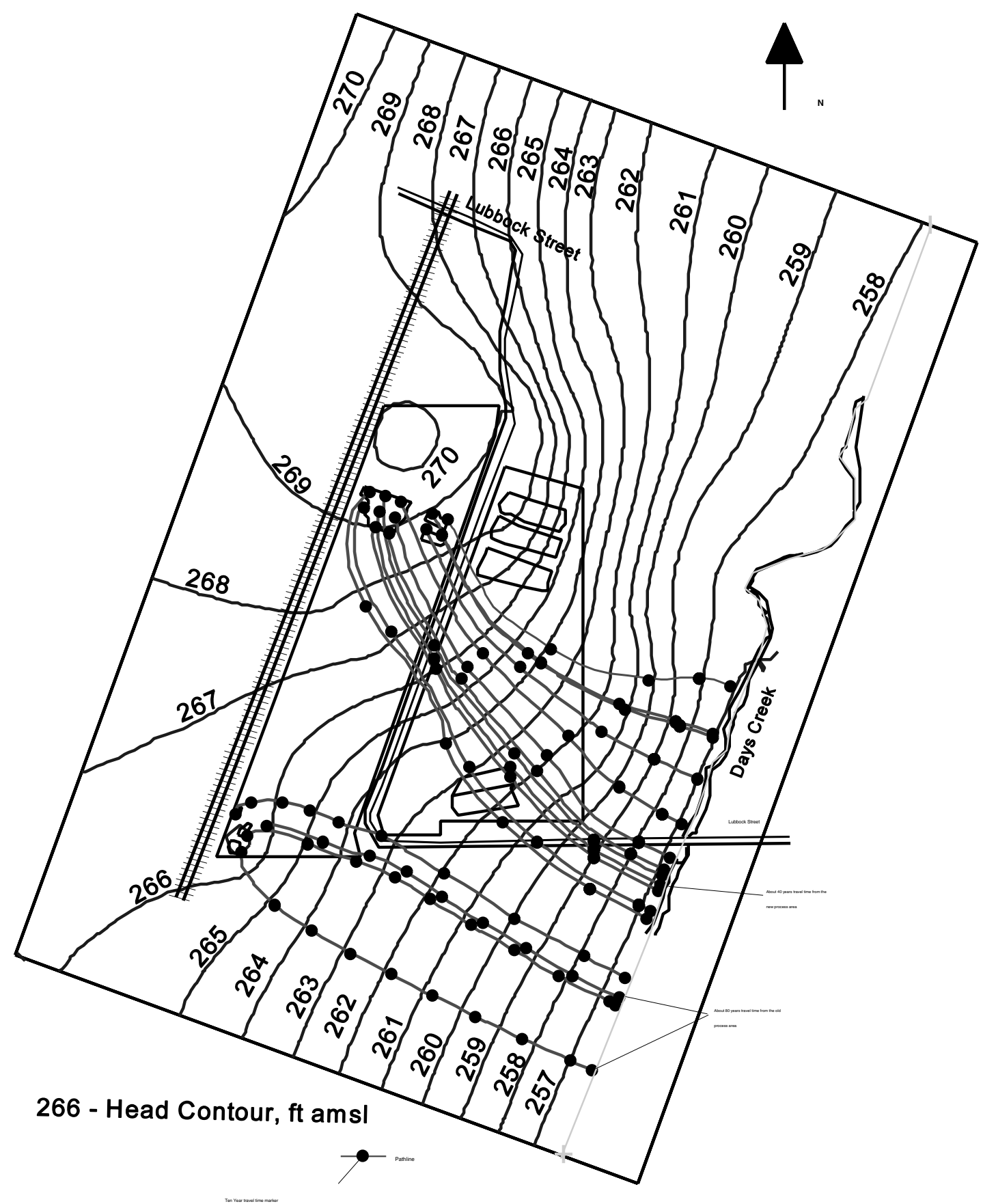

Figure 19. Shallow Aquifer Pathlines from Contaminated Areas to Day's Creek 
TWPC Fate and Transport Groundwater Model

\subsection{Aquifer Contaminant Transport and Reactions}

The results of the final RT3D runs are presented for PCP, LPAH, HPAH(BAP), DCP, and dissolved oxygen in Figures 20-24, respectively. Three categories of observed concentrations are posted on the Figures, above action limits, above detection but below action limits, and below detection limits. These postings were taken from Figure 4 of Weston (1999). The above action limit category refers only to PCP and BAP equivalents, which are the groundwater contaminants with action limits. The above detection but below action limit symbols are reported in Weston (1999) primarily as wells with measurable concentrations of non-carcinogenic PAHs (equivalent to our LPAH). BAP equivalents refer to concentrations of carcinogenic or heavy PAHs weighted by a toxicity factor relative to BAP. BAP is considered to have a toxicity factor of 1 and other HPAHs a toxicity factor much less than 1. BAP is by far the dominant carcinogenic or heavy PAH in calculating BAP equivalents. From Table 1, BAP is about $18 \%$ of the HPAHs in creosote so BAP toxic equivalents were generally estimated to represent $20 \%$ of the HPAH component of creosote.

The isoconcentration lines on Figure 22 are factors of the BAP equivalent concentration limit, but were derived from model HPAH simulated concentrations adjusted by a factor of 5 . The model calculated that BAP equivalents would not exceed that BAP action limit anywhere in the model. The contour lines on Figure 22 represent one-half the BAP action limit of $10 \mu \mathrm{g} / \mathrm{L}$ or $5 \mu \mathrm{g} / \mathrm{L}$. Figure 4 of Weston (1999) presents BAP equivalent concentrations 30-100 times the action limit. However, the solubility of BAP of $1.6 \mu \mathrm{g} / \mathrm{L}$ in Table 1 taken from EPA (1996) is much less than the action limit of $10 \mu \mathrm{g} / \mathrm{L}$. We note that all wells with BAP exceeding the action limit on Figure 4 of Weston (1999) are within or very near the estimated NAPL plume marked on the figure. Based on the solubility limit, we believe the high reported BAP concentrations represent a NAPL or undissolved contribution in the sample. The model simulated concentrations on Figure 22 are only dissolved BAP.

Figure 24 shows the oxygen concentrations in $\mathrm{mg} / \mathrm{L}$. The model units were millimoles/L, but the isopleths are plotted as $\mathrm{mg} / \mathrm{L}$. The initial and boundary condition oxygen concentration was $8 \mathrm{mg} / \mathrm{L}(0.25$ $\mathrm{mmole} / \mathrm{L}$ ) as was that of the uncontaminated infiltrating pond water in the area north of the new process area.

The model results agree reasonably well with contaminant or oxygen concentrations at monitoring wells and temporary well points. Simulated PCP concentrations are generally consistent with observations. There are concentrations exceeding the action limit north of the old process area and some wells exceed the limit east of the simulated plume. These differences probably indicate that the old process DNAPL plume was larger at some time in the past than assumed in the model. Alternatively, contaminants could be entering the aquifer from contaminated soils over a area larger than the current DNAPL plume.

The simulated LPAH plume generally agrees with observed samples as indicated by the "above detection limit" symbols on Figure 21. The model plume extends further towards Day's Creek than suggested by the field samples, indicating that the LPAH dissolution rates or concentrations in the sources may be too high or perhaps the biodegradation rate may be too low. A higher biodegradation rate for LPAH in the model would require more oxygen in the model, which is not seen either in the simulated results (Figure 24) or the field sample results (Figure 11). Including sulfate and ferric iron in the model would have supplied additional electron acceptors and allowed additional LPAH degradation, but would also have added additional equations and rate constants. In any case the model slightly over predicts the extent of LPAH transport.

As mentioned previously, the BAP equivalent results (calculated from HPAH results) are quite low and do not agree with much higher BAP equivalent results reported from the sampling program. The 
TWPC Fate and Transport Groundwater Model

model results are consistent with literature values for HPAH and BAP solubility and we believe they are more representative of the movement of dissolved BAP in the aquifer.

The DCP results presented on Figure 23 are consistent with most field observations. The extent of the observed DCP plume is not well known due to the limited number of wells sampled for DCP and CP, but it does not extend to MW-07 or MW-10 (see Figure 12). The lack of an aerobic degradation path for DCP is a model deficiency. PCP aerobic degradation is significant in the model and it is likely that DCP aerobic degradation is also significant. If DCP aerobic degradation had been included in the model, the DCP model plume would not extend as far east as shown on Figure 23 and be more consistent with field observations. DCP and CP data are given in Appendix B. 
TWPC Fate and Transport Groundwater Model

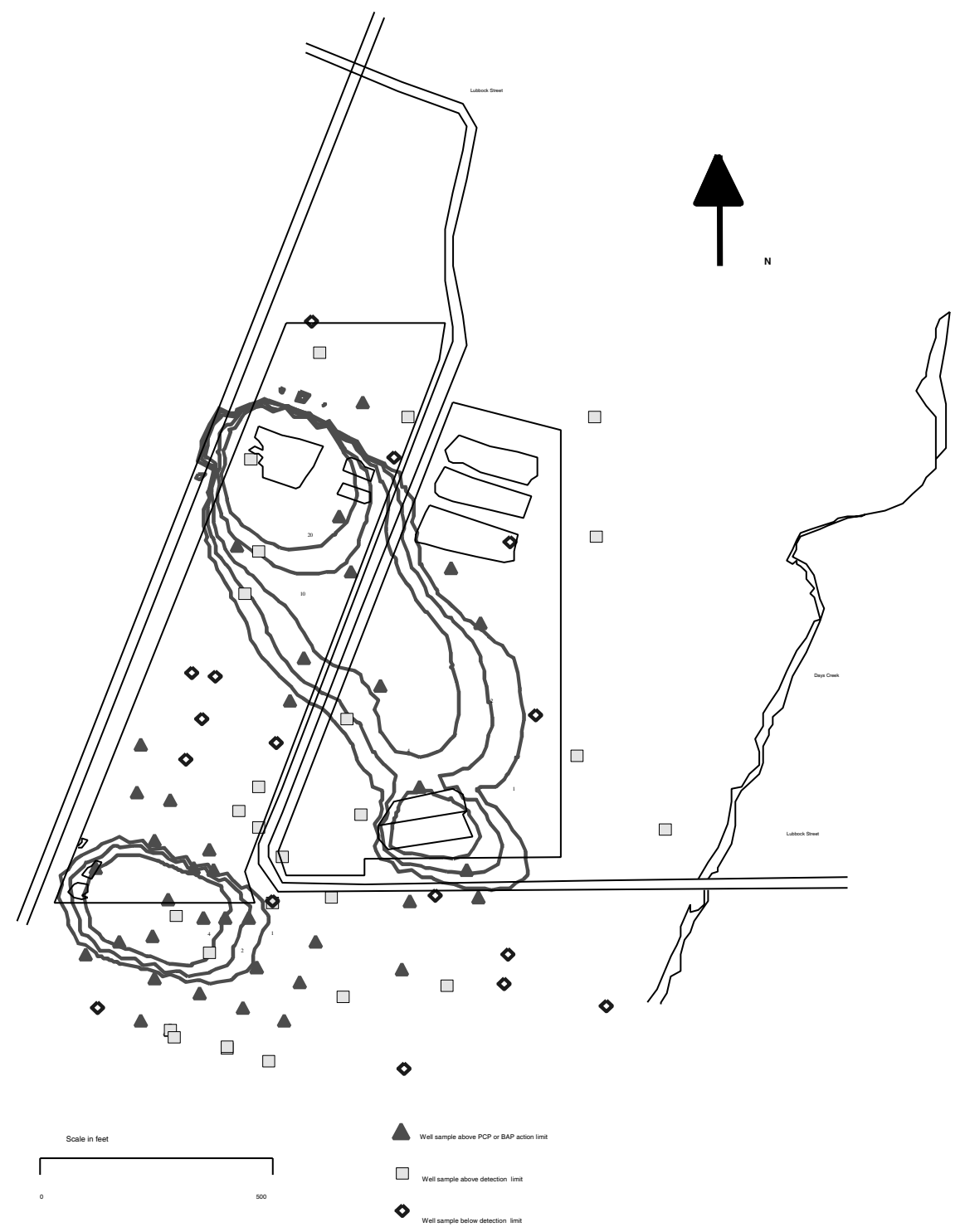

Figure 20. Model predicted PCP concentration factors (times action limit) and observed concentration categories. 
TWPC Fate and Transport Groundwater Model

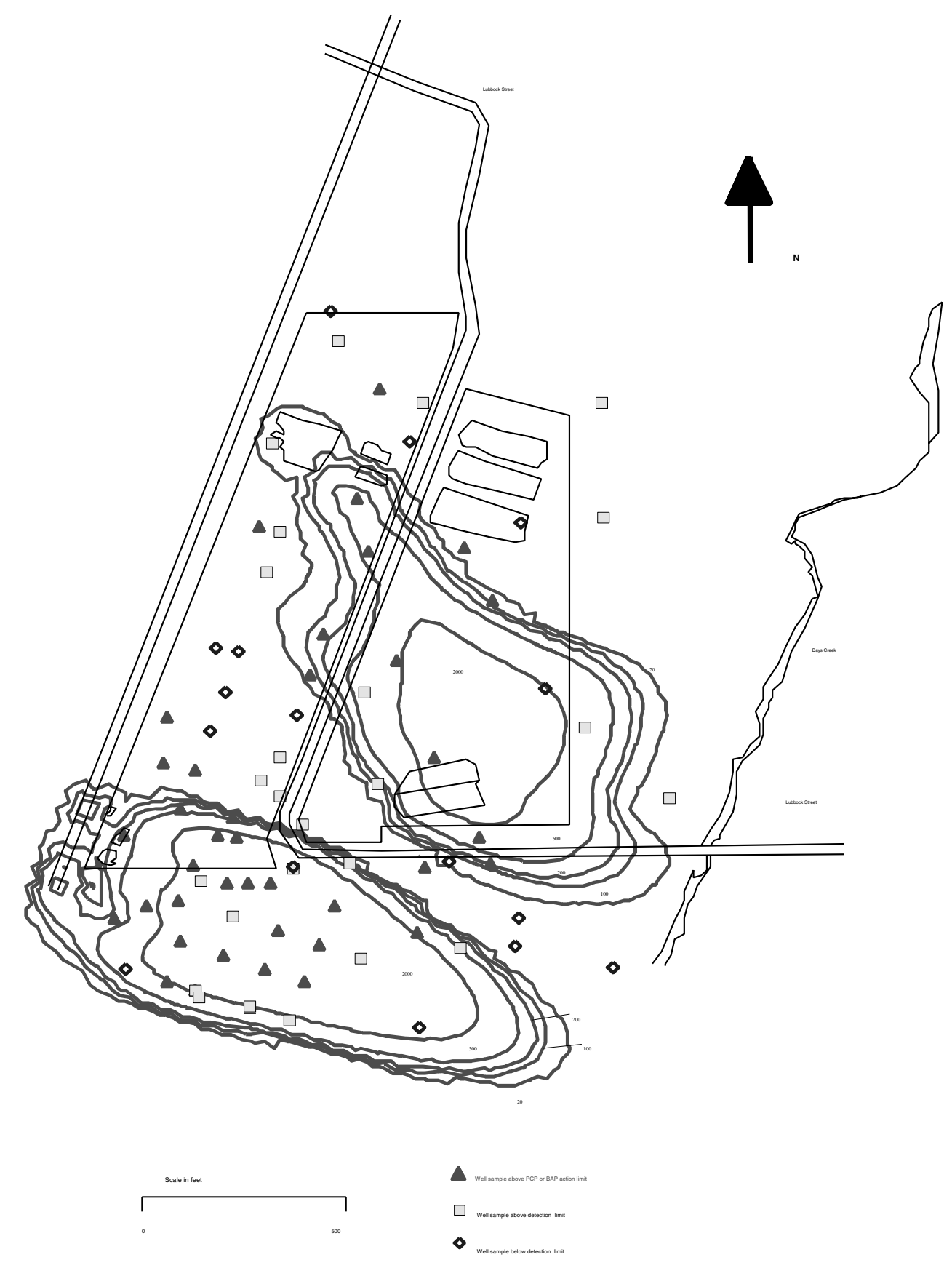

Figure 21. Model predicted light PAH concentrations and observed concentration categories (values - ug/L). 
TWPC Fate and Transport Groundwater Model
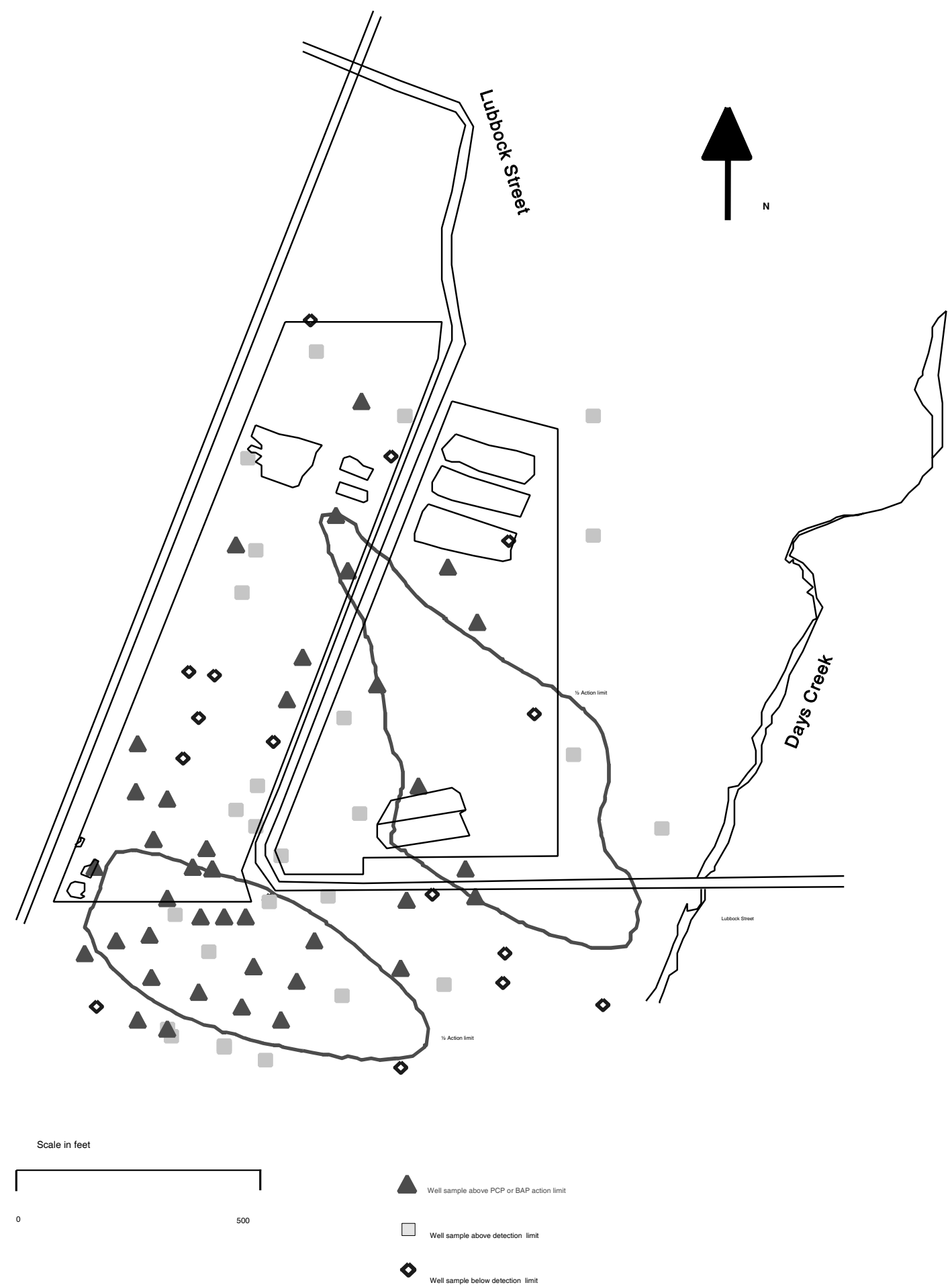

Figure 22. Model predicted BAP concentration factor isopleths (times action limit) and observed concentrations categories. 
TWPC Fate and Transport Groundwater Model

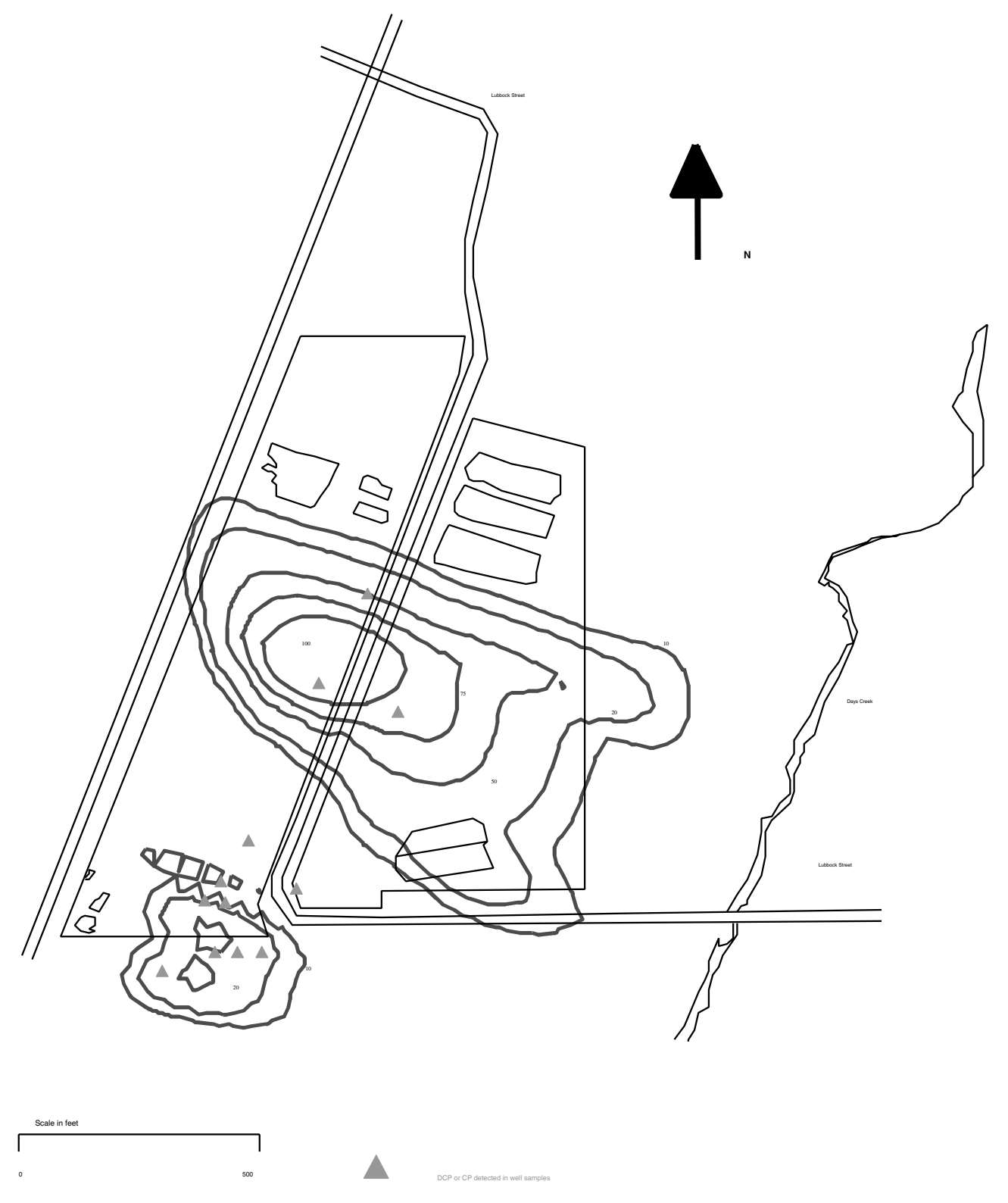

Figure 23. Model predicted DCP concentration isopleths (values - ug/L). 
TWPC Fate and Transport Groundwater Model

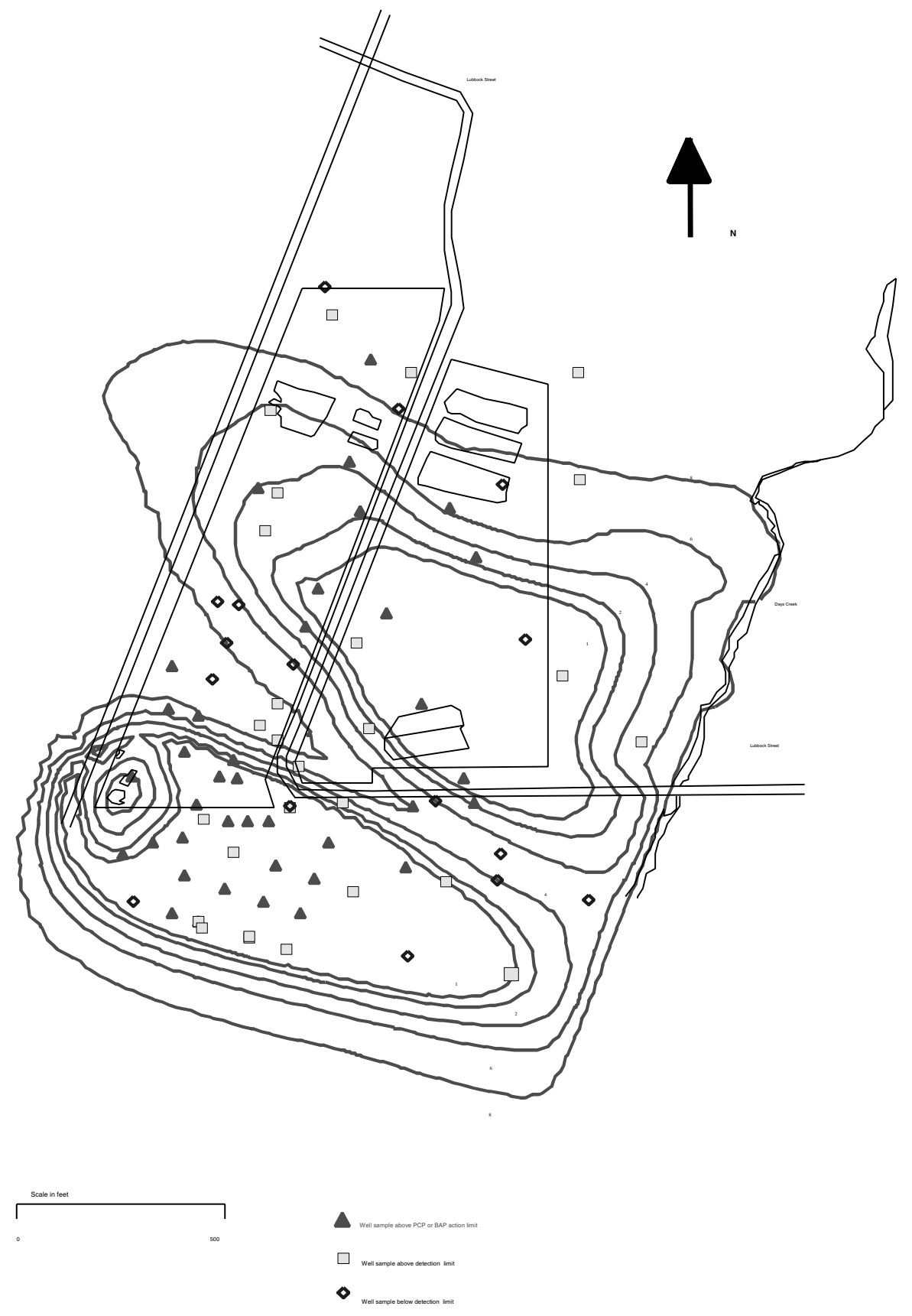

Figure 24. Model predicted oxygen concentration isopleths (values - mg/L). 
TWPC Fate and Transport Groundwater Model

\section{REACTION MODEL CONSTANTS AND SENSITIVITY ANALYSIS}

The values of calibrated model rate and other constants are presented in Table 7 below.

Table 7. Selected model constants

\begin{tabular}{|c|c|c|c|c|c|}
\hline $\begin{array}{l}\text { Contaminant/ } \\
\text { Constant }\end{array}$ & PCP & DCP & LPAH & $\mathrm{HPAH}$ & ACEX \\
\hline kla & 0.006 & -- & 2.E-04 & 0.002 & $1 \mathrm{E}-05$ \\
\hline $\mathrm{C}^{*}$ & $4.56 \mathrm{E}-04$ & -- & 0.078 & $6.8 \mathrm{E}-06$ & 1 \\
\hline Kan & 0.001 & 0.001 & -- & -- & -- \\
\hline K & 0.005 & -- & 0.005 & 2.E-04 & $1 \mathrm{E}-05$ \\
\hline $\mathrm{h}_{\mathrm{O} 2}$ & 0.125 & 0.125 & 0.125 & 0.125 & 0.125 \\
\hline B & 3 & -- & 8 & 12 & 6 \\
\hline
\end{tabular}

model units $=$ mmole, liters, days

where $\mathrm{k}_{\mathrm{la}}$ is the DNAPL dissolution constant in equations $5-8, \mathrm{C}^{*}$ is the single species effective solubility limit, $\mathrm{K}_{\mathrm{an}}$ is the anaerobic degradation rate constant in equations $9-11, \mathrm{~K}$ is the aerobic degradation rate constant in equations $12-15, \mathrm{~h}_{\mathrm{O} 2}$ is the oxygen half-saturation constant, and $\mathrm{B}$ is the estimated ratio of oxygen molecules consumed per molecule of contaminant oxidized during aerobic degradation. The values of B are $1 / 2$ the theoretical maximum (see Table 1 ) needed for total oxidation of the contaminants. Oxygen depletion suggested that total oxidation may not occur.

A sensitivity analysis was done to evaluate the relative importance of some of the key model rate constants. The rate constants included in the sensitivity analysis and ratios of their values to the calibrated values shown in Table 7 are given in Table 8 . Because of Table 8. Sensitivity study rate constant ratios

\begin{tabular}{lccc}
\hline $\begin{array}{l}\text { Contaminant/ } \\
\text { Constant }\end{array}$ & PCP & LPAH & DCP \\
\hline kla & 0.1 & 2 & -- \\
Kan & 0.5 & -- & 0.5 \\
K & 0.5 & 0.5 & -- \\
\hline
\end{tabular}
the importance of PCP as a toxic contaminant, the dissolution rate constant and both anaerobic and aerobic degradation rate constants were varied in the sensitivity analysis. The LPAH dissolution and aerobic degradation rate constants were included because LPAH influenced the size and position of the anaerobic zone and because it was used as a measure of contaminant extent in the field sampling program. The DCP anaerobic degradation constant was included because of DCP's role as a degradation product of PCP. The HPAH (including BAP) rate constants were not included in the sensitivity analysis because its low solubility product limited its dissolved concentration (see Figure 22). The ACEX constants were not included in the sensitivity analysis because ACEX was not used as a measure of contaminant extent and its questionable concentration in the aged DNAPL. 
The results of the sensitivity runs are plotted as concentration difference contour maps. The PCP sensitivity results for kla, Kan, and K are presented in Figures 25-27, respectively. LPAH sensitivity results for kla and K are presented in Figures 28 and 29, respectively and the DCP results are presented in Figure 30 .

The PCP concentration differences (decreases) presented in Figure 25 when the DNAPL rate constant is reduced by a factor of 10 are significant, ranging upward to a factor of 4 times the action limit of 13 $\mathrm{ug} / \mathrm{L}$. However, the change in the rate constant needed to cause these differences was 2.5 times greater (10 vs 2) than that needed to cause comparable differences with the degradation rate constants. The position and shape of the difference contours, like those for the calibration run, are controlled by the position and shape of the DNAPL plume. The model was also run with the DNAPL rate constant increased by a factor of 10. The concentration difference (increase) contour map was similar in shape and position to Figure 25, except the maximum difference was only a factor of 2 times the action limit.

The PCP concentration differences (increases) resulting from reducing the anaerobic degradation rate constant by a factor of 2 also ranged up to a factor of 4 times the action limit. Note on Figure 26 that the difference contours extend eastward to wells that showed PCP concentrations below the action limit. Actual field data showed that PCP was below detection in those two wells (MW-07 and C8.5).

The PCP concentration differences (increases) resulting from halving the aerobic degradation rate constant ranged up to a factor of 20 times the action limit (Figure 27). The larger range in differences compared to the differences from halving the anaerobic rate constant arises from two factors: the aerobic rate constant is much larger than the anaerobic rate constant (see Table 7) and a significant aerobic zone exists immediately down gradient of the new process area (see Figure 24). Again, the difference contours extend eastward beyond wells C8.5 and MW-07, suggesting that the halved aerobic rate constant may be too low.

The LPAH concentration differences (increases) resulting from doubling the LPAH DNAPL rate constant (Figure 28) range upward to $2000 \mathrm{ug} / \mathrm{L}$ and the $20-500 \mathrm{ug} / \mathrm{l}$ contour lines extend eastward beyond wells $\mathrm{C} 8.5$ and MW-07. The LPAH concentrations measured in the field was below detection and ranged between 2-40 ug/L at C8.5 and MW-07, respectively.

The LPAH concentration differences (increases) resulting from halving the LPAH aerobic degradation rate constant (Figure 29) range upward to $200 \mathrm{ug} / \mathrm{L}$ down gradient of the new process area an up to $2000 \mathrm{ug} / \mathrm{L}$ down gradient of the old process area. The differences indicate that LPAH concentrations are more inconsistent with values obtained from the field sampling program than concentration obtained with the calibrated rate constant. Increasing the rate constant from the calibrated value caused little change from the results using calibrated constant (Figure 21). Availability of electron acceptors was more important than a higher value for the rate constant as mentioned previously. Certainly, significant ferrous iron concentrations were observed at several wells.

Figure 30 shows the model DCP concentration difference (increase) contours caused by halving the DCP anaerobic rate constant. The differences indicate the concentrations are further removed from matching field observations than those using the calibrated rate constant. As mentioned previously, the lack of an aerobic degradation pathway is a model limitation.

The sensitivity analysis indicates that all the rate constants list on Table 8 are significant. For PCP, aerobic degradation is most significant followed by anaerobic degradation and then DNAPL dissolution. In contrast, LPAH (aerobic) degradation causes a greater change than DNAPL dissolution. This contrast is driven by the relative effective solubility limits of PCP and LNAPL. The effective solubility of LNAPL in creosote was calculated to be about 2 orders of magnitude higher than that of PCP (see Table 1). 
TWPC Fate and Transport Groundwater Model

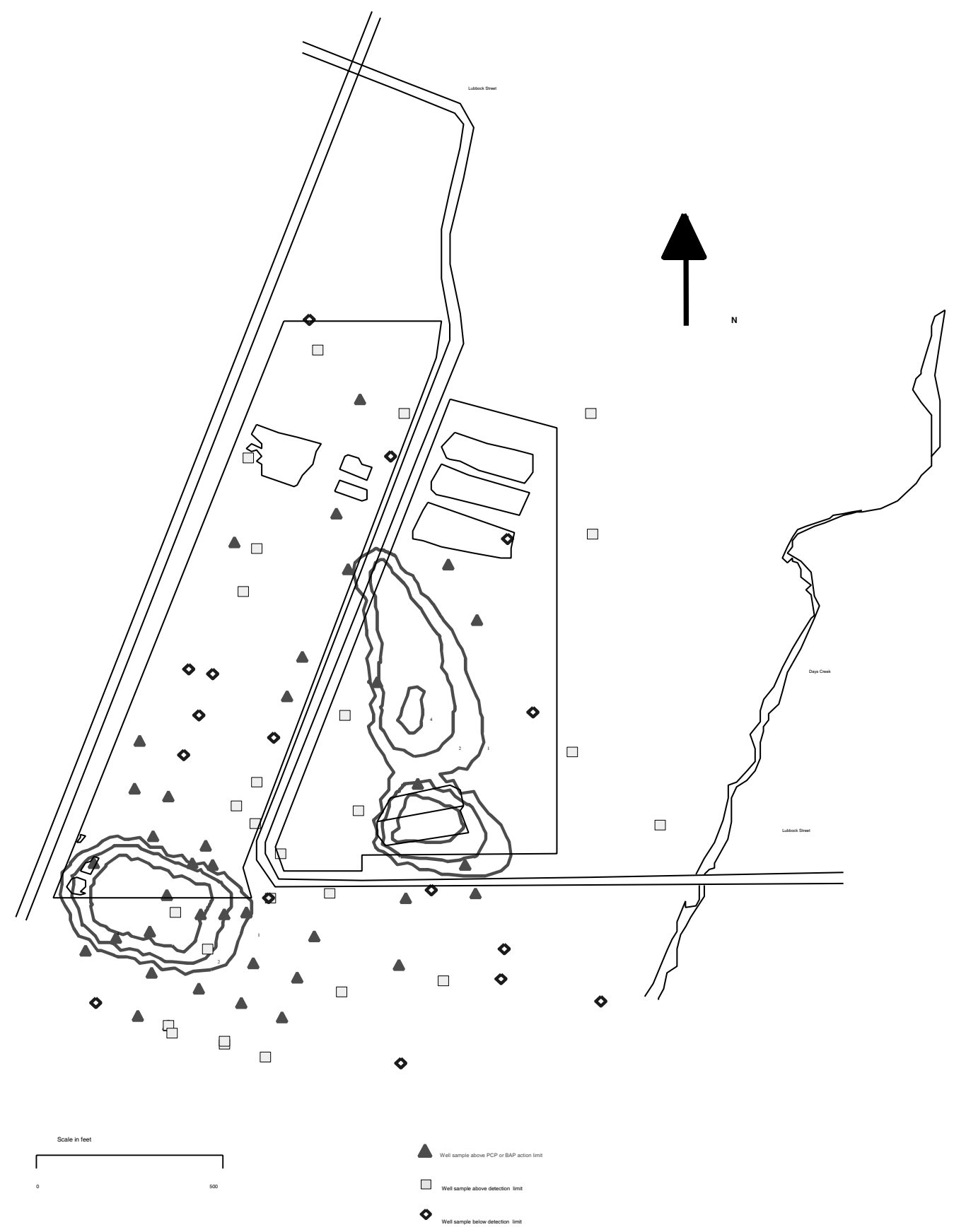

Figure 25. PCP concentration differences $-\mathrm{kla}_{\mathrm{pcp}}=1 / 10$ calibrated valued (isopleth values in multiples of action level) 
TWPC Fate and Transport Groundwater Model 
TWPC Fate and Transport Groundwater Model

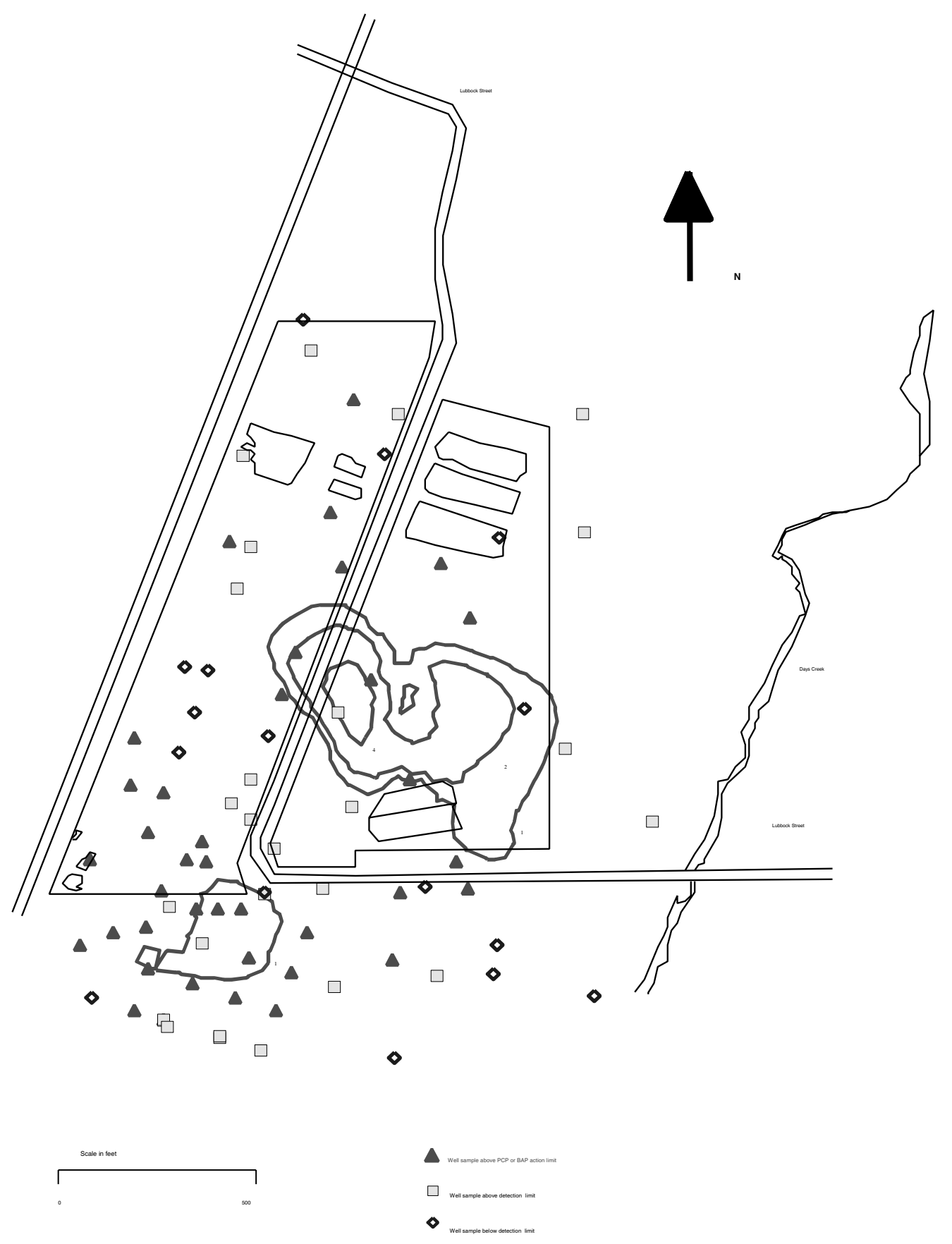

Figure 26. PCP concentration differences $-\mathrm{Kan}_{\mathrm{pcp}}=1 / 2$ calibrated value (isopleth values multiples of action limit). 
TWPC Fate and Transport Groundwater Model 
TWPC Fate and Transport Groundwater Model

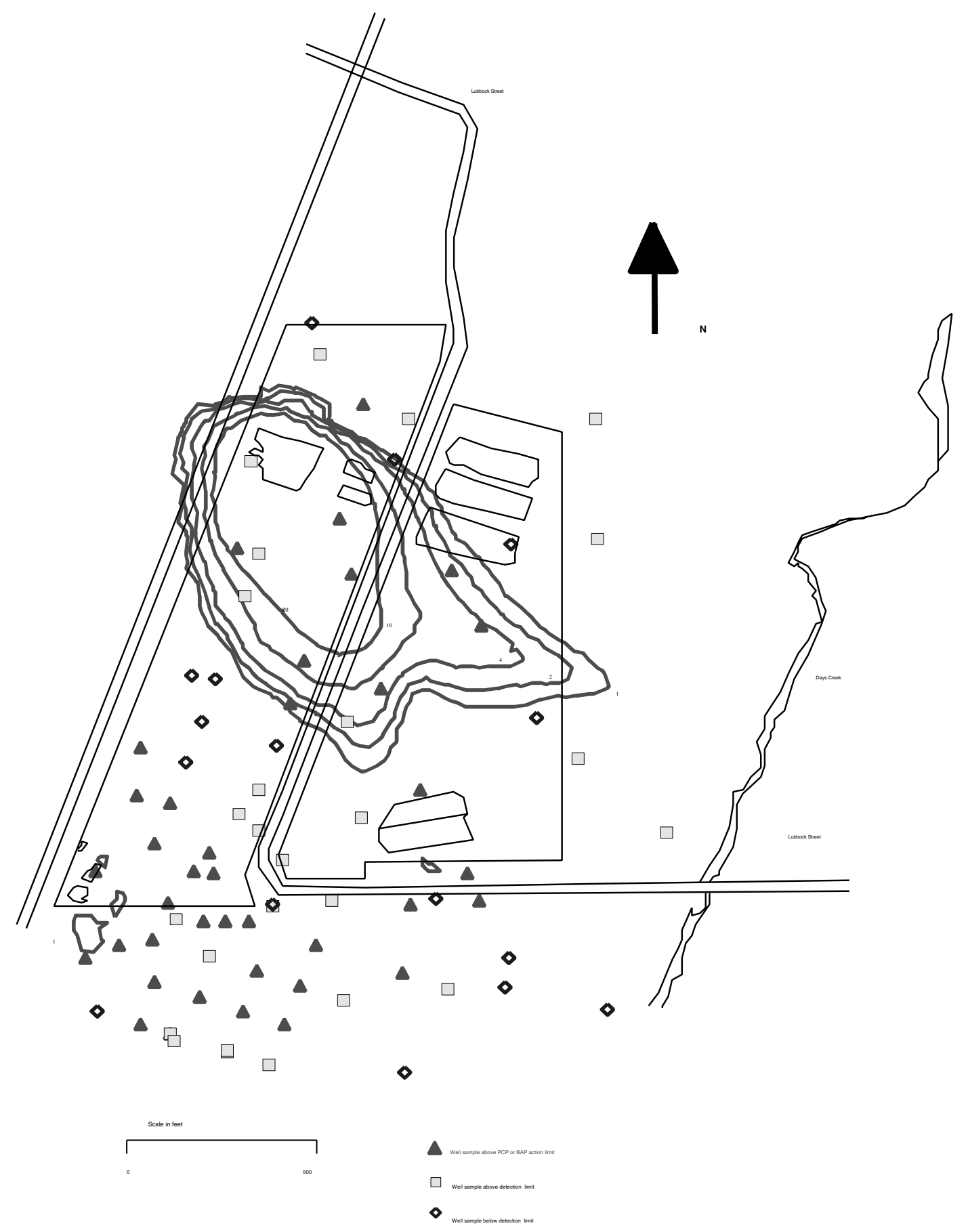

Figure 27. PCP concentration differences $-\mathrm{K}_{\mathrm{pcp}}=1 / 2$ calibrated value (isopleth values - multiples of action limit). 
TWPC Fate and Transport Groundwater Model 
TWPC Fate and Transport Groundwater Model

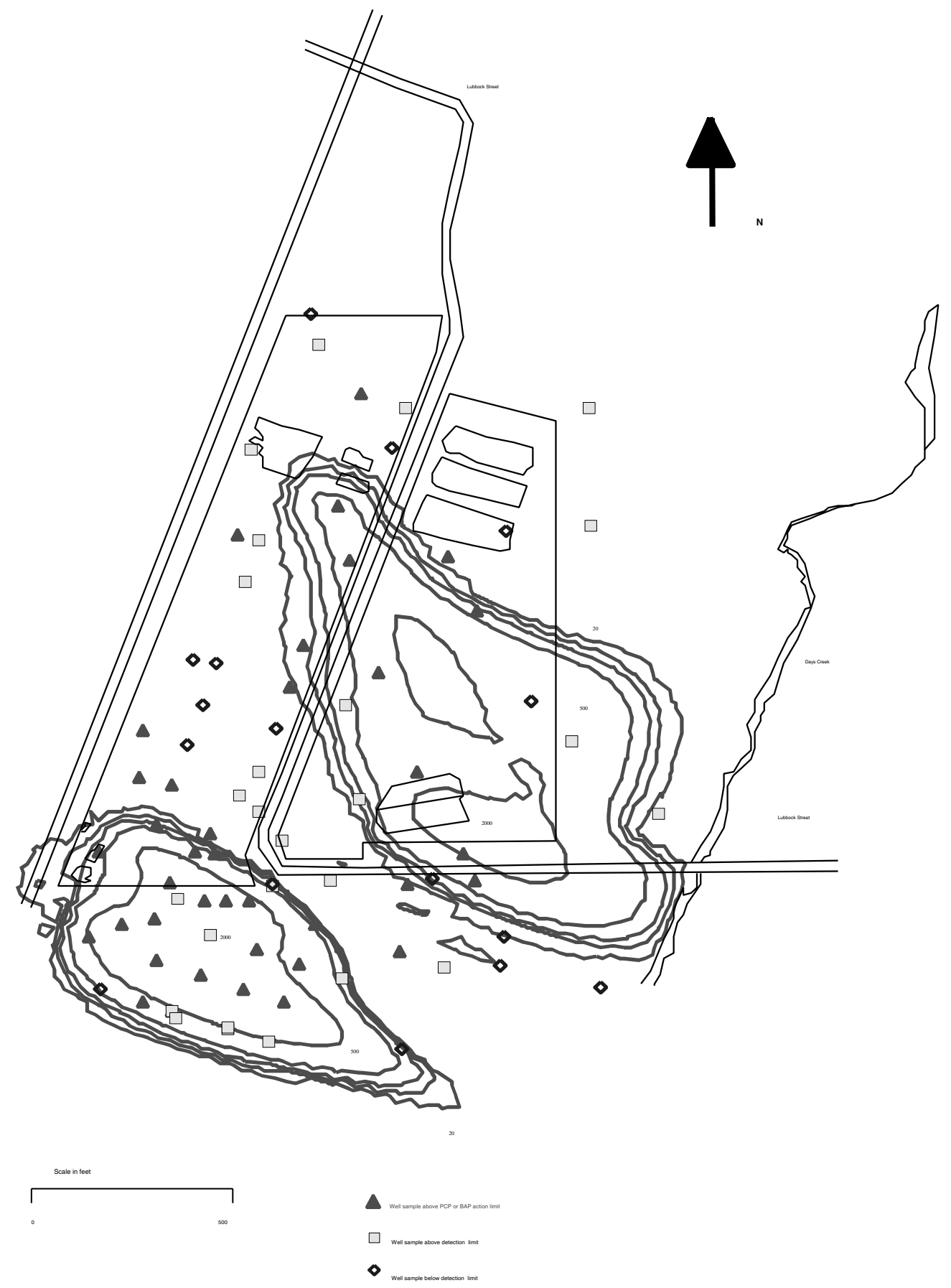

Figure 28. LPAH concentration differences $-\mathrm{kla}_{\mathrm{lpah}}=2 \mathrm{x}$ calibrated value (isopleth values in ug/L) 
TWPC Fate and Transport Groundwater Model 
TWPC Fate and Transport Groundwater Model

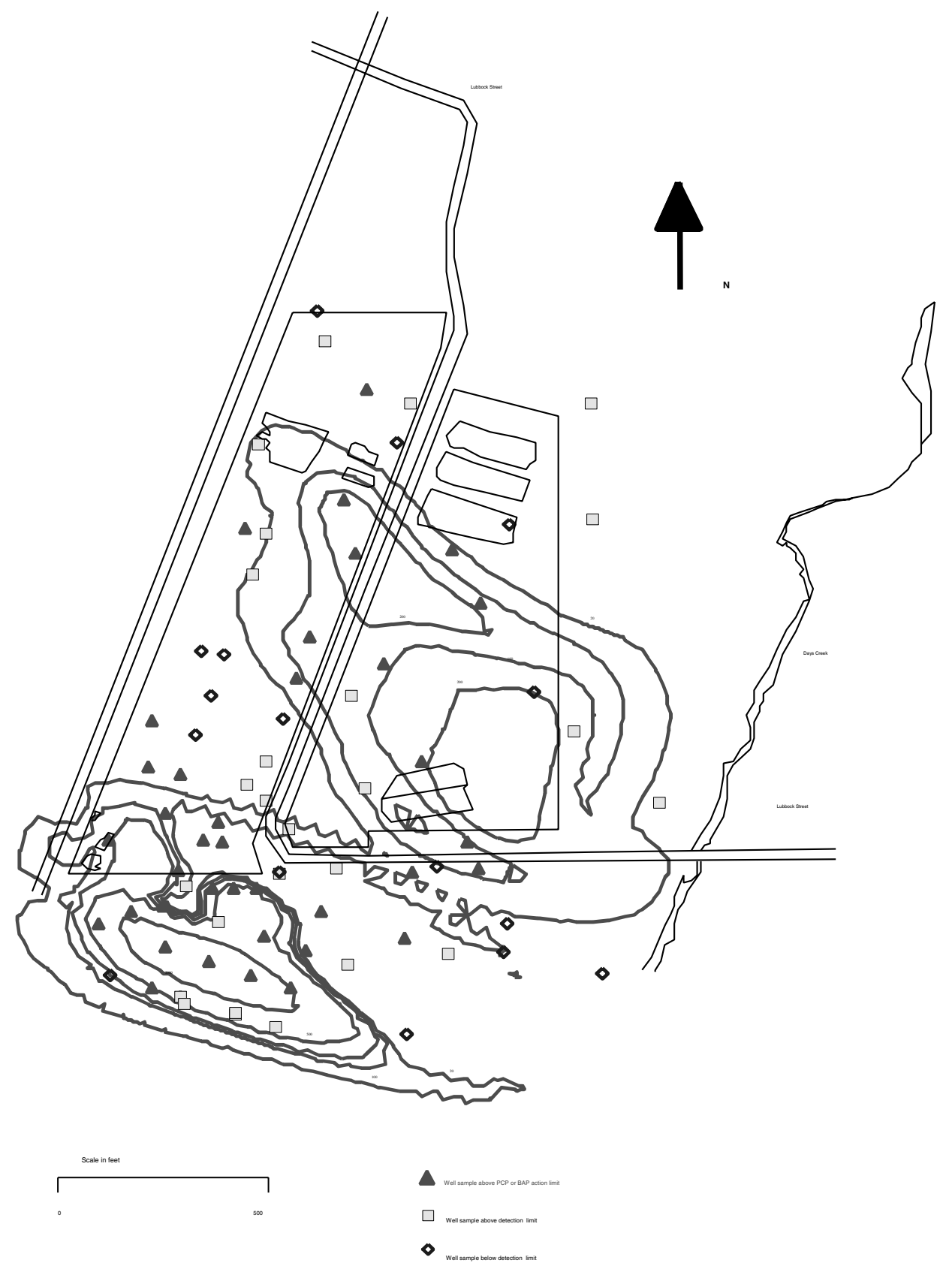

Figure 29. $\mathrm{LPAH}$ concentration differences $-\mathrm{K}_{\mathrm{lpah}}=1 / 2$ calibrated value (values ug/L). 
TWPC Fate and Transport Groundwater Model

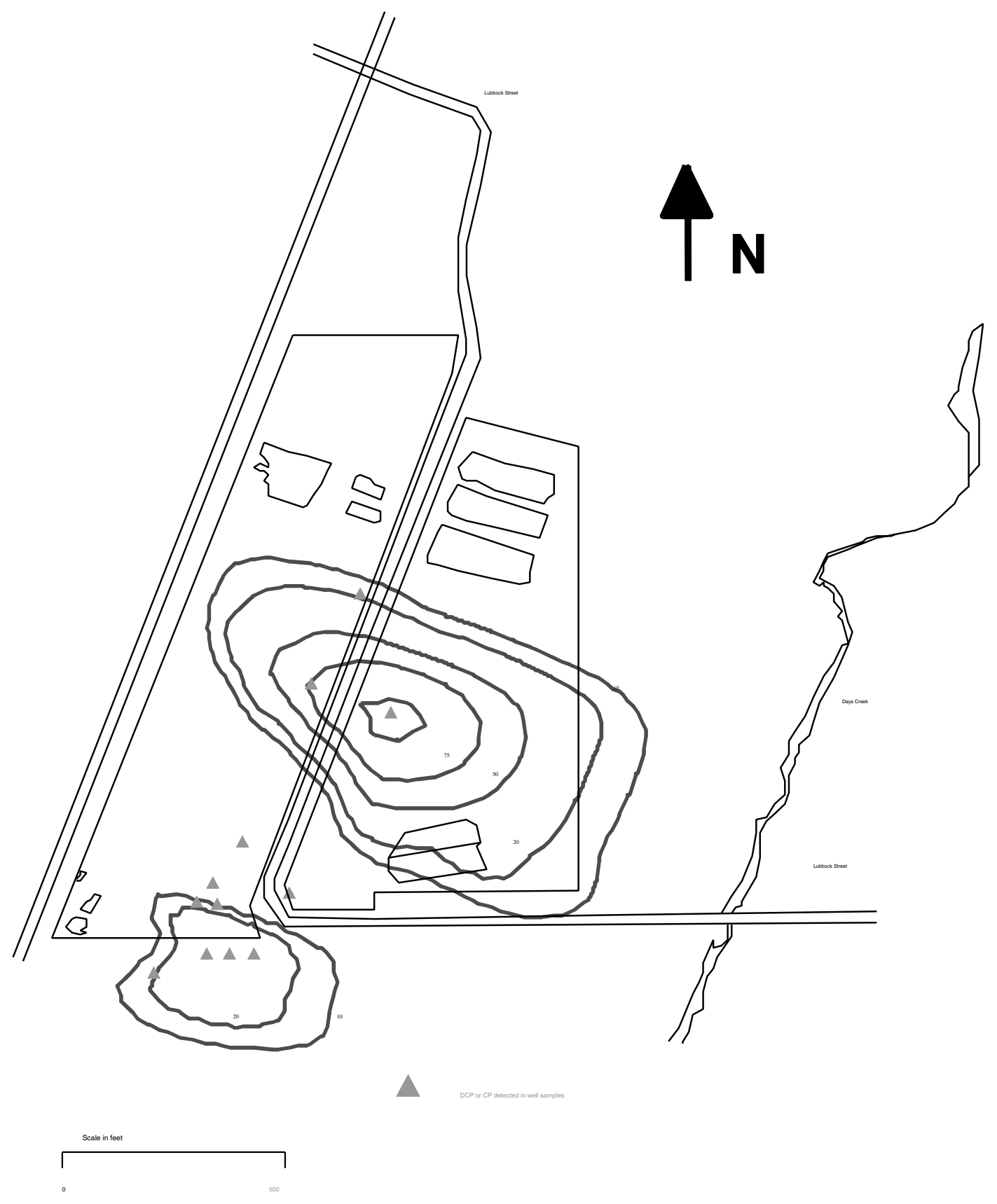

Figure 30. DCP concentration differences $-\operatorname{Kan}_{\mathrm{dcp}}=1 / 2$ calibrated value (isopleth values in $\mathrm{ug} / \mathrm{L}$ ) 
The calibrated rate constants (Table 7) appear to be reasonably consistent with observed concentrations given the model limitations. Including aerobic degradation of DCP and additional anaerobic electron acceptors (sulfate and ferric iron) would provide a more satisfying conceptual model and undoubtedly allow a better match, particularly for DCP and LPAH. Available data are probably not sufficient to adequately bound the rate constants for the additional equations.

It is important to note that only one constant was varied at a time during the sensitivity analysis, combinations of differing rates were not considered. Varying two or more constants at a time may have resulted in as good or perhaps slightly better matches than those shown. Still, we believe the relative importance of the rate constants as stated above is likely and provides valuable insight into the processes active at the site.

\section{EVALUATION AND RECOMMENDATIONS}

The model simulates the important processes of advection, dispersion, DNAPL dissolution, and anaerobic and aerobic biodegradation. All these process appear to be simulated reasonably well, at leastqualitatively. The system is complex with a number of important processes occurring and we believe the model includes most of the important phenomena and shows their relative importance.

The applicable lines of evidence necessary for considering natural attenuation are 1) historical ground water and/or soil chemistry data that demonstrate a clear and meaningful trend of decreasing contaminant mass and/or concentration over time at appropriate monitoring or sampling points and 2) hydrogeologic and geochemical data that can be used to demonstrate indirectly the type(s) of natural attenuation processes active at the site, and the rate at which such processes will reduce contaminant concentrations to required levels. We believe the first line of evidence is present, but the second line of evidence is not fully satisfied because the degradation rates are not well established given the unknowns associated with DNAPL dissolution. The strong presence of DCP and CP, PCP metabolic daughter products, adds to the evidence for loss of contaminants, but the rates are uncertain.

It is important to emphasize the important model limitations. Foremost among them is the assumption of immobile DNAPL plumes that were established as initial conditions for the two wood treating operational periods. Secondly, there a number of rate constants both for DNAPL dissolution and for biodegradation. These constants were adjusted to get the results shown on Figures 21-24, but these constants were not measured or known independently. Thus the model is primarily useful from a qualitative standpoint and the parameter values should be considered on a relative basis. Extracting a single value from Table 7 as a "true" rate constant is not justified. Other combinations of the constants might give acceptable results. The model calibration was limited by the lack of DNAPL history and very sparse or non-existent information on rate constants.

It would help the case for natural attenuation if some of the rates were determined independently of model calibration techniques. A knowledge of the present composition of the DNAPL in the aquifer, at least in terms of the four categories used in the model, would be very helpful in constraining dissolution rates. The model analysis suggests that the ACEX concentration in the presently constituted DNAPL is much less than reported for fresh creosote. Lab studies of DNAPL dissolution and biodegradation would help constrain the uncertain rates as well.

The model indicates that the PCP aerobic degradation rate may be higher that the anaerobic degradation rate. The literature certainly identifies an aerobic degradation pathway. This is in contrast to the situation with chlorinated aliphatic solvents (TCE for example) where the aerobic degradation rate is considered to be quite low. The situation for PCP suggests a possible remediation strategy, particularly if 
TWPC Fate and Transport Groundwater Model

consideration is being given to DNAPL extraction and treatment. Aerating the aquifer water (perhaps before being returned after DNAPL removal) could enhance PCP as well as LPAH and even HPAH degradation.

\section{REFERENCES}

ASTM, 1995, Standard Guide for Risk-Based Corrective Action Applied at Petroleum Release Sites, American Society for Testing and Materials, ASTM E-1739-95, Philadelphia, PA.

Borden, R. C., P. B. Bedient, M. D. Lee, C. H. Ward and J. T. Wilson, 1986. "Transport of Dissolved Hydrocarbons Influenced by Oxygen Limited Biodegradation: 2. Field Application," Water Resour. Res. 22:1983-1990.

Chanama, S, 1996, Molecular Characterization of the Catabolic Pathway of Pentachlorophenol Degradation in Flavobacterium SP. Strain ATCC 39723, PhD. dissertation in biochemistry, University of Idaho, Moscow, Idaho.

Clement, T. P., 1997, RT3D: A Modular Computer Code for Simulating Reactive Multi-species Transport in 3-Dimensional Groundwater Systems, PNNL-SA-11720, prepared for the U. S. Department of Energy by Battelle Pacific Northwest National Laboratory, Richland, Washington 99352.

Clement, T. P., 1998, RT3D Reaction Module for Modeling Biodegradation Coupled with NAPL Dissolution Processes, Draft, prepared for the U. S. Department of Energy by Battelle Pacific Northwest National Laboratory, Richland, Washington 99352.

Cohen, R. M., J. W. Mercer, and J. Mathews, 1993, DNAPL Site Evaluation, C. K. Smoley, CRC Press, Inc., 2000 Corporate Blvd., N. W., Boca Raton, Florida 33431.

Connor, J.A., C.J. Newell, J.P. Nevin, and H.S. Rifai, 1994. "Guidelines for Use of Groundwater Spreadsheet Models in Risk-Based Corrective Action Design," National Ground Water Association, Proceedings of the Petroleum Hydrocarbons and Organic Chemicals in Ground Water Conference, Houston, Texas, November 1994, pp. 43-55.

Davis, A., J. Campbell, C. Gilbert, M. V. Ruby, M. Bennet, and S. Tobin, 1994, “Attenuation and Biodegradation of Chlorophenols in Ground Water at a Former Wood Treating Facility," Ground Water, Vol. 32, No. 2, March-April 1994.

EPA, 1989, Determining Soil Response Action Levels Based on Potential Contaminant Migration to Ground Water: A Compendium of Examples, EPA/540/2-89/057, October 1989.

EPA, 1996, Soil Screening Guidance: Technical Background Document, EPA/540/R-95/128, May 1996.

EPA, 1997, Use of Monitored Natural Attenuation at Superfund, RCRA Corrective Action, and Underground Storage Tank Sites, OSWER Directive 9200.4-17, November 1997.

Jeng, C. Y., D. H. Chen, and C. L. Yaws, 1992, "Data Compilation for Soil Sorption Coefficient,"Pollution Engineering, June 15, 1992, pp. 54-60. 
TWPC Fate and Transport Groundwater Model

Key, 1997, Groundwater Fate and Transport Evaluation Report: South Cavalcade Superfund Site,

Houston, Texas, prepared by KEY Environmental, Inc. on behalf of Beazer East, Inc. for the U. S.

Environmental Protection Agency, March 1997.

Kozak, M. W., M. S. Y. Chu, and C. P. Harlan, 1990, Performance Assessment Methodology for Low-

Level Waste Facilities, NUREG/CR-5532, U.S. Nuclear Regulatory Commission, Washington, D.C. , 1990.

LMTS, 1997, Sampling Approach for Texarkana Wood Preserving Company Superfund Site, Texarkana, Texas, prepared by Lockheed Martin Technical Services for U.S. Environmental Protection Agency Technology Support Center for Monitoring and Site Characterization, July 1997.

Mueller, J. G., P. J. Chapman and P.H. Pritchard, 1989, “Creosote-contaminated sites,” Environmental Science and Technology, 23(10), pp 1197-1201.

Newell, C. J., R. K. McLeod, and J. R. Gonzales, 1996, BIOSCREEN: Natural Attenuation Decision Support System, User's Manual Version 1.3, EPA/600/R-96/087, National Risk Management Research Laboratory, Office of Research and Development, U. S. Environmental Protection Agency, Cincinnati, 45268, Ohio, August 1996.

Rifai, H.S.,1994, personal communication as quoted in Newel et al. (1996).

ROD, 1990, Record of Decision: Texarkana Wood Preserving Company Superfund Site, U. S. Environmental Protection Agency, Region 6, September 1990.

Wiedemeier, T. H., J. H. Wilson, D. H. Kampbell, R. N. Miller, and J. E. Hansen, 1995, Technical Protocol for Implementing the Intrinsic Remediation with Long-Term Monitoring Option for Natural Attenuation of Fuel-Hydrocarbon Contamination in Ground Water, San Antonio, TX: U.S. Air Force Center for Environmental Excellence.

Wiedemeier, T. H., M. A. Swanson, D. E. Moutoux, J. H. Wilson, D. H. Kampbell, J. E. Hansen, and P. Haas, 1996, Technical Protocol for Natural Attenuation of Chlorinated Aliphatic Hydrocarbons in Ground Water, San Antonio, TX: U.S. Air Force Center for Environmental Excellence.

Wiedemeier, T. H., M. A. Swanson, D. E. Moutoux, E. K. Gordon, J. T. Wilson, B. H. Wilson, D. H. Kampbell, P. Haas, R. H. Miller, J. E. Hansen, and F. H. Chappelle, 1998, Technical Protocol for Evaluating Natural Attenuation of Chlorinated Solvents in Ground Water, EPA/600/R-98/128 National Risk Management Research Laboratory, Office of Research and Development, U. S. Environmental Protection Agency, Cincinnati, Ohio 45268.

Weston, 1989, Final Remedial Investigation Report, Texarkana Wood Preserving Company Superfund Site, Texarkana, Texas, Vols. 1,2,3, prepared by Roy F. Weston, Inc. for the Texas Water Commission and the U. S. Environmental Protection Agency, June 1989.

Weston, 1992a, Groundwater Remediation System Design Flow Modeling and Trench Design, prepared by Roy F. Weston, Inc., Houston, Texas for the Texas Water Commission, October 1992.

Weston, 1992b, Texarkana Wood Preserving Company Superfund Site Supplemental Remedial Investigation and Focused Feasibility Study: Final Report, prepared by Roy F. Weston, Inc., Houston, Texas for the Texas Water Commission, December 1992. 
TWPC Fate and Transport Groundwater Model

Weston, 1996, Annual Groundwater Monitoring Report, Texarkana Wood Preserving Company Superfund Site, Texarkana, Texas, prepared by Roy F. Weston, Inc., Houston, Texas for the Texas Natural Resource Conservation Commission, April, 1996.

Weston, 1997, 1997 Third-Quarter Groundwater Monitoring Report, Texarkana Wood Preserving Co. Superfund Site, Texarkana, Tx, prepared by Roy F. Weston, Inc., Houston, Texas for the Texas Natural Resource Conservation Commission, November, 1997.

Weston, 1998, 1997 Forth-Quarter Groundwater Monitoring Report, Texarkana Wood Preserving Co. Superfund Site, Texarkana, Bowie County Tx, prepared by Roy F. Weston, Inc., Houston, Texas for the Texas Natural Resource Conservation Commission, February, 1998.

Weston, 1999, Additional Field Sampling Trip Report, Texarkana Wood Preserving Co. Superfund Site, Texarkana, Bowie County Tx, prepared by Roy F. Weston, Inc., Houston, Texas for the Texas Natural Resource Conservation Commission, February, 1998.

$\mathrm{Xu}$, Moujin and Y. Eckstein, 1995, "Use of Weighted Least-Squares Method in Evaluation of the Relationship Between Dispersivity and Scale," Journal of Ground Water, Vol. 33, No. 6, pp 905-908.

Zheng, C., 1990, MT3D: A Modular Three-Dimensional Transport Model for Simulation of Advection, Dispersion and Chemical Reactions of Contaminants in Groundwater Systems, prepared for the U. S. Environmental Protection Agency, Robert S. Kerr Environmental Research Laboratory, Ada, Oklahoma. 
TWPC Fate and Transport Groundwater Model APPENDIX A: COPIES OF SELECTED DATA REPORT FIGURES 
TWPC Fate and Transport Groundwater Model

\section{APPENDIX B: CHLORINATED PHENOL DATA}

